UNIVERSITAT

JAUME•I

\title{
AVANCES EN
}

\section{TELEROBÓTICA INALÁMBRICA SUBMARINA}

TESIS POR COMPENDio de ARTículos

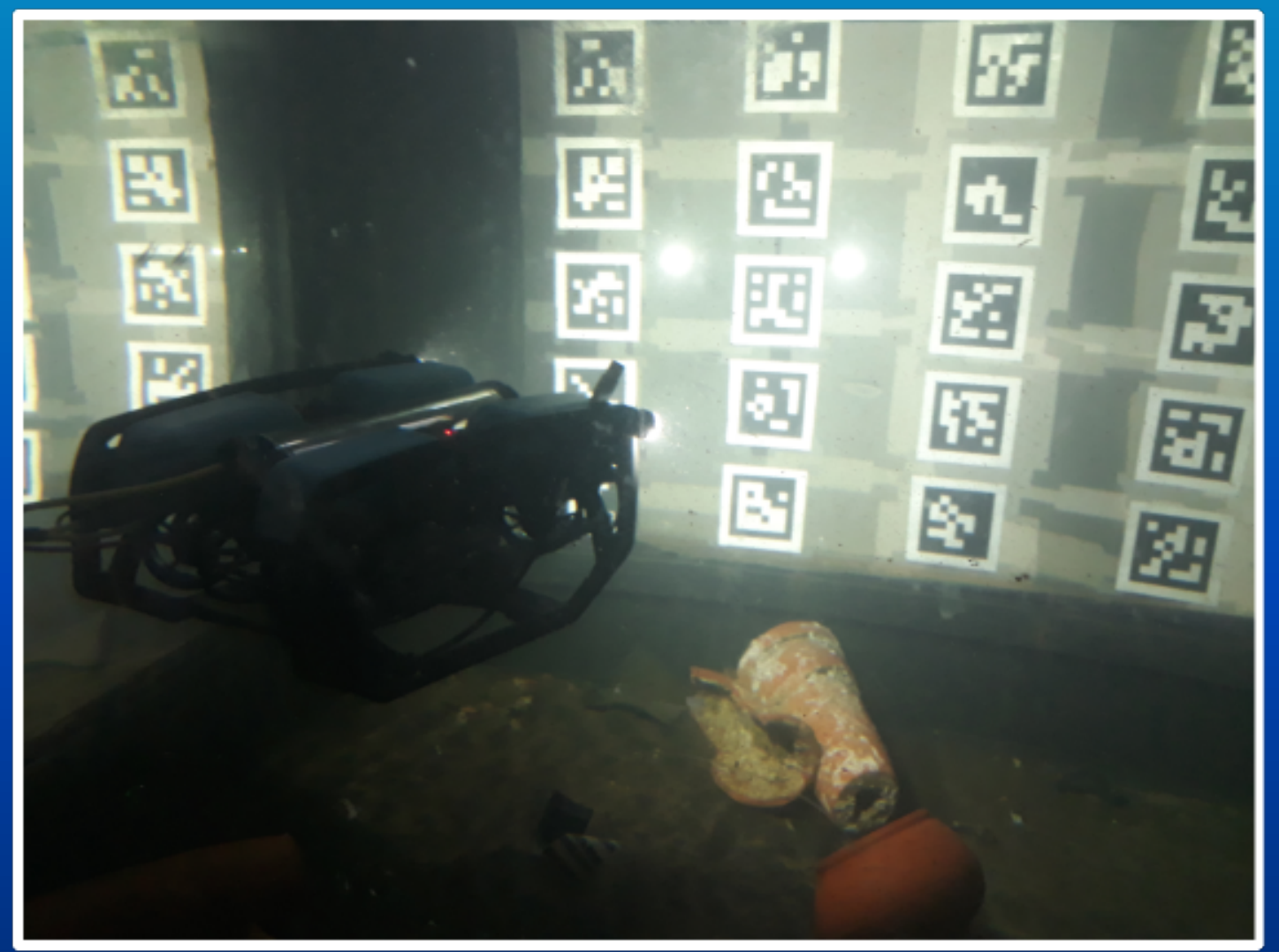

Presentada por Diego Centelles Beltran

Dirigida por José Vicente Martí Avilés PedRo José SANZ VALERo

NOVIEMBRE 2020 



\title{
AVANCES EN \\ Telerobótica Inalámbrica Submarina
}

Tesis por Compendio de Artículos

\author{
Presentada por Diego Centelles Beltran \\ Dirigida por José ViCEnte Martí Avilés \\ Pedro José Sanz Valero
}

Para obtener el título de Doctor en Informática

Castelló de la Plana A 16 De Noviembre de 2020

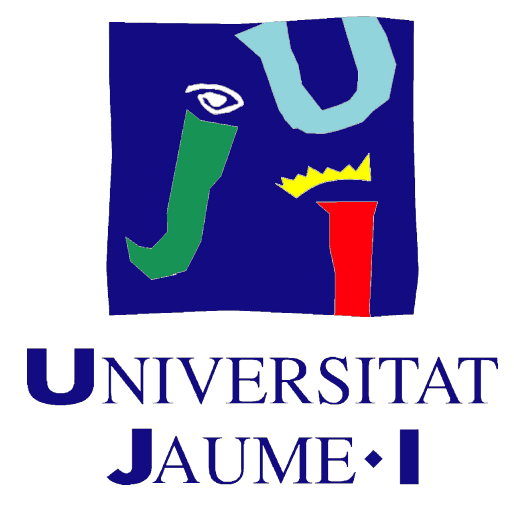

Departament D'Enginyeria y CiÈnCia Dels Computadors
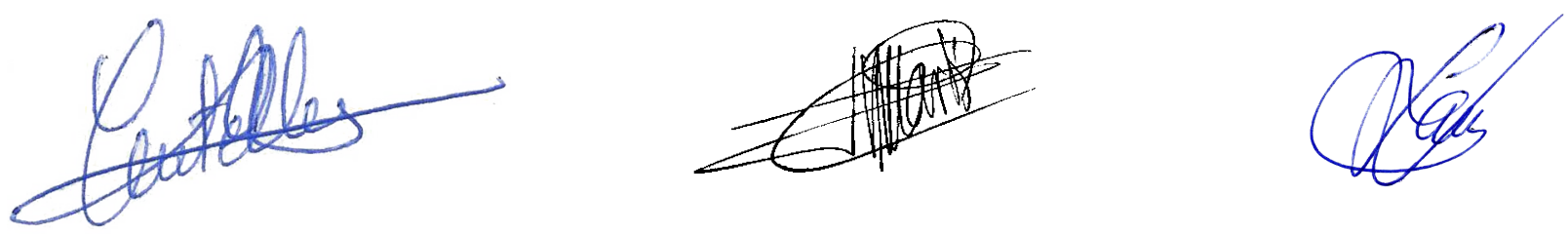



\section{Agradecimientos}

Mi más profundo agradecimiento a la vida por haber podido compartir estos inolvidables años con los mejores compañeros de equipo que se pueda tener, los del equipo IRSLab. Gracias especialmente al compañero José Javier Fernández Fresneda por sus enseñanzas y apoyo técnico en el laboratorio. También estaré eternamente agradecido al profesor Antonio Soriano Asensi de la Universidad de Valencia por sus lecciones y su ayuda en la investigación. Agradecido también a todos los miembros del equipo VICOROB de la Universidad de Girona por haberme dado la oportunidad de investigar unos meses con ellos en el Centro de Investigación en Robótica Submarina (CIRS). Por supuesto, agradecimientos especiales por el apoyo y la confianza depositada en mí por parte de mi tutor, el profesor Raúl Marín Prades, y mis directores de tesis, los profesores José Vicente Martí Avilés y Pedro José Sanz Valero. También quisiera agradecer al grupo AUTOMAR la concesión del premio AUTOMAR 2018 Profesor Jesús Manuel de la Cruz por el trabajo "Arquitectura para teleoperación inalámbrica con realimentación visual de ROVs basado en Ardusub", el cual es una de las pequeñas contribuciones de este trabajo. Por último, quisiera agradecer a mi familia y amigos su paciencia y apoyo moral desde que empecé este camino sin fin del investigador.

\section{Financiación}

La investigación ha sido financiada principalmente por el Gobierno de España a través de la ayuda predoctoral BES-2015-073112 del proyecto DPI2014-57746-C3 (MERBOTS). También ha sido financiada parcialmente por el proyecto nacional DPI2017-86372-C3 (TWINBOT); por la Generalitat Valenciana a través del programa PROMETEO y el proyecto IDIFEDER/2018/013 y por la Universitat Jaume I a través del proyecto NEPTUNO. 



\section{Motivación}

La robótica cooperativa subacuática ofrece la posibilidad de realizar aplicaciones de intervención cada vez más desafiantes, como agarrar, recuperar, transportar y ensamblar objetos que, por sus dimensiones o peso, puedan requerir más de un vehículo de intervención. Para mejorar la seguridad, durante la intervención, es razonable evitar los umbilicales, lo que también proporciona más movilidad a los robots y permite un conjunto más amplio de movimientos cooperativos. No obstante, todavía hoy día resulta extremadamente difícil no depender de los umbilicales cuando se precisa, por ejemplo, recibir video o imágenes en tiempo real de la cámara de un robot submarino. Esto es debido a que los sistemas y protocolos de comunicación inalámbrica terrestres, la mayoría basados en el uso de radiofrecuencia, no funcionan en un entorno submarino debido a la extrema atenuación que sufren este tipo de ondas en el agua. Los dispositivos de comunicación submarinos, la mayoría basados en el uso de ondas acústicas, suelen ser dispositivos muy caros que ofrecen un ancho de banda muy limitado, normalmente insuficiente para supervisar y controlar una intervención con robots sin perder el feedback visual de las cámaras. Además, los enlaces acústicos son muy propensos a errores en la transmisión por diversos factores. Por un lado, la presencia de formas sólidas cercanas y los cambios de medio, como el suelo o la superficie marina y objetos grandes en suspensión producen ruido por el efecto multi-path. Por otro lado, el ruido acústico ambiental, como motores, el oleaje o los sonidos de los animales producen interferencias en la señal de comunicación acústica.

Además, el esfuerzo de la comunidad científica se ha centrado mayormente en el diseño de protocolos ad-hoc para redes inalámbricas submarinas (UWN), compuestas mayoritariamente por nodos estáticos, como pueden ser boyas y módulos sensoriales anclados en el fondo marino. Este tipo de redes suelen usarse para estudiar el fondo marino, tareas de vigilancia, navegación asistida o prevención de desastres naturales. Es por esto que, en la mayoría de los casos, los trabajos relacionados con mejorar las UWN se han centrado en desarrollar protocolos eficientes con el objetivo 


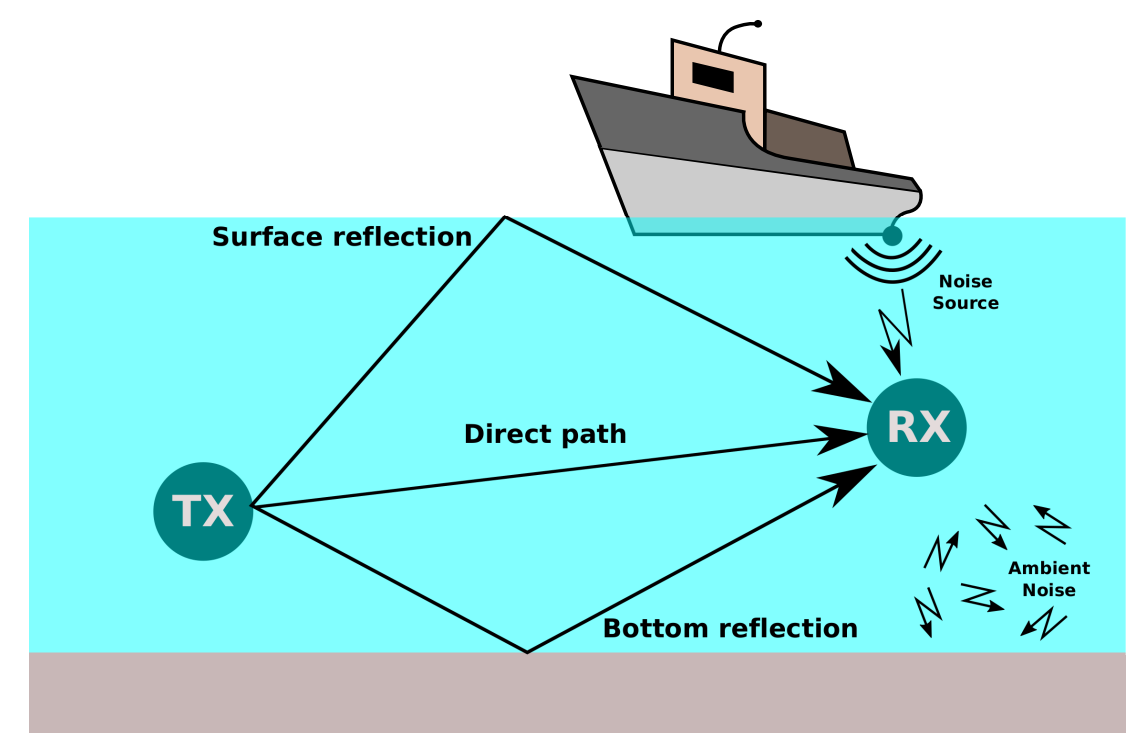

Figura 1: Multipath y ruido ambiental en comunicaciones acústicas.

de prolongar la duración de las baterías de los nodos de una red inalámbrica de sensores submarinos (UWSN). Esto se comprende por el interés de reducir los costos de mantenimiento, lo cual ha influido a que la mayoría de estos trabajos no hayan dado prioridad a optimizar aspectos esenciales de las comunicaciones para tareas de intervención robótica, como es la minimización del retardo de extremo a extremo y, sobretodo, la variación del mismo (jitter). Por otro lado, las UWSN son redes multi-hop donde los paquetes recorren distancias de un centenar de metros en cada salto. Esto ha obligado a que la mayoría de protocolos para UWN hayan sido diseñados y probados exclusivamente para enlaces acústicos, los cuales son los únicos que permiten alcanzar estas distancias. Esto hace que la variabilidad del retardo, o jitter, sea todavía más elevada en los paquetes transmitidos en una UWN por diversas razones. Por un lado, la escasa velocidad de transmisión de los dispositivos de comunicación submarina hace que las retransmisiones de paquetes perdidos provoquen grandes fluctuaciones en el retardo de los mensajes enviados. Por otro lado, teniendo en cuenta la baja velocidad de propagación de las ondas acústicas $(1500 \mathrm{~m} / \mathrm{s})$, cualquier variabilidad en las propiedades del agua durante el tiempo de vuelo de un paquete, como puede ser la temperatura o la salinidad del agua, también provoca que la velocidad de propagación del paquete no se mantenga constante desde que es enviado hasta que es recibido completamente. 
Como se ha podido observar, la eliminación completa de los umbilicales en una intervención robótica bajo el agua no resulta una tarea sencilla. Debido a que no podemos prescindir de la tecnología acústica para establecer enlaces de media o larga distancia, resulta necesario focalizar esfuerzos en el diseño de protocolos específicos óptimos para tareas robóticas submarinas que minimicen tanto el retardo como su variabilidad. Además, el supervisor de un equipo de robots submarinos suele necesitar, no sólo recibir la posición de los mismos en tiempo real, si no también la información visual proveniente de las cámaras. Esto obliga, no solo a la utilización de algoritmos de compresión eficientes, sino también a la utilización de protocolos cross-layer que maximicen la tasa de envío de este tipo de datos. Por otro lado, existen otras tecnologías, como la radiofrecuencia de onda larga o la basada en el uso de ondas del espectro de la luz visible que resultan ventajosas en distancias cortas por su inmunidad al ruido acústico ambiental, por su su alta y, prácticamente, constante velocidad de propagación y la posibilidad de incrementar considerablemente el ancho de banda disponible. Por lo tanto, parece lógico pensar que cualquier tipo de robot submarino debería, no sólo ejecutar unos protocolos de comunicación óptimos desde el punto de vista de la telerobótica, sino también incorporar un sistema de comunicación multimodal que sea capaz de utilizar un dispositivo u otro dependiendo de la distancia del enlace, la visibilidad o las propiedades del agua. Por otro lado, el desarrollo de un sistema como el que se propone requiere la utilización de una herramienta que facilite la simulación de los agentes robóticos considerando, también, el efecto de los sistemas de comunicación. Además, esta utilidad debería permitir la realización de experimentos HIL (Hardware In the Loop), es decir, la utilización de robots reales modelando las comunicaciones y viceversa. No obstante, las herramientas actuales para el modelado de las comunicaciones submarinas están orientadas a la simulación de protocolos para redes de sensores (UWSN) y no para un equipo de robots. Por otro lado, aunque existen soluciones que permiten la simulación de protocolos sobre módems reales, ninguna de estas utilidades facilita la simulación del sistema de comunicación de un equipo de robots simulados o reales teniendo en cuenta 
la disposición de los mismos en el escenario. Por lo tanto, es necesario que el primer esfuerzo se focalice en el diseño de una herramienta que facilite la labor de las futuras investigaciones en este campo. 



\section{Índice}

$\begin{array}{ll}\text { Agradecimientos } & 2\end{array}$

$\begin{array}{ll}\text { Motivación } & 4\end{array}$

1. Sinopsis de la tesis 13

1.1. Contribuciones ..................... . . 13

1.1.1. Primera contribución . . . . . . . . . . . . 13

1.1.2. Segunda contribución . . . . . . . . . . . . . . . 14

1.1.3. Tercera contribución . . . . . . . . . . . . 16

1.2. Experimentación preliminar . . . . . . . . . . . . 17

1.3. Introducción . . . . . . . . . . . . . . . . . . 20

2. UWSim-NET 22

2.1. Introduction . . . . . . . . . . . . . . . 23

2.2. UWSim-NET . . . . . . . . . . . . . . . . . 27

2.2.1. Generic Link Interface . . . . . . . . . . . . . . 29

2.2.2. DCComms Network Simulator . . . . . . . . . 29

2.2.3. UWSim-NET XML . . . . . . . . . . . . . . . . 32

2.3. Results . . . . . . . . . . . . . . . . . . . . 32 
2.3.1. Physical Layer . . . . . . . . . . . . . . . . . 33

2.3.2. MAC Layer . . . . . . . . . . . . . . . 36

2.3.3. Remote ROV Team Control in HIL . . . . . . . . . 41

2.4. Conclusions ..................... . . . 44

3. Wireless HROV Control $\quad 47$

3.1. Introduction . . . . . . . . . . . . . . 48

3.1.1. Outline .................. 50

3.2. MERBOTS and TWINBOT Projects . . . . . . . . 51

3.3. Underwater Multirobot Cooperative Intervention Network Architecture (UMCI-NA) . . . . . . . . . . . 53

3.3.1. Overall Network Architecture . . . . . . . . . . 53

3.3.2. Underwater Multirobot Cooperative Intervention Remote Control Protocol (UMCI-RCP) . . . . . . 55

3.3.3. Routing Layer . . . . . . . . . . . . . . . 60

3.3.4. Generic Link Layer . . . . . . . . . . . . . . 60

3.4. Experimental setup . . . . . . . . . . . . . . . 62

3.4.1. Upgrade of the BlueROV Platform to enable RF wireless remote control . . . . . . . . . . . . . 62

3.4.2. BlueROV Positioning Control . . . . . . . . . . 64

3.4.3. UWSim-NET . . . . . . . . . . . . . 65

3.5. Results . . . . . . . . . . . . . . . . 67

3.5.1. HIL Experiments Software Architecture . . . . . . 67

3.5.2. Teleoperation with RF modems . . . . . . . . 69

3.5.3. Position Commands and Communication Recovery 72 
3.6. Conclusions . . . . . . . . . . . . . . . . . . . 74

4. UMCI-MAC 76

4.1. Introduction . . . . . . . . . . . . . 77

4.2. UMCI-MAC . . . . . . . . . . . . . . . . . 81

4.3. Results ....................... . . 85

4.3.1. Performance evaluation of UMCI-MAC . . . . . . 85

4.3.2. UMCI-MAC Remote Control of a team of AUVs in HIL . . . . . . . . . . . . . . . . 94

4.4. Conclusions . . . . . . . . . . . . . . . 100

5. Discusión y conclusiones 103

5.1. Conclusiones . . . . . . . . . . . . . . . . 103

5.2. Trabajo futuro . . . . . . . . . . . . . 107

5.3. Lista de publicaciones . . . . . . . . . . . . . 110

5.3.1. Revistas . . . . . . . . . . . . . 110

5.3.2. Congresos Internacionales . . . . . . . . . . 111

5.3.3. Congresos Nacionales . . . . . . . . . . . . . . . . . 112 



\section{Capítulo 1}

\section{Sinopsis de la tesis}

El objetivo principal de esta tesis ha sido trabajar hacia una arquitectura y protocolos de red óptimos para las comunicaciones inalámbricas submarinas con robots.

En primer lugar, en la sección 1.1 de este capítulo se describen brevemente las tres contribuciones principales de la tesis. Estos trabajos fueron motivados por los resultados obtenidos en una primera fase de la investigación en la que se desarrollaron los primeros prototipos de sistemas de localización y comunicación inalámbrica. Este trabajo preliminar constituye la primera etapa de desarrollo de la tesis, por lo que se ha resumido muy brevemente en la sección 1.2. Por último, en 1.3 se introducen los capítulos restantes de este documento.

\subsection{Contribuciones}

Esta tesis concluye en tres contribuciones principales. Cada una de las cuales ha sido publicada en una revista de impacto JCR (Journal Citation Reports) diferente, estando cada una situada en uno de los tres primeros cuartiles.

\subsubsection{Primera contribución}

En primer lugar, durante el desarrollo de esta tesis doctoral se ha requerido la utilización de una herramienta que facilite el desarrollo de pro- 
tocolos de red y la experimentación en tiempo real de los mismos de forma completamente simulada o mediante experimentos Hardware In the Loop (HIL) con módems o robots reales. Debido a la inexistencia de esta herramienta, el primer objetivo de esta tesis doctoral ha sido el desarrollo y la integración de un módulo de comunicaciones basado en Network Simulator 3 (NS3) para el simulador de Robot Operating System (ROS) para robótica submarina UWSim (Underwater Simulator). Los resultados con UWSim-NET han demostrado ser fieles a los obtenidos en la realidad, siendo capaz de simular en tiempo real tanto enlaces half-duplex como full-duplex, teniendo en cuenta la atenuación de la señal y las posibles colisiones. UWSim-NET ha demostrado simular fielmente módems reales de tipo RF y acústicos utilizando un modelo estadístico del mismo obtenido de forma empírica. Por otro lado, UWSim-NET integra algunos protocolos MAC conocidos para redes de sensores inalámbricas submarinas (UWSN) permitiendo su experimentación sobre equipos de robots. En el artículo mostrado en el capítulo 2 se explica la arquitectura del simulador, además de demostrar mediente resultados experimentales el funcionamiento del mismo.

Esta herramienta ha sido la base de desarrollo y experimentación durante el transcurso de la investigación, siendo pieza fundamental de las siguientes dos aportaciones de este trabajo. En el siguiente apartado se resume UMCI-NA, una arquitectura para la supervisión inalámbrica de robots submarinos.

\subsubsection{Segunda contribución}

UWSim-NET se encuentra integrado en una nueva arquitectura de red a la que hemos llamado UMCI-NA (Underwater Multirobot Cooperative Intervention Network Architecture), la cual es otra aportación de este trabajo. UMCI-NA supone un avance en la supervisión y control mediante una comunicación multimodal, es decir, utilizando distintos tipos de tecnologías inalámbricas. Dentro de esta arquitectura se ha desarrollado un protocolo de control remoto cross-layer que utiliza el algoritmo de compre- 
sión de imágenes progresivo Depth Embedded Block Tree (DEBT) [61]. Este algoritmo, al que hemos llamado UMCI-Remote-Control-Protocol (UMCI$\mathrm{RCP})$ permite la transmisión de comandos e imágenes en tiempo real sobre canales half-duplex extra limitados, habiendo sido probado con éxito en entorno real en dispositivos que no superan los $1.9 \mathrm{kbps}$. La arquitectura ha sido probada en experimentos HIL de control inalámbrico de robots con módems reales, tanto de RF como acústicos, y robots reales y simulados. Estos experimentos demuestran la viabilidad de un sistema de control supervisado completamente inalámbrico, sin perder la retroalimentación visual, utilizando un protocolo ad-hoc basado en el uso del algoritmo DEBT y realidad virtual. El uso de DEBT para la compresión de las imágenes se justifica por ofrecer mejor calidad que otros algoritmos como JPEG cuando se requiere mayor compresión de los datos. Además, los algoritmos de compresión progresivos como DEBT funcionan especificando el tamaño deseado de la codificación de la imagen. Esto facilita la reducción de la variabilidad en el tamaño de los paquetes y, en consecuencia, la reducción del jitter (variación del retardo). Por otra parte, este funcionamiento posibilita que el protolo UMCI-RCP pueda mantener una tasa de recepción de imágenes adecuando el tamaño de las mismas al ancho de banda disponible. Otra capacidad de DEBT es la posibilidad de especificar una región de interés en la imagen o ROI (Region Of Interest), de manera que sea posible obtener más detalle en esa región, sacrificando la calidad del resto de la imagen, pero manteniendo el mismo tamaño de compresión. Estas capacidades se explotan en un HRI (Human Robot Interface) desarrollado por encima de UMCI-RCP, permitiendo al operador modificar los parámetros de la imagen (ROI, calidad), obtener feedback del robot y enviar comandos de control de bajo y alto nivel. Todos los detalles y experimentos relacionados con este trabajo se explican en el artículo mostrado en el capítulo 3 .

Cuando el dispositivo de comunicación no integra un protocolo de acceso al medio, UMCI-RCP ejecuta una modalidad basada en una estrategia Time Division Multiple Access (TDMA) maestro-esclavo que evita las colisiones en la comunicación entre el supervisor y los robots. En este modo, 
cada esclavo (robot) sólo transmite datos cuando el nodo máster (lado del supervisor) le pregunta directamente. No obstante, este protocolo resulta poco escalable debido a que el tiempo de ocupación del canal por parte del máster depende directamente del número de esclavos. Esto hace que añadir un robot más al escenario repercuta en un aumento considerable del retardo. Con el fin de mejorar la escabilidad sin afectar tan negativamente al retardo y, al mismo tiempo, manteniendo un jitter mínimo, se ha diseñado un protocolo MAC para equipos de robots cooperativos. Este protocolo, el cual constituye la tercera y última contribución importante de esta tesis, se resume brevemente en la siguiente sección.

\subsubsection{Tercera contribución}

La última aportación de este trabajo ha sido el diseño de un protocolo de acceso al medio para equipos de robots cooperativos submarinos. Este protocolo ha recibido el nombre de UMCI-MAC por haber sido integrado en la arquitectura presentada en la sección anterior.

$\mathrm{Al}$ igual que en el caso de UMCI-RCP, UMCI-MAC utiliza un algoritmo TDMA maestro-esclavo para evitar completamente las colisiones. No obstante, UMCI-MAC evita ocupaciones del canal innecesarias por parte del maestro otorgando una pequeña ranura de tiempo fija a cada esclavo para que éste pueda solicitar la ocupación del canal. El protocolo divide el tiempo en ciclos, cada uno de los cuales empieza con una señal de sincronización por parte del maestro. Dentro del mismo paquete de sincronización también se incluyen flags de reconocimiento de recepción de paquetes enviados por los esclavos con destino al maestro. Tras la señal de sincronización empieza una fase donde los esclavos pueden pedir la ocupación del canal y notificar la recepción de paquetes en el ciclo anterior. En la siguiente fase del ciclo el maestro otorga, por orden de prioridad, la ocupación del canal a cada uno de los esclavos que lo ha pedido en la fase anterior del mismo ciclo. En esta última fase el maestro también puede enviar paquetes de datos a los esclavos en cualquier momento. Por último, el maestro empieza un nuevo ciclo enviando, otra vez, un paquete de sin- 
cronización desencadenando una nueva ronda de peticiones por parte los esclavos.

UMCI-MAC ha sido comparado con otros dos protocolos MAC para UWN utilizando diversas topologías de red y mediante experimentos HIL con robot real y tres robots simulados ejecutando movimientos de forma coordinada. Los resultados han demostrado que UMCI-MAC ofrece una clara ventaja en términos de retardo y jitter, además de mantener una eficiencia igual o superior a la obtenida con los otros dos protocolos. Todos los detalles sobre el funcionamiento del algoritmo y los experimentos ejecutados se encuentran explicados en el artículo expuesto en el capítulo 4.

\subsection{Experimentación preliminar}

Los resultados de trabajos previos a los introducidos anteriormente motivaron el desarrollo de UWSim-NET y toda la experimentación de protocolos de comunicación posterior con robots y módems inalámbricos submarinos.

El primero de estos trabajos se inspiró en el proyecto nacional de investigación TRITON [72]. TRITON abordaba el problema de la manipulación autónoma sobre paneles submarinos (ver Fig.1.1(a)) en el contexto de los observatorios permanentes (apertura/cierre de válvulas o inserción/extracción de conectores). El primer trabajo relacionado con las comunicaciones inalámbricas para tareas de intervención robótica consistió en el desarrollo de un sistema de localización de un brazo robótico mediante tres balizas con transmisores acústicos y de RF. El objetivo del sistema de balizas era posibilitar una localización precisa incluso en condiciones de escasa visibilidad en las que los algoritmos basados en visión no son de utilidad. El sistema estimaba las distancias entre las balizas utilizando la técnica Time Difference of Arrival (TDoA) para posteriormente obtener la posición relativa del objetivo a manipular con respecto al brazo (ver algoritmo en Fig. 1.1(b)). En la Fig. 1.1(a) se puede observar la disposición de las balizas en el panel y la del brazo en un experimento real en el 
laboratorio. Aunque este sistema no llegó a utilizarse en los experimentos finales del proyecto TRITON, los detalles y resultados del trabajo fueron presentados en el congreso nacional organizado por el Comité Español de Automática (CEA)[9].

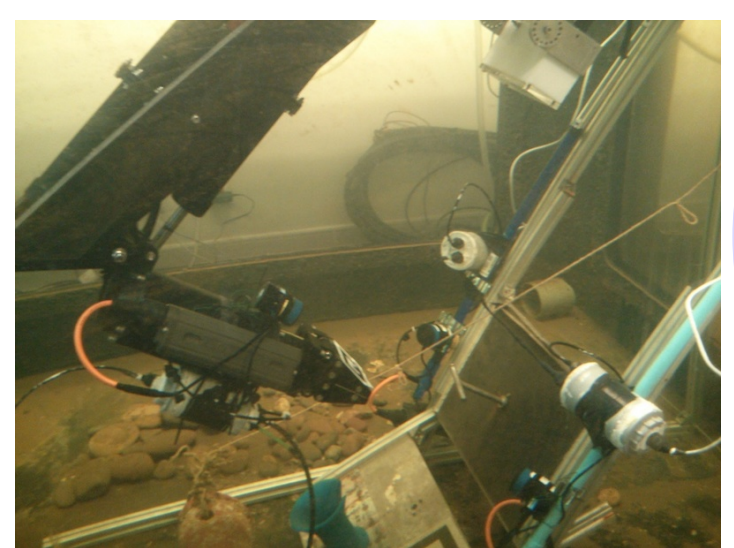

(a)

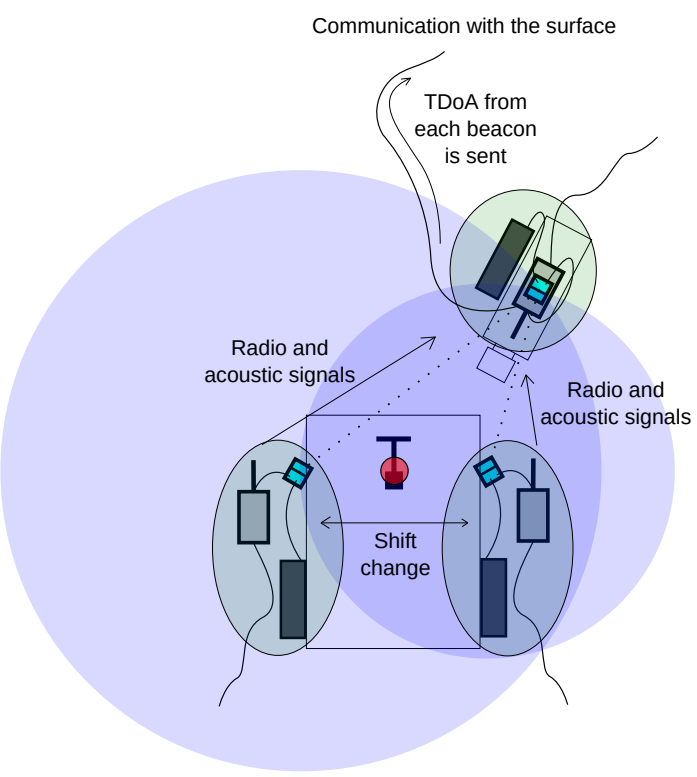

(b)

Figura 1.1: Localización de un brazo robótico mediante triangulación utilizando señales acústicas y de RF.

Los resultados del sistema de localización mediante TDoA motivaron la investigación para el desarrollo de un dispositivo subacuático para la transmisión de imágenes por radiofrecuencia en entornos de agua dulce. En primer lugar se desarrolló un prototipo de un sistema para la transmisión de imágenes comprimidas mediante JPEG (Joint Photographic Experts Group ) utilizando la banda UHF (Ultra High Frequency), con modulación FSK (Frequency-shift keying). Los resultados de este prototipo fueron publicados en [63] y [7]. Posteriormente se mejoró el prototipo sustituyendo el algoritmo JPEG por el algoritmo de compresión progresivo DEBT, citado anteriormente en la sección 1.1.2. Esta segunda versión del sistema de transmisión de imágenes se integró en una mejora del HRI (Human Robot Interface) de un ROV (Remotely Operated underwater Vehicle) basado en la plataforma de código libre OpenROV ${ }^{1}$. Los resultados de esta mejora

\footnotetext{
${ }^{1}$ https://github.com/OpenROV
} 
fueron publicados en [62] y motivaron el desarrollo del HRI y el protocolo UMCI-RCP integrados en la arquitectura UMCI-NA, introducida en 1.1.2 y desarrollada en el capítulo 3 como una de las tres contribuciones más relevantes de esta tesis. Como se verá en el capítulo 3, los últimos experimentos con vehículo submarino se han realizado utilizando un robot basado en la plataforma BlueROV ${ }^{2}$, la cual ofrece mayor número de grados de libertad y facilidad para la integración de nuevo hardware.

Los resultados con el prototipo del sistema de comunicación por RF fueron esperanzadores puesto que se demostró la posibilidad de transmitir imágenes bajo el agua de forma completamente inalámbrica a muy bajo coste. No obstante, este sistema tenía serios problemas que no lo hacían interesante para su integración en un vehículo submarino real. Por un lado, las frecuencias utilizadas eran todavía demasiado altas para poder propagarse correctamente a través de agua salada. Por otro lado, el prototipo era poco robusto y muy dependiente de las características del escenario puesto que la distancia máxima conseguida en los experimentos ejecutados en agua dulce variaba entre los 0.7 y 6 metros. Posteriormente, con el propósito de incrementar el alcance del enlace se intentó mejorar el prototipo utilizando una banda inferior de frecuencias para mejorar la propagación de la señal en el agua. No obstante, aunque se obtuvieron resultados prometedores en experimentos en el aire mediante dispositivos SDR (Software Defined Radio) y usando la banda HF (High Frecuency), la falta de un diseño para el encapsulado de la electrónica y el acoplamiento de una antena, necesariamente de mayores dimensiones, obligó a que la repetición de un experimento similar en un entorno submarino no se ejecutase, siendo éste establecido como trabajo futuro. Un vídeo del experimento en el aire con SDR transmitiendo imágenes comprimidas con DEBT y modulando con FSK a $5 \mathrm{MHz}$ fue presentado en las jornadas de automática marítima (AUTOMAR) del $2015^{3}$.

Tras estos intentos de mejora de la capa física de las comunicaciones se decidió focalizar esfuerzos en la mejora de las capas superiores para

\footnotetext{
${ }^{2}$ urlhttps://bluerobotics.com/

${ }^{3} \mathrm{https}$ ://www youtube. com/watch?v=SL41DRIt0sE\&feature=emb_title
} 
contrarrestar los inconvenientes de la mayoría de módems inalámbricos submarinos. De esta manera se inició el desarrollo de UWSim-NET y la experimentación con módems acústicos y de RF comerciales para su posterior modelado en el simulador.

\subsection{Introducción}

Tal y como ya se ha introducido en la sección 1.1, cada uno de los tres capítulos siguientes desarrolla una de las tres contribuciones principales de esta tesis. El contenido de cada uno de ellos corresponde con un artículo de investigación publicado en una revista de impacto. El orden de estos capítulos se ha establecido según el orden cronológico de los trabajos expuestos en los mismos. De esta manera, en el primero de estos tres (capítulo 2) se exponen los detalles de la nueva herramienta para simulación de redes de robots submarinos UWSim-NET. Utilizando esta herramienta se desarrolló la segunda parte de esta tesis, la arquitectura UMCI-NA para la supervisión de robots submarinos sin umbilicales, la cual está desarrollada en el capítulo 3. Finalmente, en el capítulo 4 se desarrolla la tercera parte importante de la tesis, la cual corresponde con el protocolo UMCI-MAC, integrado en la arquitectura UMCI-NA.

Por último, en el capítulo 5 se resumen los resultados de esta tesis y se exponen algunas propuestas de trabajos futuros. En el mismo capítulo se muestra un listado de publicaciones donde se incluyen aquellas desarrolladas en los capítulos 2,3 y 4. 



\section{Capítulo 2}

\section{Underwater Wireless Communications for Cooperative Robotics with UWSim-NET}

\section{Publicación}

Diego Centelles, Antonio Soriano-Asensi, José Vicente Martí, Raúl Marín y Pedro J. Sanz. "Underwater Wireless Communications for Cooperative Robotics with UWSim-NET". En: Applied Sciences 9.17 (2019). ISSN: 2076-3417. DOI: 10 .3390/app9173526. URL: https : // www.mdpi . com/2076-3417/9/17/3526

The increasing number of autonomous underwater vehicles (AUVs) cooperating in underwater operations has motivated the use of wireless communications. Their modeling can minimize the impact of their limited performance in real-time robotic interventions. However, robotic frameworks hardly ever consider the communications, and network simulators are not suitable for HIL experiments. In this work, the UWSim-NET is presented, an open source tool to simulate the impact of communications in underwater robotics. It gathers the benefits of NS3 in modeling communication networks with those of the underwater robot simulator (UWSim) and the robot operating system (ROS) in modeling robotic systems. This article also shows the results of three experiments that demonstrate the capabilities of UWSim-NET in modeling radio frequency (RF) and acous- 
tic links in underwater scenarios. It also permits evaluating several MAC protocols such as additive links online Hawaii area (ALOHA), slotted floor acquisition multiple access (S-FAMA) and user defined protocols. A third experiment demonstrated the excellent capabilities of UWSim-NET in conducting hardware in the loop (HIL) experiments.

\subsection{Introduction}

Marine environments are not easy scenarios for human activities, especially when the operations have to be performed at depths larger than $50 \mathrm{~m}$. Underwater research is hampered by the requirement of developing waterproof and weight compensated devices, protected against high pressure. Despite these limitations, the range of underwater applications continuously increases. Research on archaeology or marine environment, maintenance and inspection of oil and gas infrastructures, and fish farming are some examples of human activities conducted at sea. Technological advances have enabled the automation of some of these activities, and also the cooperation of several devices in order to conduct complex tasks. The rise of the number of devices employed in underwater activities has motivated intense research in the field of underwater wireless networks to interconnect all these devices.

A current trend in robotic intervention is focused on cooperative applications with multiple remotely operated vehicles (ROV) or I-AUVs (Autonomous Underwater Vehicles for Intervention). For this, some robots conduct a given task while others perform additional activities, such as visual surveying, to provide the operator with visual feedback of the progress of the operation. The communication between the ROVs or autonomous underwater vehicles (AUV) and the operator is usually based on umbilical cables or acoustic transducers. While these approaches are valid in experiments with a small number of vehicles, the participation of more and more robots in underwater interventions require novel solutions. In general, acoustic communications are a good solution for long range transmissions (¿1000 m), but having several robots sharing the same acoustic 
channel might degrade the performance of the communication link. Therefore, alternative solutions based on radio frequency $(\mathrm{RF})[18,25,65]$ are also considered for short range communications between ROVs. The problem with $\mathrm{RF}$ is the strong attenuation of electromagnetic signals in marine water, which limits the communication range to $15 \mathrm{~m}$ [75]. Visual light communication (VLC) $[36,29,23]$ is another alternative that has a higher range than $\mathrm{RF}$, but requires that the transmitter and the receiver are aligned. The communication link based on VLC is heavily influenced by water turbidity, being hard to operate in dirty water.

The TWINBOT research project [35] is funded by the Spanish Government and led by some of the authors. It extends previous research on autonomous underwater robotic interventions $[42,55]$. TWINBOT is aimed at providing experimental evidence about cooperative manipulation with several AUVs. Several wireless approaches for underwater communication will be explored within the TWINBOT project (Figure 2.1). The communication between the operator on the surface and the AUVs will be based on an umbilical or an acoustic link (Figure 2.1a). The surface modem will be mounted either on the ship or a buoy via a Wi-Fi connection to the ship. Another goal of the TWINBOT project is to explore the suitability of a VLC or a RF network as possible solutions for communicate the two I-AUV on the seafloor (Figure 2.1b). The leader AUV will have an acoustic modem for communication with the surface, and will route the commands to the follower via an RF (or VLC) modem. The work presented in this manuscript is the simulation package developed to evaluate the communication technologies to be explored within the TWINBOT project. 


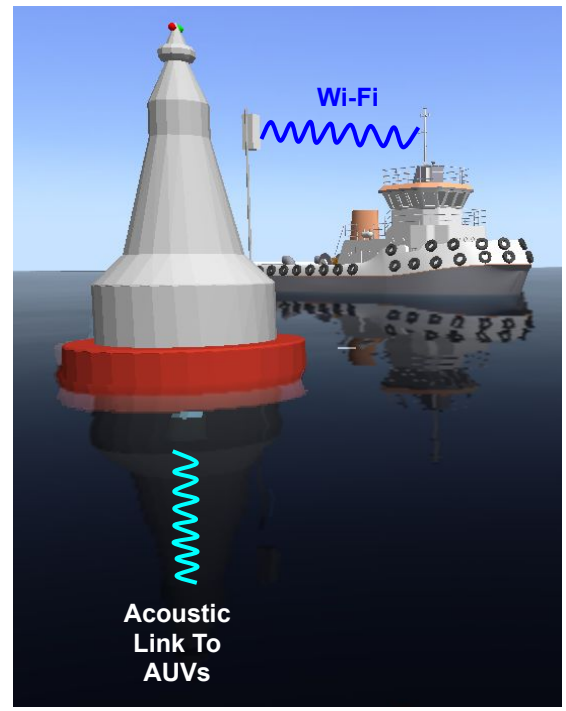

(a)

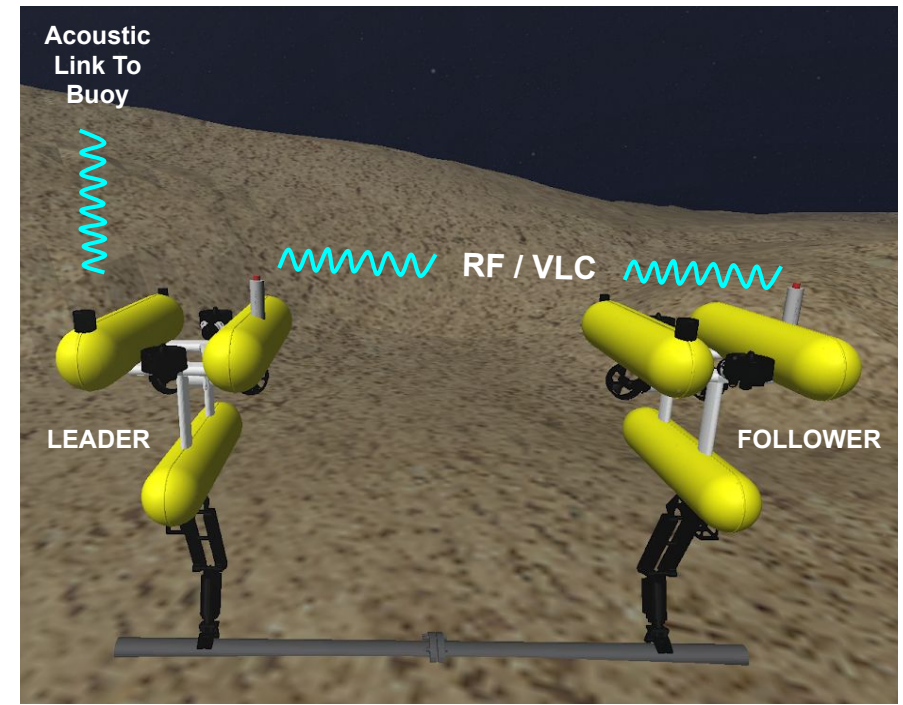

(b)

Figura 2.1: Illustration of the underwater wireless communication system envisioned for the TWINBOT project: (a) on the surface, an acoustic link from the boat or a buoy will provide communication with the AUVs; and (b) on the seafloor, the leader will incorporate an acoustic modem to communicate with the surface. A short range communication based on RF or VLC will be used between the AUVs on the seafloor.

The poor performance of wireless technologies at sea has a heavy impact on underwater applications. The modeling of the communications is therefore required to account for their high attenuation, large delay, low range, low bandwidth and low bitrate in underwater scenarios, and the limitations they impose on the application. Several software packages aim at modeling underwater wireless sensor networks (UWSN) [24]. Among them, AquaSim (github: https://github.com/rmartin5/aqua-sim-ng) $[78,39]$ is one of the most popular packages that permits the modeling of acoustic communications in UWSN. It has been implemented as a Network Simulator 3 (NS3) module, and models the majority of network protocols, from physical to routing layers. Among the UWSN protocols implemented in AquaSim [32, 3], the experiments in this manuscript consider CSALOHA and SFAMA that will be briefly described later in Section 2.2.2. The underwater acoustic network (UAN) framework is another module available in NS3, which models the physical and link layers of acoustic communications in underwater network scenarios, and also allows modeling AUVs. Its major limitation is the small number of medium access control (MAC) protocols that can be used CW-MAC [46], RC-MAC, and 
ALOHA. AquaSim permits a higher variety of MAC protocols than UAN. However, they both only permit the modeling of acoustic modems. AquaSim and UAN are excellent tools for modeling UWSN with static nodes. They are able to model moving nodes, but the movement of the nodes is required to be defined in advance, before the simulation starts, which strongly limits them to be considered as simulation tools in cooperative robotics.

Research in underwater environments requires that multiple hardware elements such as experimentation platforms, sensors and modems are properly assembled, which have to work together. Tests at sea are not appropriate for experimentation during the assembly and evaluation stages because of the high number of devices involved. Spatial limitations in the laboratory also complicates the evaluation of the complete system. Hardware-in-the-Loop (HIL) experiments take a key role during the experimentation, since they permit evaluating some of the hardware devices while the remaining devices are modeled by software. The underwater simulator (UWSim), developed by the authors [52], has proven to be an excellent tool in modeling underwater robots, and also as a Human-Robot Interface (HRI) in robotic experimentation.

In this work, we discuss some of the characteristics of UWSim-NET, an extension of UWSim for modeling the behavior of underwater wireless communications for a network of robots. UWSim-NET permits modeling the physical and link layers of an underwater wireless communication system. It also permits evaluating several MAC protocols and to freely modify the position of the nodes during the simulation in order to perform HIL tests. Some experiments conducted with UWSim-NET are also presented in order to show how it can be exploited to benefit the research community in communications for underwater robotic swarms. The remainder of the manuscript is organized as follows. The UWSim-NET is presented in Section 2.2, which details its architecture and the way the UWSim-NET elements are configured for each simulation. In Section 2.3, experiments demonstrating the capabilities of the simulator are presented. Firstly, an 
experiment with two ROVs was performed to demonstrate the modeling of the properties of the physical layer such as the packet loss, collisions, propagation delay and FIFOs. The second experiment aimed to demonstrate the ability to compare different MAC layers in a more complex scenario, such as in the case of the TWINBOT project. The last experiment consisted of the remote control of a team of cooperative robots in HIL (Hardware In the Loop), comparing the results of a teleoperation protocol over two MAC protocols. Finally, Section 2.4 summarizes the most relevant contributions presented in this manuscript.

\subsection{UWSim-NET}

On the one hand, the tools used in robotics allow modeling the kinematics of the robots, but hardly ever account for the communications. On the other hand, there are excellent tools, such as NS3, that permit the modeling of communication networks [39]. However, NS3 simulations require the position of communication nodes to be defined in advance, which hampers the realization of HIL experiments. UWSim [52] has been upgraded to model the behavior of underwater wireless communications for a network of robots. The new extension has been named UWSim-NET (github: https://github.com/uji-ros-pkg/underwater _ simulation/tree/uwsimnet-devel) [13].

The main advantage of UWSim-NET is that it is a system integrated in Robotic Operating System (ROS) [53], thus it can not only to simulate the network, but also perform a complete simulation of both the robots and the network in real-time. The movements of the robots and packet flows can be predefined before the start of the simulation as in UAN and AquaSim. UWSim-NET also allows the user to move the devices during the simulation by calling the ROS API as well as permits real traffic sent by the user applications. These two characteristics are essential to conduct HIL experiments in order to test the modems or the user application as well as to model the modems and their impact on the user application without needing to assemble real devices. 
The simulation of the communications network in UWSim-NET is based on the real-time event scheduler and other utilities of the NS3 library. It allows simulating both acoustic and custom modems. The modeling of acoustic devices is based on the NS3 module AquaSim NG [39], while RF and VLC devices are simulated as custom modems, based on a high-level statistical model that allows adjusting its bit-rate, intrinsic jitter and delay. Thus, it can reproduce the performance of a real modem. The custom device introduced in UWSim-NET allows modeling half and full duplex links. It also accounts for transmission errors caused by either signal attenuation or packet collisions. The user is able to define the behavior of a generic device by indicating the bitrate, the intrinsic delay, the jitter and the relationship of the bit error rate (BER) with the distance, which can be obtained from experimental measurements.

The architecture of UWSim-NET, shown in Figure 2.2a, is based on a modular structure. The user application module can be either a real ROV or a simulated ROV. The Generic Link Interface (GLI) is an abstraction layer between the user application and the communication layer. It is aimed at easing the realization of HIL experiments by replacing the modem (Figure 2.2b) by its model (Figure 2.2c) when the physical devices are not available. This modular architecture also permits testing the user application even when the modems are not present. AquaSim and UAN allow modeling predefined transmission fluxes between the nodes of the network. This modular architecture of UWSim-NET also allows modeling the impact of the transmission fluxes generated by user applications. 


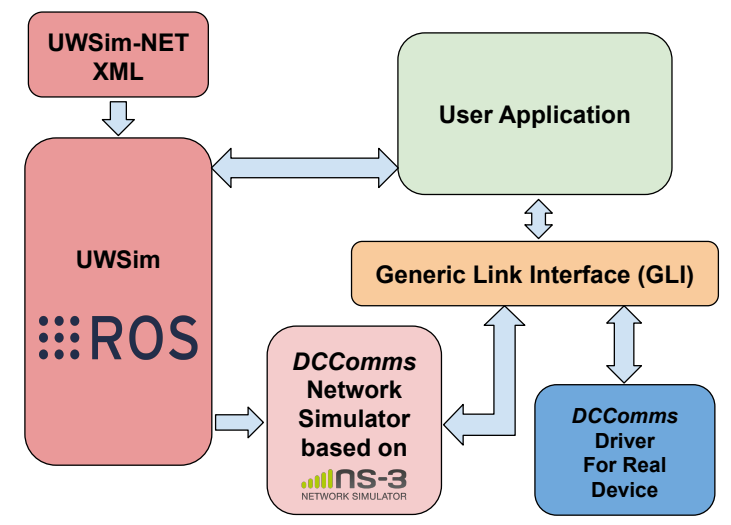

(a)

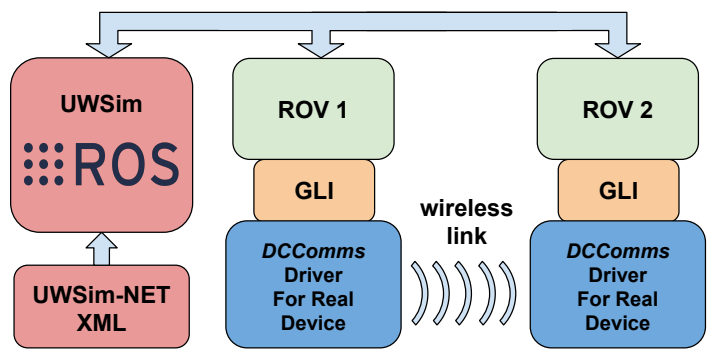

(b)

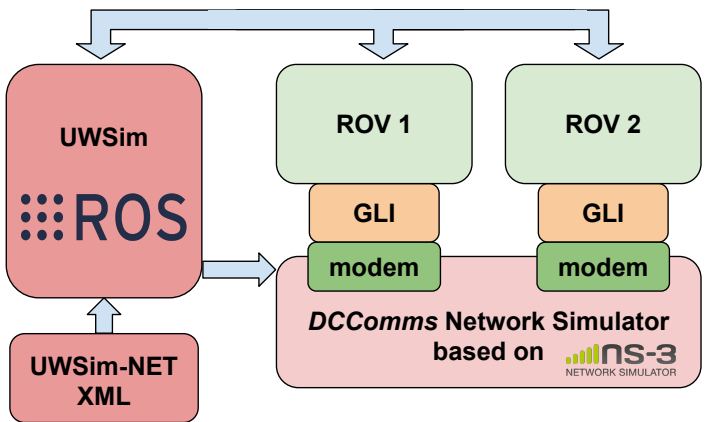

(c)

Figura 2.2: UWSim-NET Architecture: (a) block diagram of the UWSim-NET elements; (b) block diagram of an experiment with two ROVs using real modems; and (c) block diagram of an experiment with two ROVs modeling the communications.

\subsubsection{Generic Link Interface}

The GLI is a generic application program interface (API) responsible for the communication between the user application and the communication layer. The purpose of the GLI is to ease the realization of experiments either with a real device or with a modeled device with the UWSim-NET. The interchange of packets between the user application and the UWSimNET in the GLI is based on POSIX message queues [34]. To exchange messages between the user application and the module in charge of sending the message (either the simulator or the driver of a real device), they are both required to configure the same DCComms identifier.

\subsubsection{DCComms Network Simulator}

The modeling of the data link and physical layers of the underwater communication system is in charge of the DCComms Network Simula- 
tor module. An accurate modeling of signal propagation (acoustic, RF, VLC, etc.) in sea water requires the characterization of physical parameters such as temperature, salinity, etc. Such a simulation is far from the scope of UWSim-NET purposes. Instead, UWSim-NET pretends to model communication impairments caused signal propagation in physical media as propagation delay and packet loss due to signal attenuation, which depend on the distance between transmission and reception devices. Periodic requests to the transformations tree $(\mathrm{TF})$ system in ROS permit tracking the positions of the devices, and to calculate the distances among them.

- Propagation delay is calculated considering this distance and the propagation speed in the physical medium.

- The likelihood of losing a packet is determined by means of the length of each packet, and a user provided mathematical expression that relates this distance and the BER. Lost packets are randomly discarded according to it.

UWSim-NET also accounts for the communication impairments introduced by real devices as packet collisions and the time the modem requires to process and transmit (receive) each packet, which is modeled by means of an intrinsic delay and a jitter. The communication impairments considered in UWSim-NET are:

- The time the modem requires to process one packet is modeled by the addition of a fixed intrinsic delay and a Gaussian random delay (jitter): Different intrinsic delays can be defined for the transmission and the reception of a packet.

- Transmit and receive delays: The small transmission rates of underwater modems, typically of several kilobits per second (kbps), causes that the times required to transmit or receive a packet being non-negligible. These delays are modeled considering the bitrate of the modem and the length of each data packet. 
- Packet collisions: In the case a new packet arrives in a device during the transmission or reception of another packet, both packets are marked as collisions and discarded.

- Transmission FIFO stack: This is where transmission messages are stored temporarily when the device is busy. It has a finite size. Messages arriving when the transmission FIFO is full are thrown away, as occurs in real devices.

- Communication Range: Some modems specify a maximum and minimum distances that guarantee the correct performance of the device. The user can specify these distances and the UWSim-NET will discard all packets sent between two devices whose separation is outside these limits.

The incorporation of NS3 and AquaSim-NG permits UWSim-NET to use the MAC protocols implemented in AquaSim-NG. The two MAC protocols used in the experiments shown in this manuscript are:

- CS-ALOHA is a carrier sense version of the ALOHA MAC protocol. When the transmitter detects that the channel is empty, it starts to send the message. The receiver responds with an acknowledgement (ACK) after a successful read. If the transmitter does not receive the ACK within a predefined time, it considers that that the transmission failed and tries to retransmit the message.

- SFAMA (Slotted Floor Acquisition Multiple Access) divides the time into slots of fixed duration. Slot duration is related with the delay at the maximum communication distance in order to prevent the overlap of RTS messages sent by different ROVs. At the beginning of a slot, the transmitter sends a Request To Send (RTS) message and waits for the Clear To Send (CTS) message sent by the receiver on the reception of CTS. Then, the transmitter starts to send a variable length DATA message. If the transmitter does not receive the CTS message, it assumes that a collision has happened and waits for a number of slots (backoff) before the retransmission of the RTS. 


\subsubsection{UWSim-NET XML}

All the information required for each experiment is specified by the user in the UWSim-NET XML scene file, whose use is described in detail in [13]. As in UWSim, this file contains the vehicles and their initial positions. The communication channels and the communication devices on board each vehicle are also indicated in the UWSim-NET XML file which includes the following sections:

- NetTracing Script: It is the block of the xml file that allows the user to specify the NetSimTracing class with the callbacks that will handle NS3 events triggered by UWSim-NET, the library with its implementation and the name of the file where the logs will be stored.

- Communication Channels: Each channel, RF, VLC or acoustic, available in the scene will be configured in a CustomCommsChannel block of the xml file. For each channel in the scene, the user is expected to specify a unique identifier and the propagation speed.

- Communication Devices: They are defined in the block of the vehicle, or ROV, and are onboarded. Each vehicle can have as many communication devices as would be required. The user is required to indicate the DCComms identifier that has to coincide with that specified in the user application that communicates with the device via the DCComms API. The user is also expected to provide the channel identifiers the device sends and receives messages, the bitrate, the jitter, the intrinsic delay and the mathematical expression that relates the BER with the distance. The user can also select the medium access control (MAC) protocol to be used by the device.

\subsection{Results}

Several experiments were performed to demonstrate the capabilities of UWSim-NET to model the communications of a group of underwater autonomous vehicles. First, an experiment with two robots is presented 
to illustrate the communication mechanisms modeled in UWSim-NET. A second experiment simulating the teleoperation of two groups of robots is presented to demonstrate the capabilities of UWSim-NET in modeling acoustic and RF communications and several MAC protocols. A final teleoperation experiment combining a real robot and three modeled robots illustrates the possibility to conduct HIL experiments with UWSim-NET.

\subsubsection{Physical Layer}

The experiment shown in this section consisted of two robots moving away and approaching each other. The block diagram of this experiment is shown in Figure 2.2c. It illustrated the packet loss due to attenuation, and packet collisions when both robots try to transmit a message at the same time. This experiment also showed the modeling of the transmission FIFO stacks. Both robots were equipped with Seathooth S100 RF modems [76], by Wireless For Subsea. Packet loss was due to RF attenuation in sea water. The attenuation model used in this experiment was obtained empirically: $B E R=610^{-13} d^{13,7}$, being $d$ the distance between devices (in meters). The maximum and minimum ranges of the device were set to $6 \mathrm{~m}$ and $0.5 \mathrm{~m}$, respectively. 


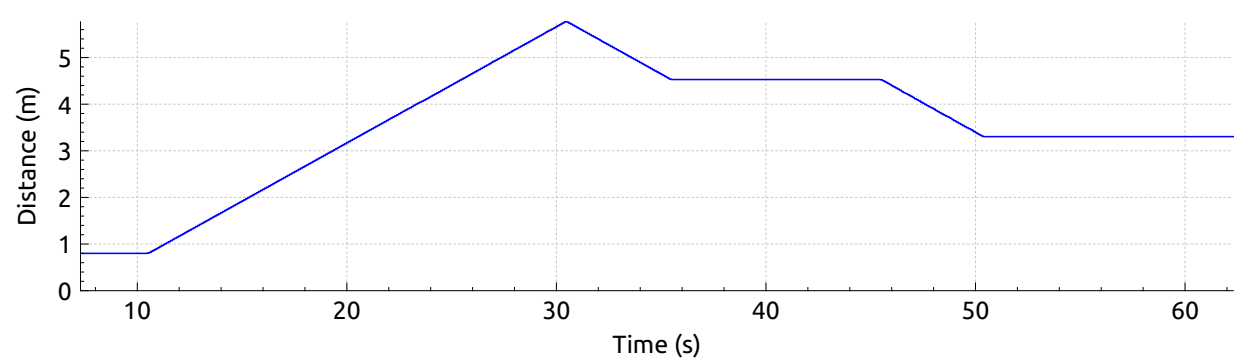

(a)

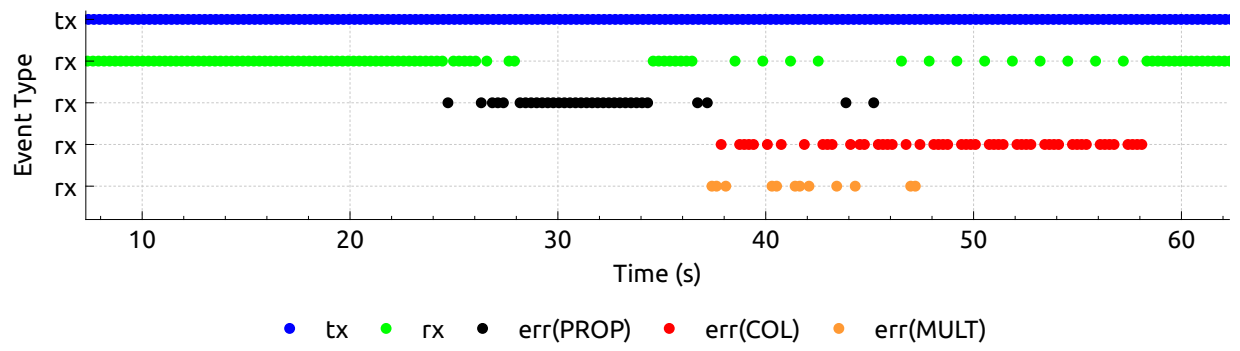

(b)

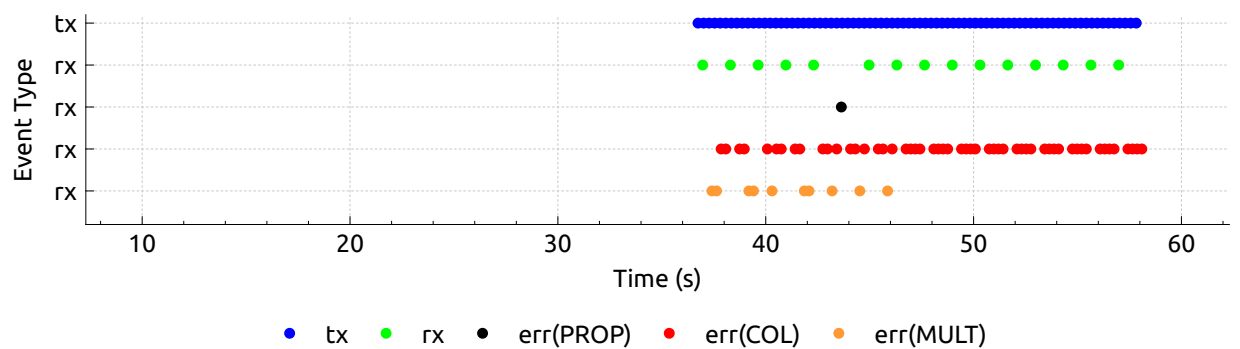

(c)

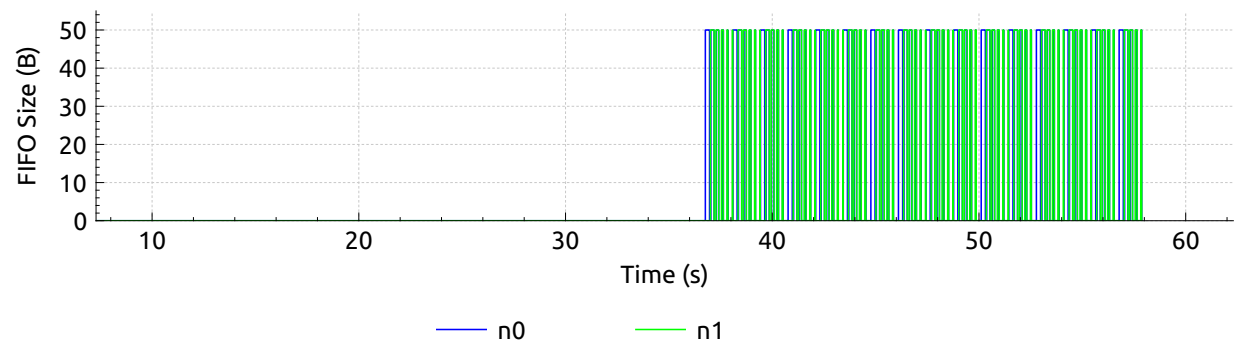

(d)

Figura 2.3: Collision of packets when two ROVs are transmitting at the same time. Transmitted packets (tx), successfully received packets (rx), packets lost due to attenuation (err(PROP)), packets lost due to collision (err $(\mathrm{COL})$ ) and packets that have suffered attenuation and collision (err(MULT)) are presented: (a) distance between the ROVs during the experiment; (b) flux of packets of the ROV that is transmitting continuously; (c) flux of packets of the ROV that starts a transmission while the other ROV is transmitting; and (d) occupation of the transmission FIFO stack.

The motion of the robots during the experiment is shown in Figure 2.3a. At the beginning of the simulation, the distance between the ROVs was 
$80 \mathrm{~cm}$. They held the position for $11 \mathrm{~s}$, and then one of the ROVs moved away from the other at a constant speed of $0.25 \mathrm{~m} / \mathrm{s}$ for $20 \mathrm{~s}$. To ensure that the loss of packets was due to attenuation and to avoid packet collisions, only one ROV transmitted while the other received the packets. The moving ROV returned at the same speed for $5 \mathrm{~s}$ and held the position at $4.5 \mathrm{~m}$ for $10 \mathrm{~s}$. Then, it moved again towards the fixed robot for $5 \mathrm{~s}$ at $0.25 \mathrm{~m} / \mathrm{s}$ and held the position at $3.3 \mathrm{~m}$. To show the packet collision, the second ROV transmitted during Seconds 37-58 during its return.

Figure 2.3b,c shows transmitted (blue dots), received (green dots) and lost (black, red and orange dots) packets when two transmission fluxes were considered from node 0 to node 1 and from node 1 to node 0 , respectively. Different colors are used to illustrate the packet loss mechanism. The packets dropped because of attenuation are marked in black, while red dots correspond to those that suffered collision. The ones that suffered both attenuation and collision are shown in orange. When the second robot started its transmission at Second 37, when the distance between the ROVs was about $4.5 \mathrm{~m}$ both, signal attenuation and collision mechanisms occurred. However, as the second ROV approached, no packets suffered from attenuation, and loses were due to packet collision.

The results shown in Figure 2.3b illustrate the continuous transmission, and how most of the packets were successfully transmitted. As the second ROV started to transmit (see Figure 2.3c), it is appreciated in both figures how many packets suffered collisions. The number of successfully transmitted packets was small in both fluxes. As the second ROV stopped sending packets, the situation of the transmission flux, as shown in Figure $2.3 \mathrm{~b}$, returned to the original situation. Both ROVs were configured to transmit at $1500 \mathrm{bps}$, which is close to the $1800 \mathrm{bps}$ maximum bitrate of the modems. When both ROVs were transmitting, some packets were stored in the transmission FIFO, as can be seen in Figure 2.3d.

The same experiment shown in Figure 2.3 was repeated modeling acoustic modems to measure the end-to-end delay, as shown in Figure 2.4. It accounted for the times required to transmit and receive the packet, and 
the propagation time. The low bitrate of the modems caused the major contributions to the end-to-end delay to be the transmission and reception times. However, it is appreciated in Figure 2.4 how the end-to-end delay increased and decreased with the distance between the robots. As it can be seen in Figure 2.3b, when node 1 started the transmission at $37 \mathrm{~s}$ the end-to-end delay rose to $\approx 430 \mathrm{~ms}$. After the transmission from node 1 stopped, the end-to-end delay values corresponded to those observed at $3.3 \mathrm{~m}$.

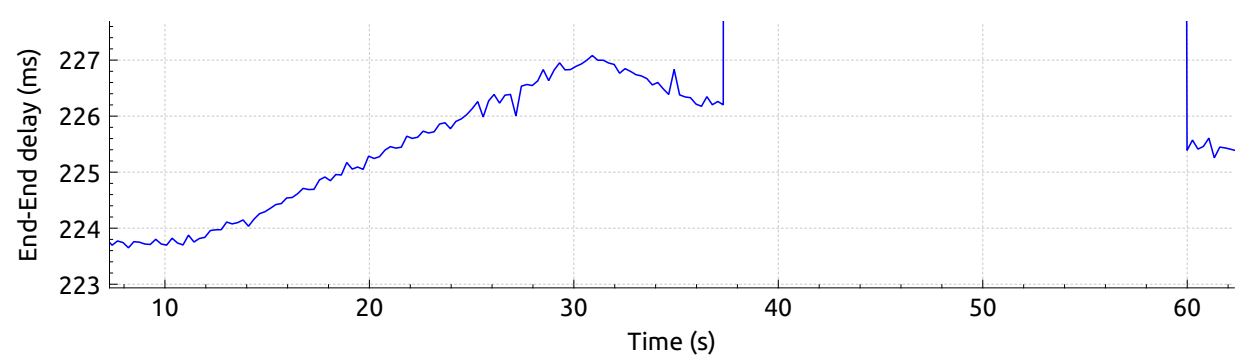

Figura 2.4: End to end delay measured with the model of an acoustic modem.

\subsubsection{MAC Layer}

This second experiment demonstrated the ability of UWSim-NET to use different MAC protocols. A scene inspired by the TWINBOT project was used as an example of a real multi-robot scenario (see Figure 2.5a). This scenario consisted of two Girona500 [54, 45] intervention AUV (IAUV), shown in yellow in Figure 2.5b, whose objective was to grasp an underwater pipe in a cooperative manner. These two vehicles shared a $\mathrm{RF}$ channel to communicate with each other. At the same time, a support vehicle (BlueROV) was connected through an umbilical to a buoy, which was connected with the operator using a WiFi link. The support vehicle tried to follow the trajectory of the I-AUVs in order to implement a communication bridge between the RF channel and the operator. In addition, four extra cooperative AUVs (BlueROV) shown in Figure 2.5a acted as explorers, making a survey over the seafloor in order to detect other objects of interest for the operator. All explorers shared an acoustic channel to communicate with a buoy in order to send visual data and receive commands from the operator. Seven ROVs were considered in this scenario: 
the two I-AUV and one BlueROV shared a RF channel and the four BlueROV shared an acoustic channel with the buoy on the surface. The block diagram of the software elements of this experiment is depicted in Figure 2.5c. The trajectories of each ROV during the experiment are shown in Figure 3.1(b).

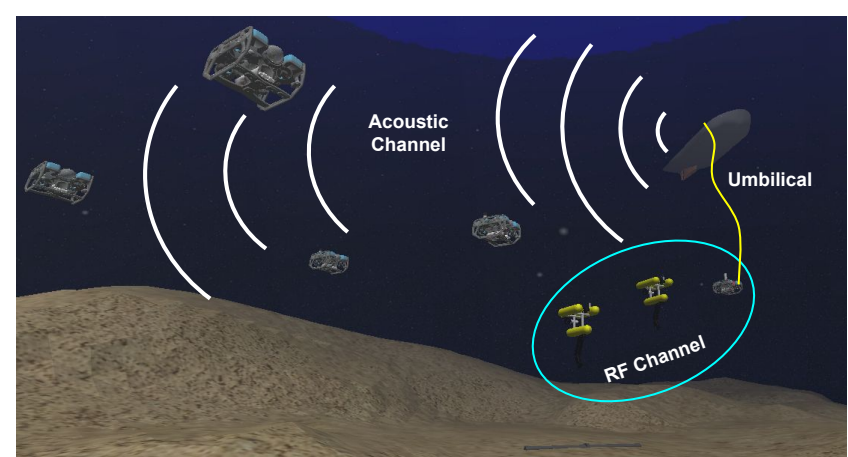

(a)

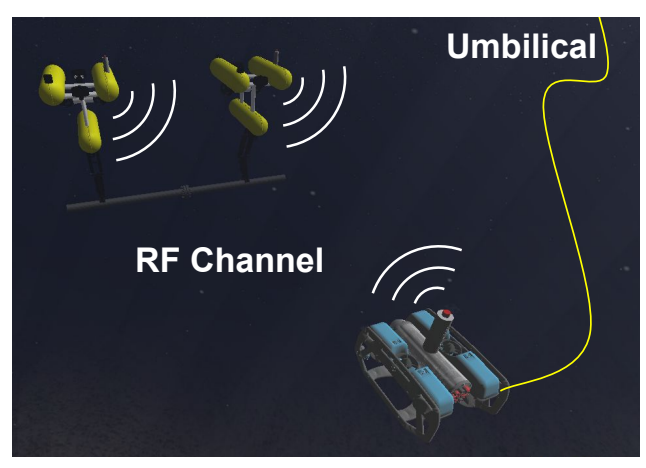

(b)

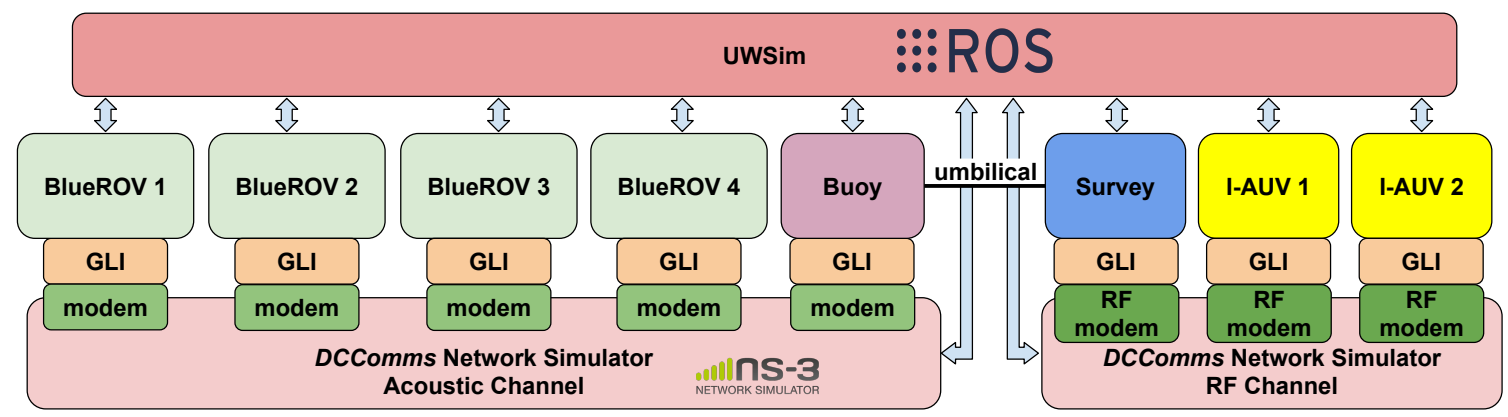

(c)

Figura 2.5: Illustration of the scenario of the second experiment. The four BlueROVs in charge of the visual surveying share the acoustic channel with the buoy on the surface. The communication between the two I-AUVs and the survey vehicle is based on an RF network: (a) general view of the scene; (b) details of the RF communication network between the two I-AUVs and the survey AUV with the umbilical to the surface; and (c) block diagram of the elements considered in this second experiment.

For this experiment, all communication devices were configured to have a transmission rate of $1.9 \mathrm{kbps}$ and a $1 \mathrm{~ms}$ intrinsic delay. Table 2.1 details the eight data flows defined for this experiment, three for RF communications and five sharing the same acoustic channel. On the one hand, each explorer sent large packets to the surface simulating the transmission of low resolution images. Simultaneously, the buoy sent small broadcast packets with commands destined to the explorers. On the other hand, the remaining three packet flows transmitted between the robots sharing the RF channel. Two of the RF packet flows corresponded to the communi- 
cation between the two I-AUV, while the third one was the packet flow transmitted from the support vehicle to the I-AUVs.

Cuadro 2.1: Throughput (Bytes per second) of each packet flow stream during the second experiment.

\begin{tabular}{lcccccccc}
\hline & \multicolumn{3}{c}{ RF } & \multicolumn{5}{c}{ Acoustic } \\
\cline { 2 - 9 } & Leader & Follower & Support & Buoy & E0 & E1 & E2 & E3 \\
\hline CS-ALOHA & 62.5 & 62.5 & 4 & 4 & 30 & 30 & 30 & 30 \\
S-FAMA & 27.5 & 27.5 & 4 & 4 & 27.5 & 27.5 & 27.5 & 27.5 \\
\hline
\end{tabular}

This experiment was repeated considering two MAC protocols: the ALOHA with carrier sensing (CS-ALOHA) and slotted FAMA (S-FAMA). First, the data rates required to send the operator's commands to the ROVS was established at $32 \mathrm{bps}$, identified as support and buoy in Table 2.1. The data flows transmitted by the I-AUV (leader and follower in Table 2.1) were expected to have a throughput as high as possible, since they were devoted to exchange the pose of leader and follower for the cooperative intervention. The same occurred with the transmissions from the explorers (E0-E3 in Table 2.1), which were expected to provide the operator with visual feedback of the seafloor, thus to adjust the data rate of each transmission at the maximum value allowed for each protocol. The resulting data rates for each experiment are shown in Table 2.1. To illustrate the relevance of the MAC layer, the same experiment was done without considering any MAC protocol. The data flows were configured as with the CS-ALOHA. 


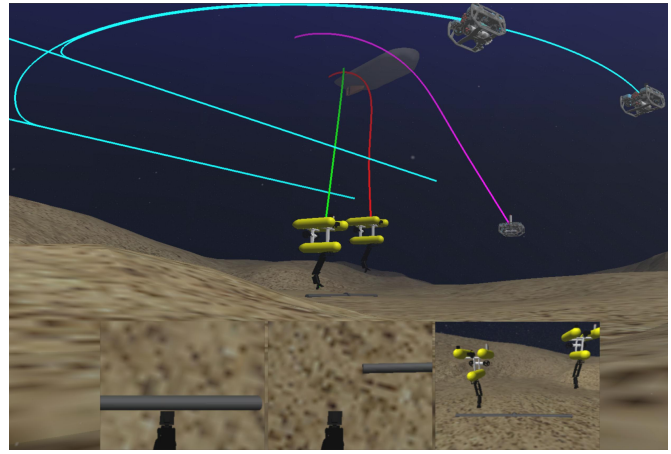

(a)

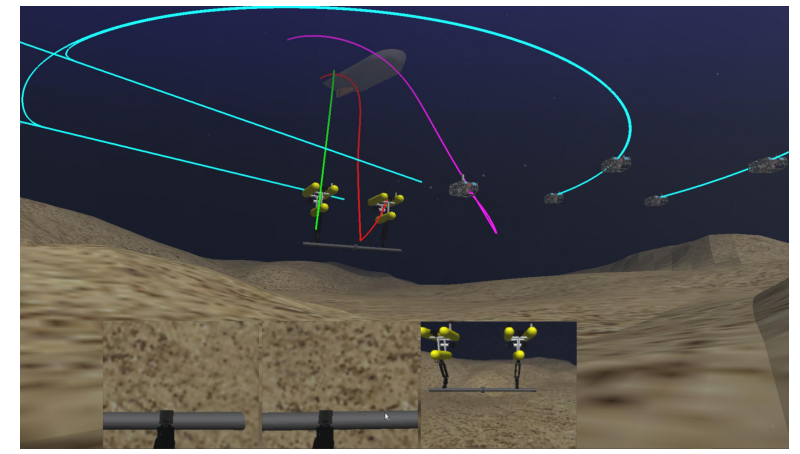

(b)

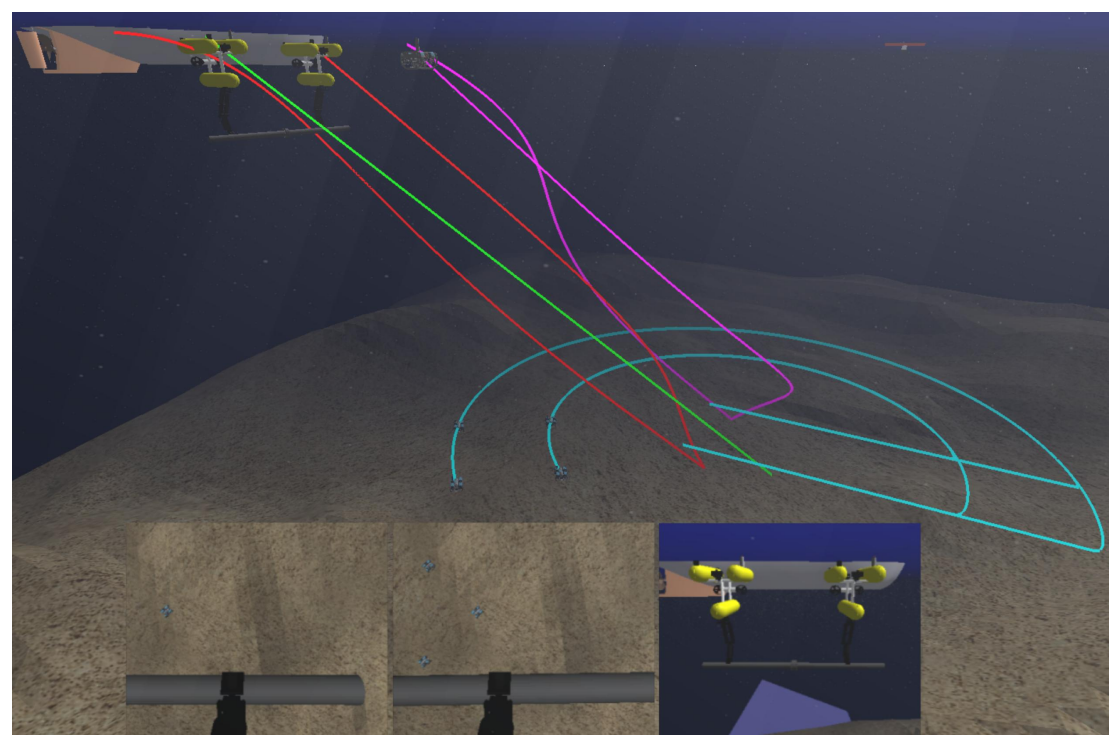

(c)

Figura 2.6: Trajectories followed by the ROVs during the experiment. The trajectories of the explorers are represented in white lines. The lines in yellow and red correspond to the trajectories of the two I-AUVs, and the line in magenta corresponds to the support ROV. Each image corresponds to a different stage of the experiment: (a) approaching; (b) cooperative grasping; and (c) transportation.

The performance achieved with each MAC protocol was compared in terms of throughput, efficiency, end-to-end delay and jitter. As expected, the throughput measured after the experiment (see Figure 2.7a), coincided with the values indicated in Table 2.1. However, when no MAC protocol was considered, only the data flows transmitted by the support, buoy and E2 succeeded in sending packets. The efficiency is the ratio of bytes successfully received to the total number of transmitted bytes. It is related with the power consumption of the communications system. It is appreciated in Figure 2.7b that the S-FAMA had a higher efficiency than CS-ALOHA in the acoustic channel, but the opposite occurred with RF channel between 
the I-AUVs and the support. This behavior might be understood considering the two different sizes of the packets used in each flux: data packets transmitted by leader, follower, support and buoy were 20 bytes long, but the image packets transmitted by the explorers were 400 bytes long. The less overhead of the CS-ALOHA, the smaller number of nodes in the RF channel and the small likelihood of small packets to collide favored the better results observed with the CS-ALOHA. On the contrary, the larger packet sizes and the higher number of nodes favored the better performance of the S-FAMA in the acoustic channel. When no MAC protocol was considered, no positive results were obtained because very few packets were successfully transmitted and the efficiency was near zero.

The end-to-end delay (Figure 2.7c), and jitter (Figure 2.7d) are related with the time lapse required to send the information between the ROVs. In general, S-FAMA achieved a lower end-to-end delay than CS-ALOHA (see Figure 2.7c). The low end-to-end delay achieved when no MAC protocol was used was due to the very low number of successfully transmitted packets. If the transmission succeeded, the packet was delivered immediately, and it had little contribution to the end-to-end delay. Concerning the jitter, comparable results were obtained with both protocols. 


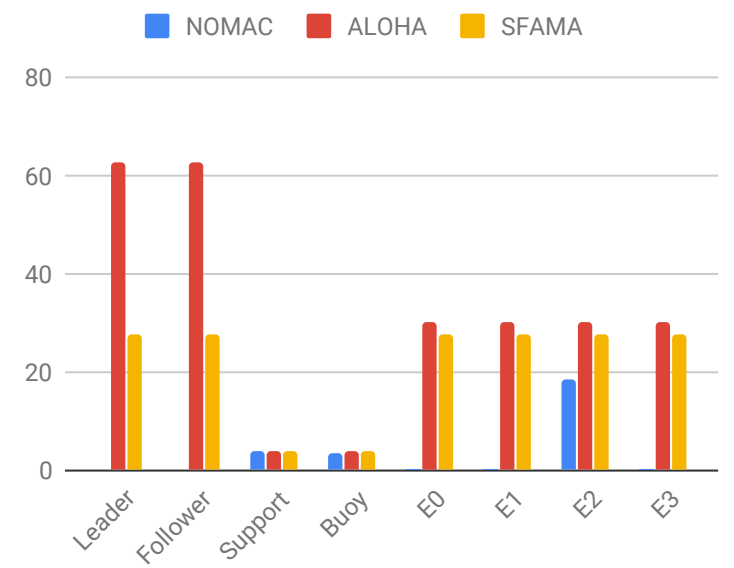

(a)

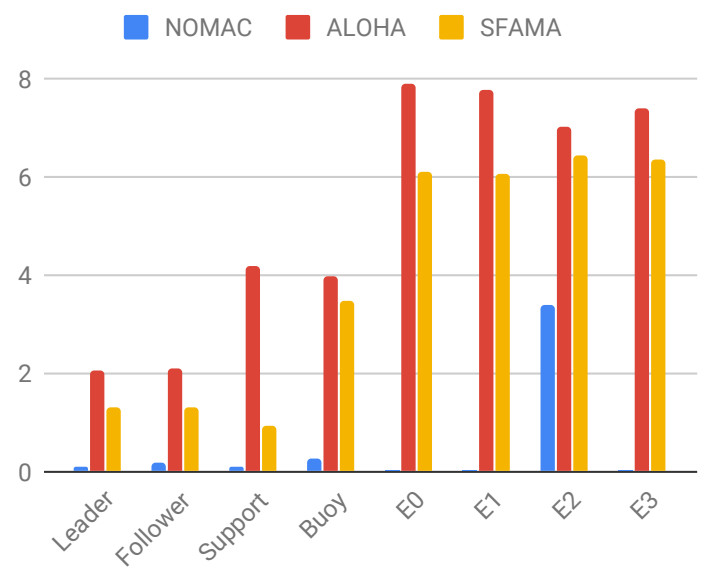

(c)

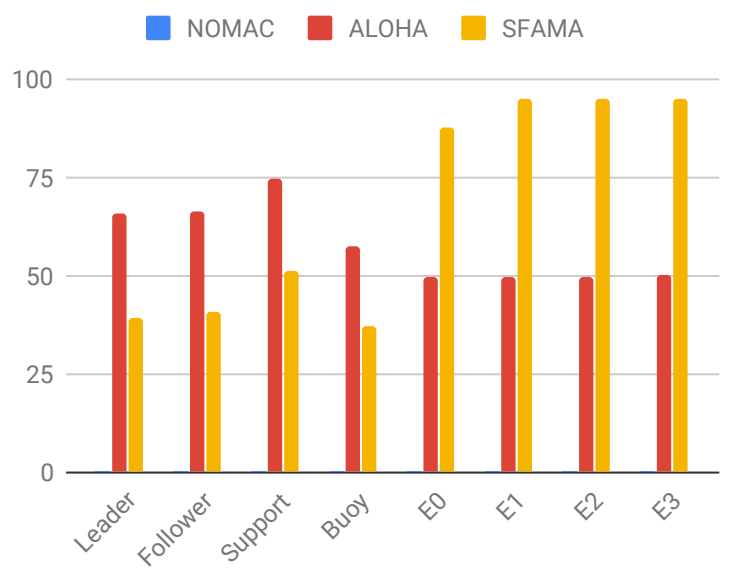

(b)

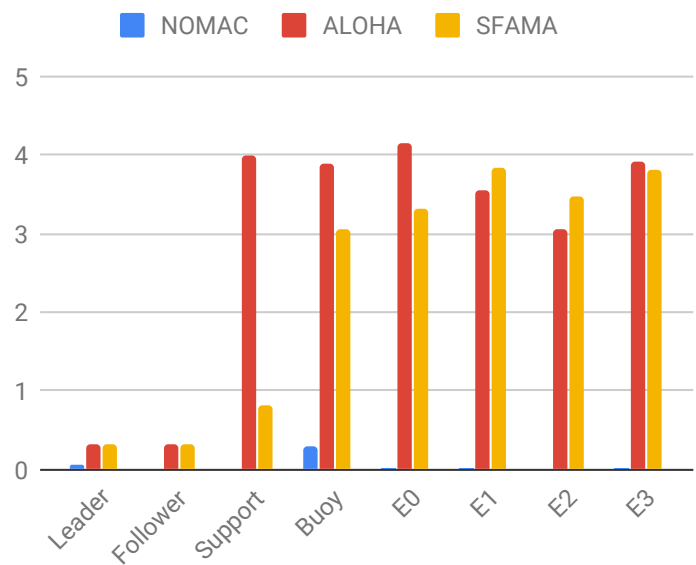

(d)

Figura 2.7: Results for the TWINBOT based scenario without considering any MAC protocol (NOMAC), considering CS-ALOHA MAC protocol (ALOHA) and the S-FAMA MAC protocol (SFAMA), in terms of: (a) throughput (bytes per second); (b) efficiency (\%); (c) end-to-end delay (s); and (d) jitter (s).

\subsubsection{Remote ROV Team Control in HIL}

The third experiment presented in this paper demonstrated the capability of UWSim-NET in performing HIL experiments. It corresponded to the four exploration AUVs detailed in Section 2.3.2. The four AUVs were arranged in a squared formation and the distance between adjacent vehicles was $1.5 \mathrm{~m}$. The leader AUV was replaced by a real BlueROV; it is identified with the marker in Figure 4.14. The operator sent positioning commands to the leader, and the rest of the AUVs followed the movements of the leader trying to maintain the formation of the AUVs. The block dia- 
gram with the software and hardware elements used in this experiment are shown in Figure 4.14c.

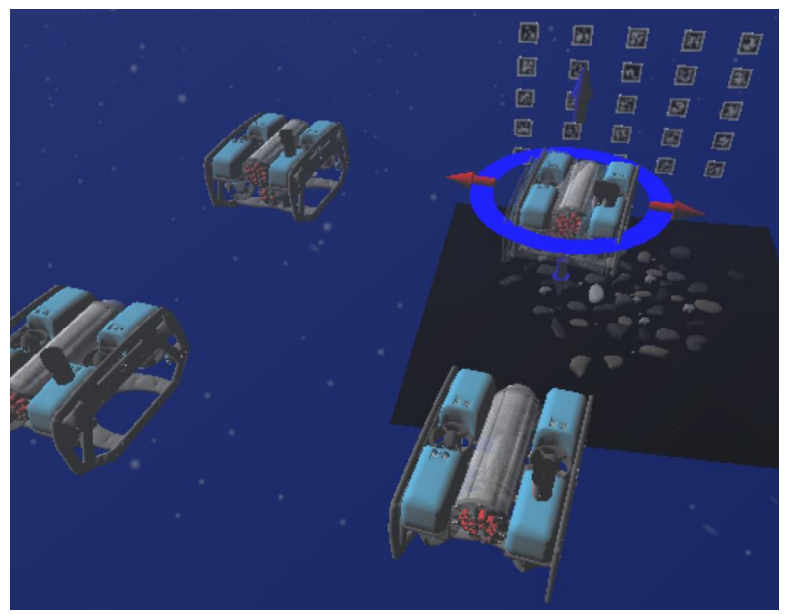

(a)

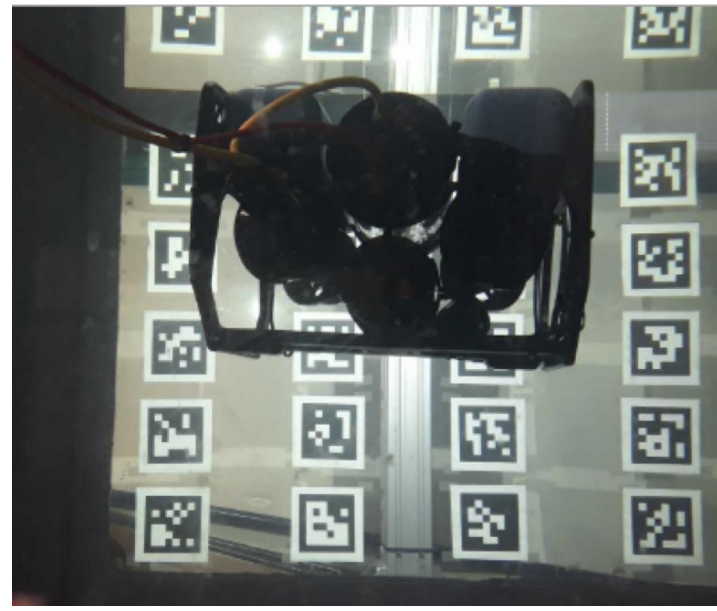

(b)

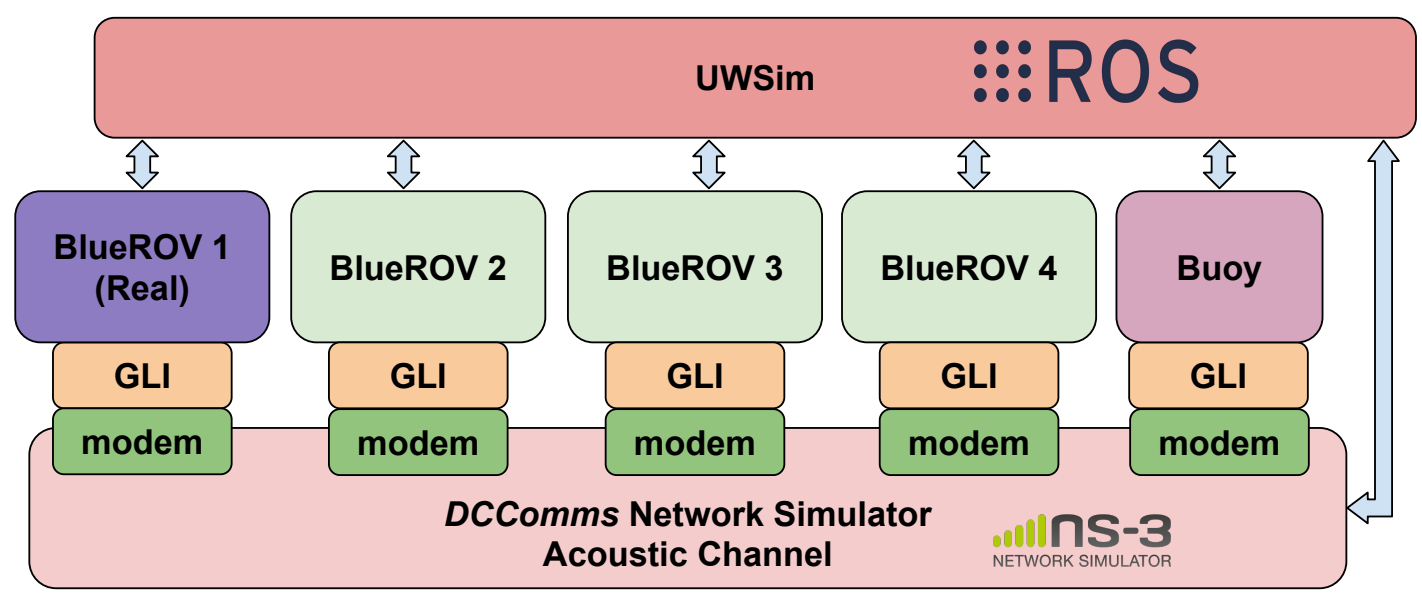

(c)

Figura 2.8: Cooperative AUV Control in HIL. (a) UWSim visual interface of the HIL experiment with the four robots. The one with the marker is the real BlueROV. The floor of the water tank and the Aruco markers have also been represented in the UWSim visualization. (b) Image of the real BlueROV in the water tank at the IRSLab. (c) Block diagram of the elements used in this experiment.

All the AUVs were equipped with acoustic modems; the modems modeled in this experiment are the S2CR 7/17, by Evologics [26]. Despite the umbilical link between the leader and the operator, this communication was simulated with UWSim-NET as an acoustic channel. The transmission fluxes were the same as those indicated in Section 2.3.2. Since GPS positioning does not work properly in the lab we have at UJI, we developed a positioning feedback based on Aruco markers [30] (see Figure 4.14). 


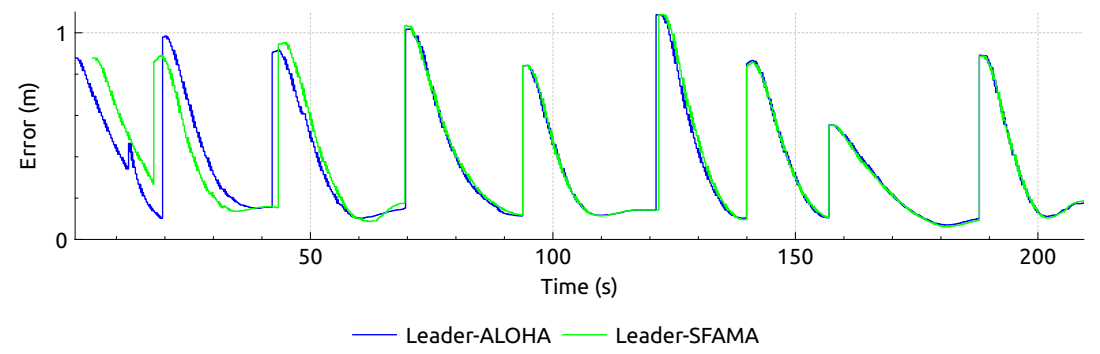

(a)

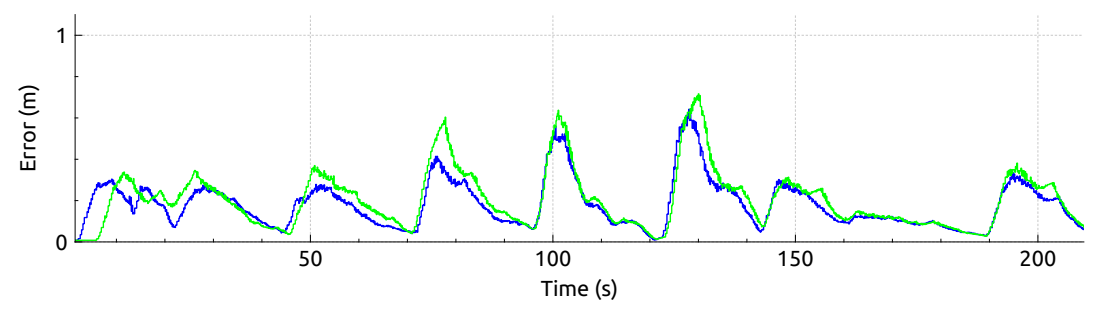

- FO-ALOHA - FO-SFAMA

(b)

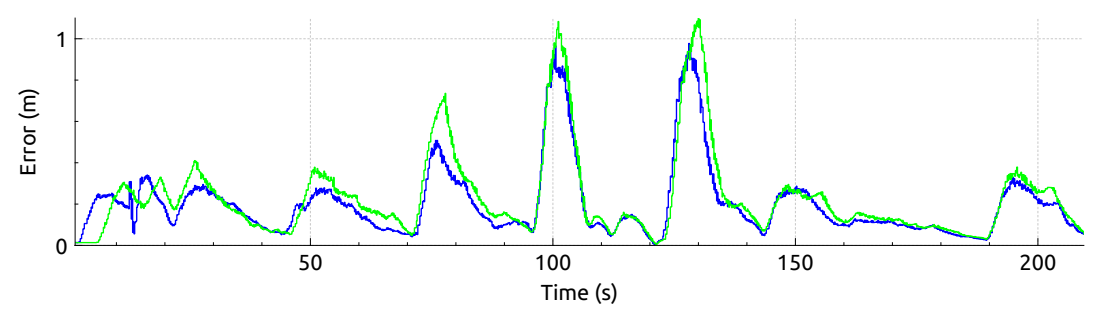

- F1-ALOHA - F1-SFAMA

(c)

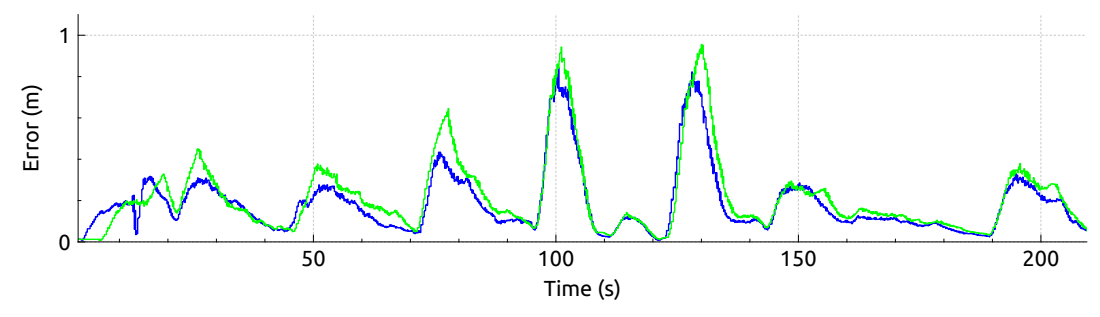

- F2-ALOHA - F2-SFAMA

(d)

Figura 2.9: Waypoint distance error for each AUV for the CS-ALOHA and S-FAMA MAC protocols. (a) Distance between commanded position and actual position of the leader. Distance between actual position and expected position based on leader's for: (b) the AUV on the left of the leader; (c) the AUV placed back and left; and (d) the AUV placed behind the leader.

The same experiment was performed considering CS-ALOHA and SFAMA MAC protocols. Positioning commands were sent from the operator to the leader that moved towards the commanded position, while the other AUVs tried to keep the formation by following the movements of the 
leader as they noticed them. The comparison among algorithms, as shown in Figure 2.9, was based on the error distance between real and expected position for each AUV. In the case of the leader, the error was the distance between actual and commanded position (see Figure 2.9a). A rapid increase of the error is appreciated in Figure 2.9a every time the leader received a new positioning command. The error for the follower AUVs was the distance between their actual position and their expected position based on the actual position of the leader. As expected, a rapid increase of the error can be appreciated in Figure 2.9b-d when the leader moved. As appreciated in Figure 4.14, comparable performance was achieved when CS-ALOHA and S-FAMA MAC protocols were considered.

\subsection{Conclusions}

Devices for underwater wireless communications suffer from small bandwidth, high attenuation and large delay. The modeling of these systems might contribute to minimize the impact of their limited performance in cooperative robotic applications. On the one hand, software applications used in robotics such as ROS hardly ever account for the modeling of the communications. On the other hand, network simulators such as NS3 require the user to define in advance all the fluxes and the movements of the nodes during the modeling, which hampers their use in HIL experiments. This manuscript introduces UWSim-NET, an extension of UWSim that permits the modeling of underwater communications for wireless sensors and robots (e.g., AUVs). The modeling of the dynamics of the robots is based on UWSim and ROS, while the communication network is modeled using the NS3. A modular architecture is proposed for UWSim-NET. One of the modules is a Generic Link Interface, which acts as an abstraction layer for the devices. This module facilitates the replacement of real and modeled communication devices, and also permits HIL experimentation.

Three experiments are presented in this article to demonstrate the capabilities of UWSim-NET in modeling communication impairments, allowing RF and acoustic channels, modeling several MAC protocols and per- 
forming HIL experiments (see Table 2.2). The first one modeled an RF and an acoustic link between two robots, and showed the capabilities of UWSim-NET in modeling losses by signal attenuation or packet collisions. The measurement of end-to-end delay and the modeling of the transmission FIFO stack of the modems were also illustrated in this first experiment. The second experiment was the simulation of a search and recovery intervention with autonomous vehicles. The experiment was composed of two groups of three and four AUVs, respectively. The first group of robots, in charge of the intervention, was equipped with RF modems, while the second group was in charge of the search, communicating with acoustic devices. Efficiency, throughput, end-to-end delay and jitter were evaluated when using teh CS-ALOHA and S-FAMA MAC protocols. The results of this experiment demonstrate the relevance of the MAC protocol, and that, depending on the traffic characteristics, a given protocol or another might be preferable. In the third experiment, one of the four BlueROVs modeled in the second experiment was substituted by a real BlueROV. The performance of the supervised remote control was assessed by measuring the distance between expected and real positions of each robot. This experiment demonstrated the capability of UWSim-NET in performing HIL trials.

Cuadro 2.2: Summary of the main findings of each experiment.

\begin{tabular}{lll}
\hline Experiment & \multicolumn{1}{c}{ Description } & \multicolumn{1}{c}{ Findings } \\
\hline Physical Layer & $\begin{array}{l}\text { Two moving AUVs sending } \\
\text { data at the same time }\end{array}$ & $\begin{array}{l}\text { Demonstration of the correct modeling of } \\
\text { end-to-end delay, packet loss, packet colli- } \\
\text { sions and the transmission FIFOs. }\end{array}$ \\
\hline MAC layer & $\begin{array}{l}\text { Cooperative intervention with } \\
\text { 4 AUVs sharing an acoustic } \\
\text { channel and 3 I-AUVs sharing } \\
\text { an RF channel. }\end{array}$ & $\begin{array}{l}\text { Demonstration of the capability of } \\
\text { RF devices, and the possibility to use } \\
\text { different MAC protocols. }\end{array}$ \\
\hline \multirow{3}{*}{ HIL } & $\begin{array}{l}\text { Demonstration of the capability of } \\
\text { Of them being a real BlueROV } \\
\text { in a water tank }\end{array}$ & $\begin{array}{l}\text { ments in a real application, in which the } \\
\text { positions of the AUVs vary arbitrarily } \\
\text { during the experiment. }\end{array}$ \\
\hline
\end{tabular}





\section{Capítulo 3}

\section{Wireless HROV Control with Compressed Visual Feedback Using Acoustic and RF Links}

\section{Publicación}

Diego Centelles, Antonio Soriano, Raul Marin y Pedro J Sanz. "Wireless HROV Control with Compressed Visual Feedback Using Acoustic and RF Links". En: Journal of Intelligent 8 Robotic Systems (2020), págs. 1-16

Underwater cooperative robotics offers the possibility to perform challenging intervention applications, such as recovering archeological objects as within the context of the MERBOTS research project, or grasping, transporting and assembly of big objects, using more than one mobile manipulator, as faced by the TWINBOT project. In order to enhance safety during the intervention, it is reasonable to avoid the umbilical, also giving more mobility to the robots, and enabling a broader set of cooperative movements. Several solutions, based on acoustic, radiofrequency (RF) or Visual Light Communication (VLC) have been proposed for underwater communications in the literature. This paper presents the architecture of an underwater wireless communication framework for the control of multiple semi-autonomous robots in cooperative interventions. The proposed framework is composed of several modules as the virtual reality interface 
using UWSim, the Underwater Multi-robot Cooperative Intervention Remote Control Protocol (UMCI-RCP) and a Generic Link Layer (GLL). $U M C I-R C P$ allows the control of an underwater robot over limited communication links. UMCI-RCP integrates a progressive compression algorithm that provides visual feedback at a constant rate and ensures image reception even in channels with loses. The Time Division Multiple Access (TDMA) medium access strategy minimizes the jitter of transmitted packets. The GLL has been designed in order to provide support for multimodal transmission (i.e. acoustic, RF and VLC) and also to interface with the UWSim-NET simulator so that facilitates the experimentation either with a real or with a simulated modem. The possibility of exchange real and simulated devices in the proposed framework are demonstrated by means of a teleoperation experiment with a BlueROV equipped with the S100 RF modems. Hardware-In-the-Loop (HIL) capabilities are demonstrated repeating the experiment with the real modems and modeling the BlueROV, and also modeling both the modems and the BlueROV.

\subsection{Introduction}

The use of robots in underwater operations such as archaeology, marine research and off-shore industries are becoming more necessary in order to enhance safety, while increasing the possibilities to perform advanced interventions in underwater hazardous environments. In fact, some tasks require the use of sophisticated cooperative robotic teams, in order for example to be able to transport and assemble big objects and structures [73]. These refined applications are faced nowadays by research projects such as MERBOTS [42] and TWINBOT [35], being necessary to avoid umbilicals, in order to enable higher mobility and security of the robot's team.

Acoustic communication for underwater applications has the advantage of long range connectivity (i.e. several kilometers). But it can be disturbed by multi-path and acoustic noise, affecting to the communication quality (e.g. variable time-delays). In practice, the range of frequencies is limi- 
ted to a few $\mathrm{kHz}$. Besides this, the low bandwidth and associated delays $(\approx 0,6 \mathrm{~ms} / \mathrm{m})$ make difficult to implement a full-duplex underwater robot remote control with this technology. Moreover, the multi-path effect in the vicinity of solid objects (e.g. rocks, ships, and robots) needs a serious study in order to design a communication framework for underwater robot's team. Despite all these inconveniences, underwater video transmission through acoustic channels has been demonstrated in previous experiments, thanks to the use of advanced compression techniques for very constrained links [58].

Some previous works have presented very interesting solutions for communicating with a team of wireless underwater mobile sensors, focusing on the use of sonar solutions. In fact, in [64] a network framework architecture has demonstrated to be very useful during real survey and data acquisition interventions with USCs and AUVs. More details on the low level behaviour of underwater sensor networks based on acoustic modems, evaluating their performance in real field survey experiments, can be found in $[6]$.

Table 3.1 shows some acoustic based solutions and their performance in terms of data rate, range, and the supported link type.

Cuadro 3.1: Acoustic solutions for underwater data transmission

\begin{tabular}{llllll}
\hline Data Rate & Range & Band & Link & Year & Ref. \\
\hline $19.2 \mathrm{kbps}$ & $2 \mathrm{~km}$ & $53 \mathrm{kHz}$ & Vertical & 1991 & {$[4]$} \\
$16 \mathrm{kbps}$ & $6.5 \mathrm{~km}$ & $20 \mathrm{kHz}$ & Vertical & 1992 & {$[69]$} \\
$1200 \mathrm{bps}$ & a few km (telemetry) & $15 \mathrm{kHz}$ & Vertical and Horizontal & 1993 & {$[43]$} \\
$150 \mathrm{kbps}$ & (tested at) $10 \mathrm{~m}$ & $75 \mathrm{kHz}$ & Vertical & 2003 & {$[48]$} \\
$90 \mathrm{kbps}$ & (tested at) $200 \mathrm{~m}$ & $115 \mathrm{kHz}$ & Vertical and Horizonal & 2010 & {$[56]$} \\
\hline
\end{tabular}

Visual light communication (VLC) [36] can be considered as an alternative. VLC provides larger bandwidth than acoustic links, and its range is limited due to the strong attenuation of light in water. It can be considered a solution in good visibility conditions for robot teams communication. Table 3.2 shows some VLC based solutions. 
Cuadro 3.2: VLC solutions for underwater data transmission

\begin{tabular}{lllll}
\hline Data Rate & Range & Wavelength & Year & Ref. \\
\hline $10 \mathrm{Mbit} / \mathrm{s}$ & $20 \mathrm{~m}$ & $450 \mathrm{~nm}$ (blue light) & 1995 & {$[5]$} \\
$1 \mathrm{Mbit} / \mathrm{s}$ & $30 \mathrm{~m}$ & $450 \mathrm{~nm}$ (blue light) & 1995 & {$[5]$} \\
$10 \mathrm{Mbit} / \mathrm{s}$ & $100 \mathrm{~m}$ & $400-500 \mathrm{~nm}$ (blue/green light) & 2010 & {$[29]$} \\
$58 \mathrm{Mbit} / \mathrm{s}$ & (tested at) $2.5 \mathrm{~m}$ & 470 (blue light) & 2013 & {$[23]$} \\
\hline
\end{tabular}

Another alternative to acoustic links is based on radio frequency $(\mathrm{RF})$ modems [18], which are not affected by multipath, turbidity and water light conditions. However, the high conductivity of sea water limits its communication range to a few meters, being necessary to reduce the transmission frequency, augment signal power, and design specific antennas. The authors in [65] conclude that an RF link over a distance of $90 \mathrm{~m}$ in sea water could be established using frequencies up to $5 \mathrm{MHz}$. Also, in [25] experiments with the WFS Seatooth S100-L modem using external loop antennas are presented demonstrating ranges up to $30 \mathrm{~m}$ through seawater. For cooperative robotics RF is an interesting solution due to the fact that it provides lower and constant time-delays, which is very convenient for team intelligent behaviours.

\subsubsection{Outline}

The present paper describes some of the wireless communications experiments performed for the MERBOTS Project, while also presenting the new UWSim-NET tool that is being used to design more sophisticated underwater protocols, specially for the multi-robot TWINBOT scenario. The proposed protocol offers a cross-layer architecture for network optimization, which focuses specially on the transport layer, continuing previous work on Internet protocols for master-slave robotic control Bilateral Transport Protocol (i.e. Bilateral Transport Protocol- BTP [77]).

This paper also presents the network architecture to remotely control a experimental underwater robot, having compressed visual feedback, specially optimised for very constrained $\mathrm{RF} /$ sonar channels. This architecture includes also a user interface to configure the communication parameters. 
The paper is organized as follows:

- First of all, the context of MERBOTS and TWINBOT projects is presented, where the necessity of wireless underwater communications is justified.

- Secondly, the designed communication framework for the underwater wireless control of a single robot is described in detail, including the data frames and the particularities of the cross-layer protocol, considering experiments and tools for image compression, and region of interest selection. The framework provides a user interface that enables the expert operator to select communication parameters, in terms of image resolution, size, and congestion control, among others.

- Finally, in order to be able to design more advanced underwater wireless protocols for robot teams, in the context of the TWINBOT Project, the UWSim simulator has been extended, jointly with NS3 (Network Simulator 3). The new UWSim-NET simulator is described and provided as open source to the research community for further research on network protocols for underwater multi-robot cooperative teams.

\subsection{MERBOTS and TWINBOT Projects}

This work has been conducted within the framework of the MERBOTS project [42], including further experiments to prepare the communication architecture of the more advanced underwater cooperative mobile manipulators TWINBOT project. MERBOTS, which has been funded by the Spanish Government, is aimed at the development of tools and techniques that permit the semi-autonomous control of cooperative robots to accomplish tasks in underwater archaeological scenarios. In fact, MERBOTS has developed techniques to study or even recover archaeological objects located at the seafloor. Moreover, one of the objectives of the project is to combine different wireless technologies to link the cooperative robots 


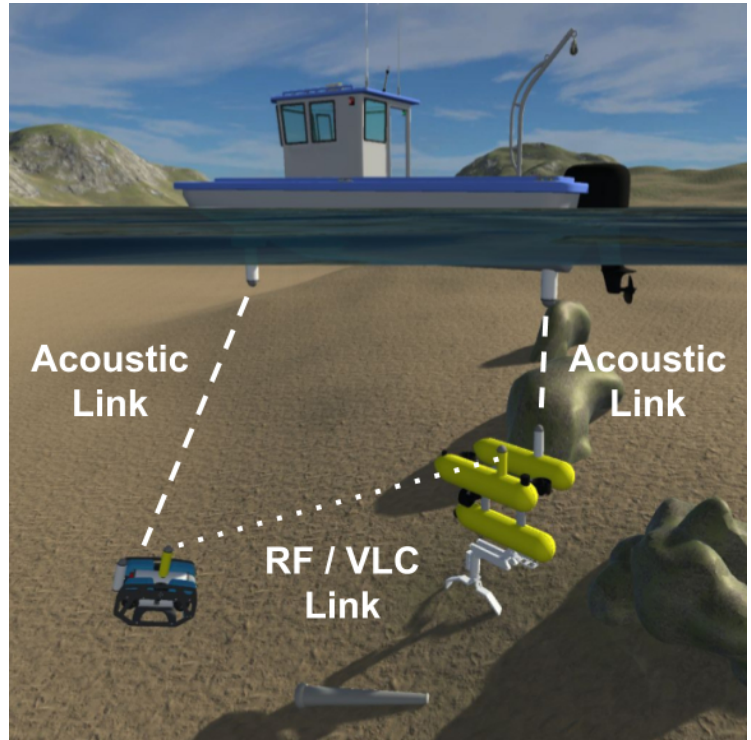

(a)

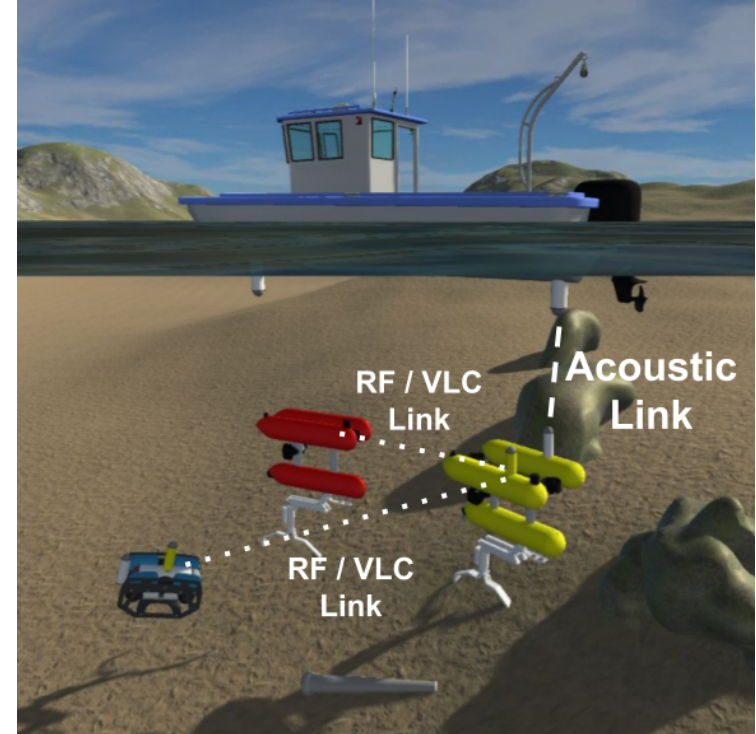

(b)

Figura 3.1: (a) Scenario of the MERBOTS project including acoustic communication to the surface and RF/VLC between the mobile manipulator and the auxiliary inspection robot. (b) Scenario of the TWINBOT project for cooperative intervention, including two mobile manipulators and an auxiliary inspection robot.

and the user interface located in the surface vehicle, as can be seen in Figure 3.1(a).

The TWINBOT project aims at achieving a step forward in the underwater intervention state of the art. A set of two I-AUV's will be able to solve strategic missions devoted to cooperative survey and cooperative manipulation (transport and assembly) in a complex scenario (see Figure 3.1(b)). The project faces the problem of underwater cooperative intervention which, in a first stage, will be able to pick up, recover and transport objects such as pipes, using two intervention vehicles, wireless communications, a supervisory control human-robot interface, and an auxiliary robot for giving the user and the robot team external views for enhancing the intervention efficiency. The system uses as knowledge base previous results from the FP7 TRIDENT [55] and MERBOTS [15] projects. 


\subsection{Underwater Multirobot Cooperative Interven- tion Network Architecture (UMCI-NA)}

The small bandwidth of underwater wireless modems hampers the transmission of all the messages exchanged between the operator and the ROVs during an intervention. The UMCI-NA (Underwater Multirobot Cooperative Intervention Network Architecture), specific for underwater applications, has been developed in order to make the most of the limited bandwidth available in these scenarios. UMCI-NA is a minimalist architecture, out of the TCP/IP stack for wireless communications. It enables the remote control of a ROV through multi-hop communication links, like those considered in MERBOTS and TWINBOT projects, as illustrated in Figure. 3.1.

\subsubsection{Overall Network Architecture}

The goal of the network architecture is to allow the delivery of commands from the operator to the ROVs, and the messages with the ROVs odometry and visual feedback in the opposite direction. The UMCI-NA allows the operator to control each ROV either in velocity or position modes. In velocity mode, the ROV is controlled with a joystic connected to the computer of the operator. The position mode is based on NED (North-East-Down) coordinate system. The operator moves a semitransparent image of the ROV to the desired position. All these controls have been implemented in the Human-Robot Interface (HRI) layer. The appearance of the HRI is shown in Figure 3.2. It is on top of the UMCI-NA architecture, as can be appreciated in Figure 3.3.

The HRI layer is based on UWSim [52] and ROS (Robot Operating System)[53]. Its function is to collect the information from the operator and send the corresponding commands to the ROS layer. The interface also notifies the operator on the reception of the command by the ROV and its accomplishment, while allowing the operator to cancel each command 


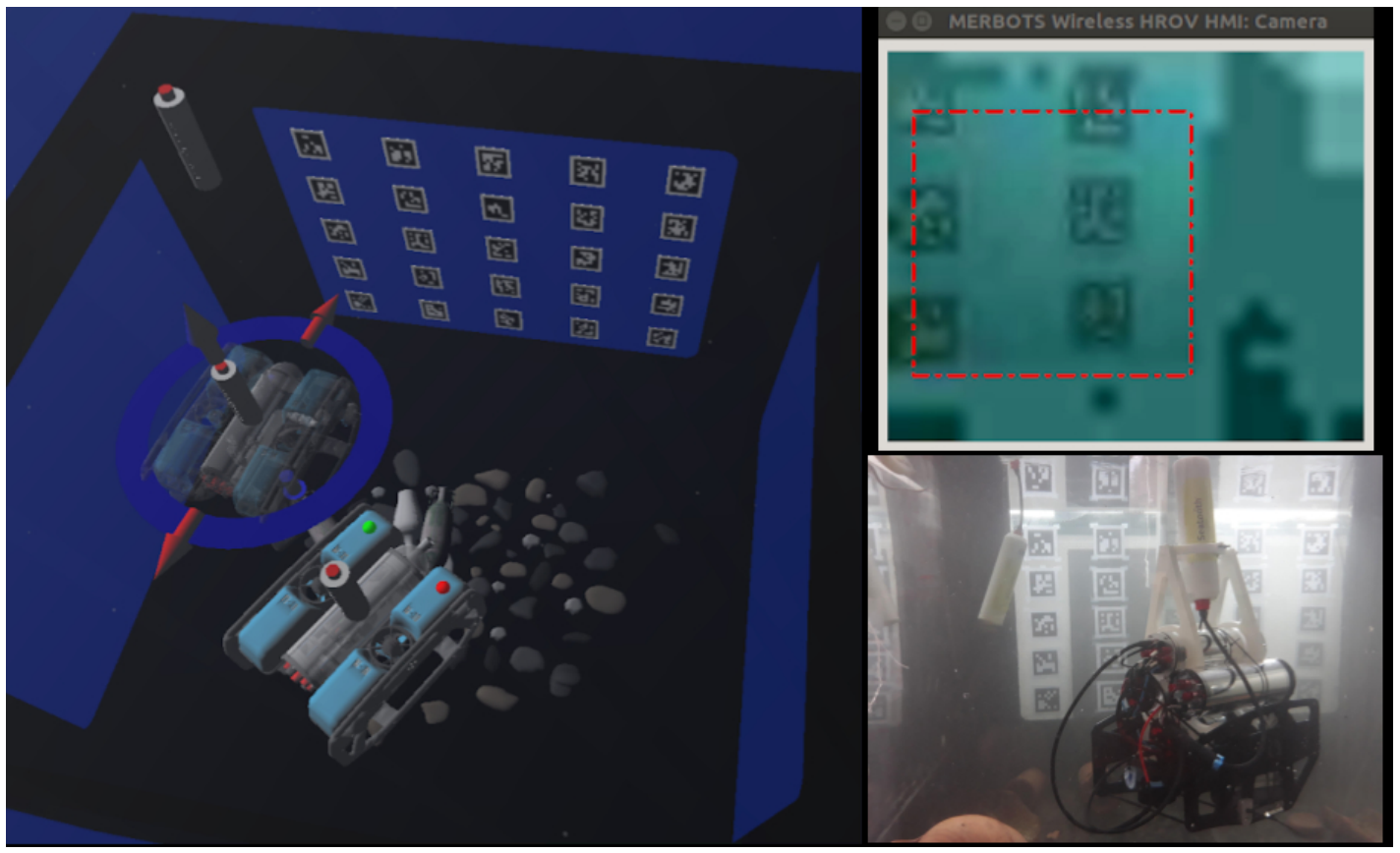

(a)

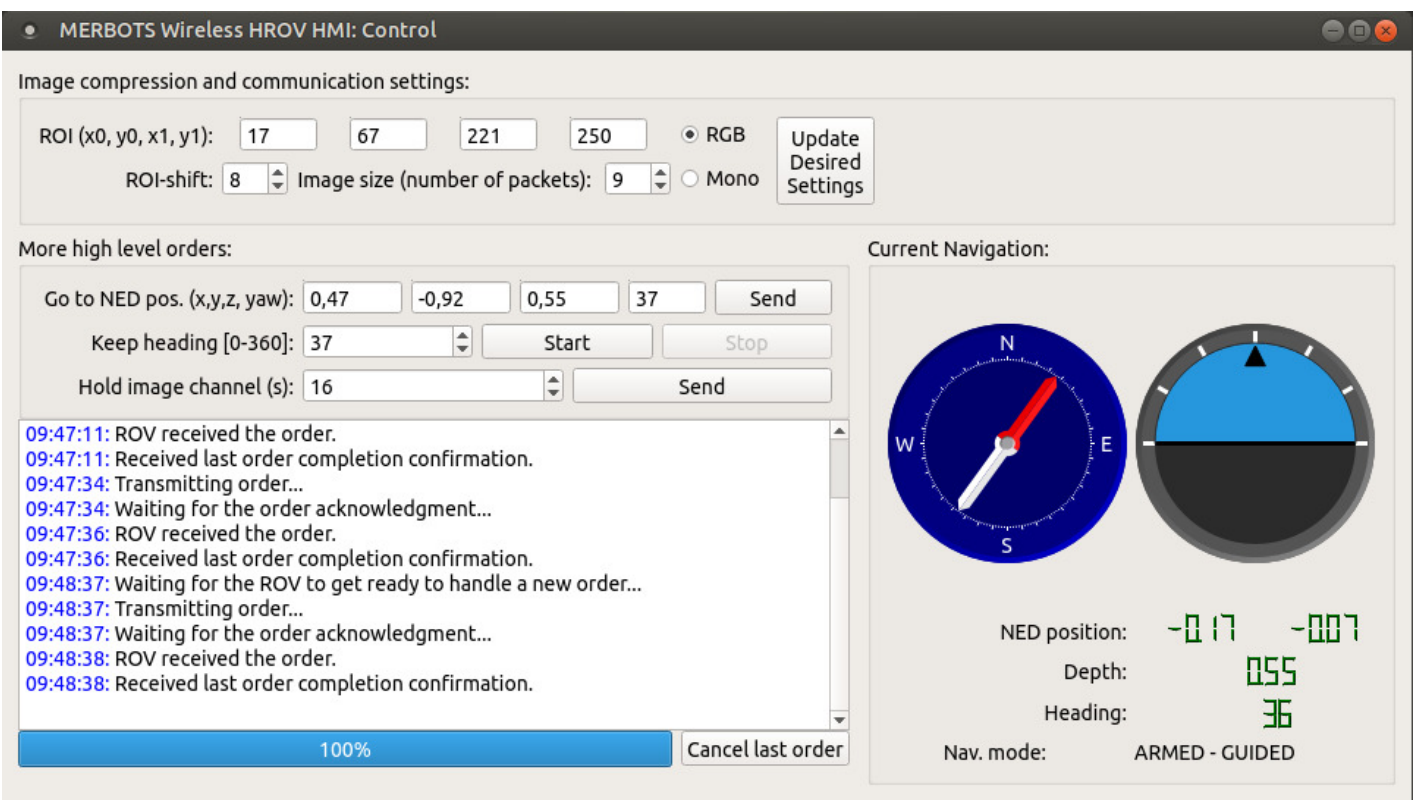

(b)

Figura 3.2: Virtual reality Human-Robot Interface: (a - left) UWSim-NET window; (a - top right) Compressed image with ROI from the ROV's camera; (a - bottom right) Real robot; (b) Dedicated UI to send orders and receive feedback messages. 


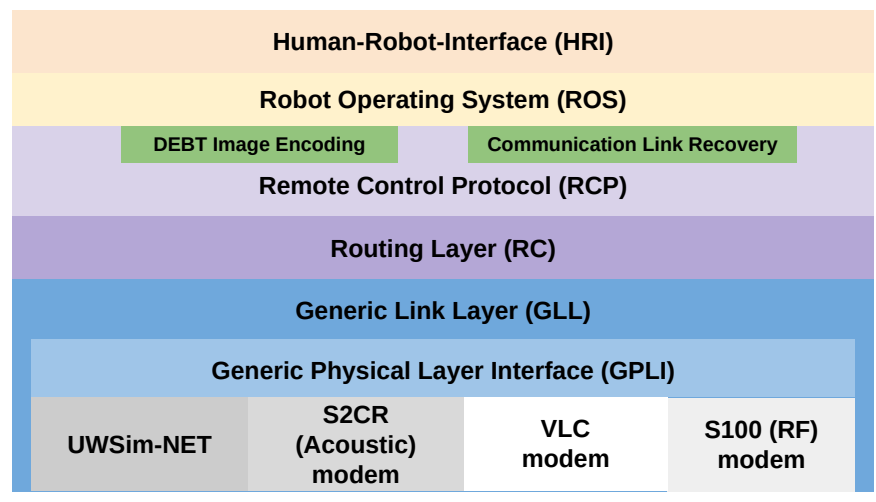

Figura 3.3: UMCI-NA architecture

before its completion. The HRI interface incorporates a set of controls that permit to adjust the image feedback to the available bandwidth. By means of high level commands, the operator can adjust the image compression parameters like the image size, the number of packets required to send a full image, and the region of interest (ROI). The ROI is an area of the image of special interest that will be codified with improved quality in detriment of the rest of the image. The HRI allows the operator to select the desired ROI by drawing a rectangle on the control that represents the feedback image sent by the ROV.

\subsubsection{Underwater Multirobot Cooperative Intervention Remo- te Control Protocol (UMCI-RCP)}

The UMCI-NA includes a Remote Control Protocol (UMCI-RCP) that determines how the information is codified into the packets exchanged between the ROV and the operator. The UMCI-RCP also permits the transmission of image feedback from the ROV to operator. The DEBT (Depth Embedded Block Tree) algorithm [61] is embedded into the UMCI-RCP in order to make the most of the small bandwidth available in underwater environments. DEBT is a progressive compression algorithm that allows the user to establish a specific size for the transmitted image. Moreover, DEBT permits the operator to define a ROI in the image that will be codified with higher quality at the expense of reducing the resolution in the rest of the image.

The format of the packets sent by the ROV is shown in Figure 3.4. It 


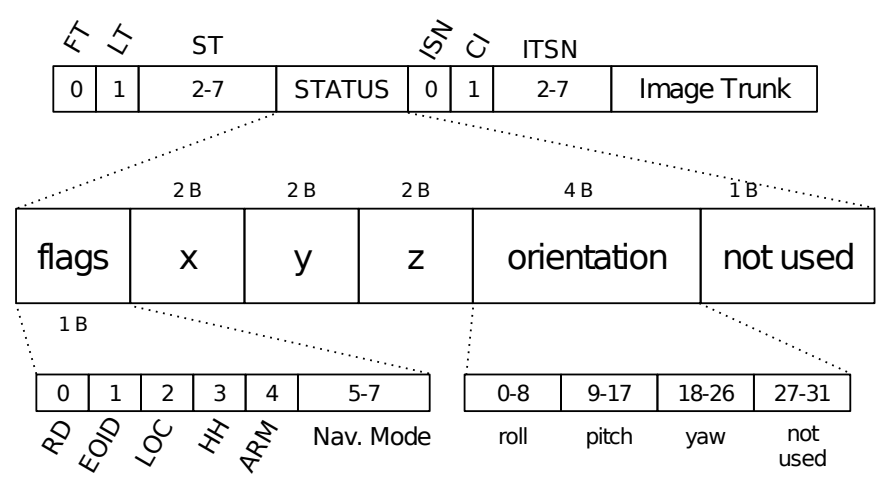

Figura 3.4: Structure of the message transmitted by the ROV, with the detail of the codification of the ROV status.

encodes the current ROV odometry, status flags, packet information, and a portion of the image registered by the ROV.

- FT and LT are the (First Trunk) and (Last Trunk) flags, respectively. Their activation indicates that the content in the image trunk field corresponds to the start or the end of an image.

- ST (Status Type) is a 6 bit field that identifies the structure of the status information codified in the following 12 bytes.

- ISN (Image Sequence Number): a bit to encode the sequence number of the captured image. to capture a new image and update the ISN.

- CI (Cancel Image): a bit to indicate the operator that the transmission of the last image has been cancelled and must prepare the reception of a new image.

- ITSN (Image Trunk Sequence Number): six bits which encode the sequence number of the portion contained in the message of the last captured image.

- IT (Image Trunk) field containing part of the DEBT compressed image.

- RD (Ready) remains deactivated if the ROV is executing a high level task.

- EOID (Expected Order ID) single bit codifying the sequence number of the next high level order the ROV expects to receive. 


\begin{tabular}{|c|c|c|c|}
\hline & \multicolumn{2}{|c|}{ Order } \\
\hline \\
\hline & \begin{tabular}{l|l} 
tlags \\
\multicolumn{2}{c}{$2 \mathrm{~B}$} \\
0 & 1
\end{tabular} & \multicolumn{2}{|c|}{$2-7$} \\
\hline \multicolumn{2}{|c|}{ 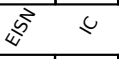 } & \multicolumn{2}{|c|}{ RIT } \\
\hline 8 & $\frac{9}{0}$ & & $12-15$ \\
\hline \multicolumn{2}{|c|}{$\therefore 8$} & \multicolumn{2}{|c|}{$\begin{array}{ll}\text { not used } & \text { OT }\end{array}$} \\
\hline
\end{tabular}

(a)

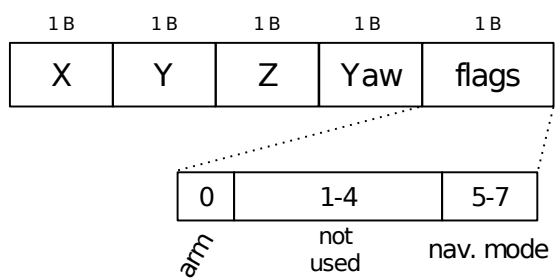

(b)

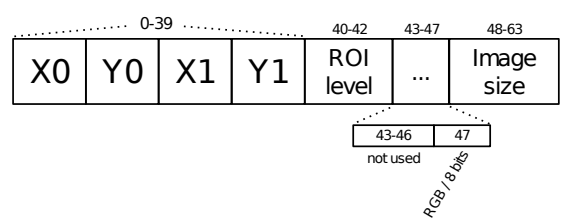

(c)

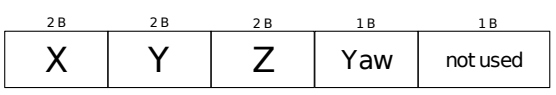

(d)

Figura 3.5: Format of the messages sent from the operator to the ROV. (a) Message format. (b) Velocity command. (c) Image compression command. (d) "Go To" command.

- LOC (Last Order Cancelled) one bit flag that is active when the previous order was cancelled because OID and EOID did not match.

- HH (Hold Heading) is active when the ROV is holding a specific yaw. A high level order is used to activate / deactivate this flag.

- ARM (Armed) flag that indicates whether the motors of the ROV are active in order to execute operator commands or not.

- NAV MODE (Navigation Mode) three bits field that codifies the current navigation mode of the ROV. Available modes are: Manual, Stabilize, Depth Hold, Hold Position and Guided.

- X, Y, Z (NED Position) six byte field (two bytes per axis) that contains the position of the ROV in a NED coordinate system.

- Orientation four bytes field that contains three nine bits values with the roll, pitch, yaw of the ROV. Bits 27 to 31 of this field remain unused.

The format of the packets sent by the operator is shown in Figure 3.5(a). They contain information related with the desired status of the ROV. The first byte contains control flags. The rest of the message is used to encode the command sent to the ROV. 
- OID (Order ID) one bit flag with the sequence number of the order. This field is considered by the ROV with high level orders only.

- CLO (Cancel Last Order) single bit flag activated to cancel the previous order. The ROV will cancel the order only if the OID matches the last EOID set by the ROV (see Figure 3.4).

- OT (Order Type) four bits field that codifies the type of order sent to the ROV.

- EISN (Expected Image Sequence Number): encodes in a bit the sequence number of the image that the operator is expecting to receive. It serves to avoid confusing chunks of an image with those of another and to confirm the reception of the whole image.

- IC (Image Cancelled): confirms to the ROV the cancellation of the reception of the last image. The operator changes the EISN and marks all the image chunks as not received when the reception of the last image is cancelled.

- RIT (Requested Image Trunk): the operator checks which portions of the image are missing and updates this six-bit field with the sequence number of one of them in order to ask the ROV to retransmit any lost portion of the image.

The commands sent from the operator to the ROV are differentiated as high and low level commands. Low level commands are those that continuously indicate what the ROV is expected to do. The only low level command considered in RCP is the one used to control the ROV in velocity mode, shown in Figure 3.5(b). High level commands indicate what is the desired status of the ROV. After its reception, the ROV executes a series of operations which allows it to reach the status indicated in the command. The two high level commands considered in RCP are: (1) the one used to control the ROV in position mode (Figure 3.5(d)), and (2) the one that configures the DEBT compression algorithm (see Figure 3.5(c)). $\mathrm{RCP}$ is periodically sending messages from the operator to each ROV. High level commands are sent by RCP on operator request. In the absence of a 
high level command, the RCP sends a low level command, Figure 3.5(b), with the current status of the joystick.

\section{Communication Recovery Module}

The RCP integrates a module whose mission is to recover the connection between the robot and the operator when it is lost. The robot considers that the connection has been lost when it does not receive a message from the operator for five seconds. In other words, operator messages can be considered as a heartbeat and the communication is considered recovered when a heartbeat is received again.

The position of the ROV is stacked every two seconds while the communication is active, i.e. heartbeats are received. In case it is lost, the previous ROV positions are recovered from the stack, and the ROV is forced to undo his way back until the communication is recovered. The pseudocode of the Communication Recovery Algorithm (CRA) is shown in algorithm 1.

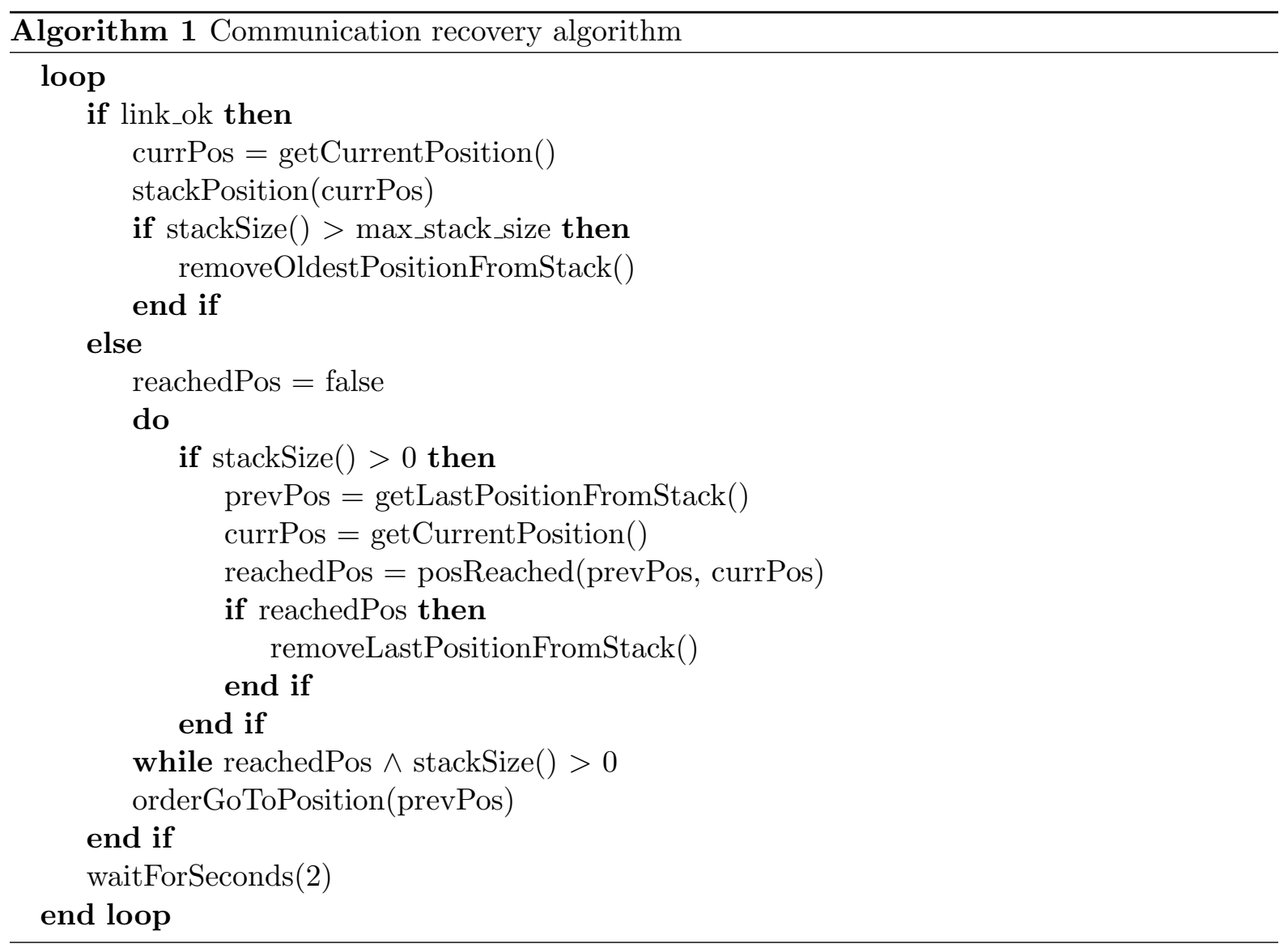




\begin{tabular}{|c|c|c|c|c|c|}
\hline 0x55 & DST & SRC & Length & Payload & CRC16 \\
\hline 1 Bytes & 4 bits 4 bits & 1 Bytes & \\
\hline
\end{tabular}

Figura 3.6: Frame structure.

\subsubsection{Routing Layer}

In MERBOTS and TWINBOT scenarios, shown in Figure 3.1, one of the ROVs establishes a high speed link with the surface boat by means of an acoustic link or an umbilical cable. The ROVs that cooperate in the underwater scenario are connected via low range RF or VLC modems. In order to extend the communications range, the ROVs form a multi-hop network. ROVs act as routers that re-transmit the traffic from each ROV to the operator in the surface, and vice versa.

The goal of the routing layer is to permit that each RCP message reaches the ROV it is destined for. Due to the small bandwidth available in underwater scenarios, a minimum overhead routing protocol has been proposed. No more than five ROVs are expected to participate simultaneously in the cooperative interventions planned in MERBOTS and TWINBOT experiments (see Figure 3.1). The routing protocol is based on the assignment of a four bits address to each ROV that will participate in a given experiment, so that a maximum of sixteen nodes can be addressed, considering both ROVs and operator nodes.

The message received from the RCP layer, shown in Figure 3.6, contains a preamble with a fixed value of $0 \times 55$, the source (SRC) and destination (DST) addresses, the length of the payload (in bytes), and CRC-16 word to verify the integrity of the message on reception.

\subsubsection{Generic Link Layer}

As previously explained, there are several technologies for underwater wireless communications, like acoustic, VLC or RF. The behaviour and characteristics of each device vary considerably. For example, the S2CR 18/34 acoustic modems manage the access to the medium while the S100 
RF modems do not. The diversity on the capabilities of the different technologies and devices supported by the UMCI-NA architecture requires a Generic Link Layer (GLL) that separates the functionality and the specific capabilities of each device. The GLL is in charge of:

- Execution of the transmission requests from the routing layer.

- Management of the modems output and collection of the received frames, and its forwarding to the routing layer.

- Optimisation of frame transmission and reception depending on the capabilities of each device.

The separation of GLL functionalities and device specific capabilities is accomplished by means of the Generic Physical Layer Interface (GPLI), shown in Figure 3.3. GPLI implementation was based on an Inter-ProcessCommunication Protocol (IPC). It allows to consider all the technologies shown in Figure 3.3.

The UWSim-NET network simulator for underwater communications, which is described in detail in Sec. 3.4.3, models the behaviour of the acoustic and RF modems to conduct HIL experiments, in those situations that do not allow the use of these communication devices in more realistic scenarios. In this case the GLL only retransmits those packets processing of the packets received from the routing layer to the simulator and vice versa.

The implementation of the module for the $\mathrm{S} 2 \mathrm{CR}$ acoustic modem is described in detail in [15]. The data link protocol used by these modems is D-MAC [37]. It defines two operation modes, short instant and burst modes. The burst mode was chosen to implement the S2CR module because it optimises the protocol parameters depending on channel conditions. It is the one with the highest data rate when transmitting large volumes of data, as in the case of image transmission. Data transmission is optimised to send information from the ROV to the operator. In order to optimise the communication, the operator commands are sent to the ROV attached 
to the next acknowledgement PDU of the D-MAC protocol.

The VLC module, which is a work in progress, has been already included in the architecture shown in Figure 3.3.

\section{WFS RF Modems S100}

The model of the RF modem used in these experiments was the S100, manufactured by Wireless For Subsea (WFS) [25]. These modems provide a half-duplex channel through RF communication. They permit transmission rates of 1,9 kbps and a maximum range of 5 meters on sea water.

The S100 modems do not execute any control on the access to the channel so that a medium access control (MAC) must be implemented in order to allow bidirectional communication. In order to maximise the throughput and minimise the delay and the jitter it is required that the MAC protocol reduces the probability of packet collision, and to maximise the channel occupation. The MAC protocol proposed for the S100 modems is based on a token passing strategy. It can be seen as Time Division Multiple Access (TDMA) controlled by the operator side of the channel that will behave as master and will send packets to the ROV periodically. The ROV side will act as slave, and will transmit the ROV odometry and image feedback only on reception of the messages from the operator. The time gap between the sending of two consecutive messages is named Inter Packet Gap (IPG). It is adjusted by the operator considering the propagation delay and the transmission time of both the operator and ROV messages.

\subsection{Experimental setup}

\subsubsection{Upgrade of the BlueROV Platform to enable RF wireless remote control}

The platform used to evaluate the performance of the proposed architecture is shown in Figure 3.7. It is based on a BlueROV (version 1), 


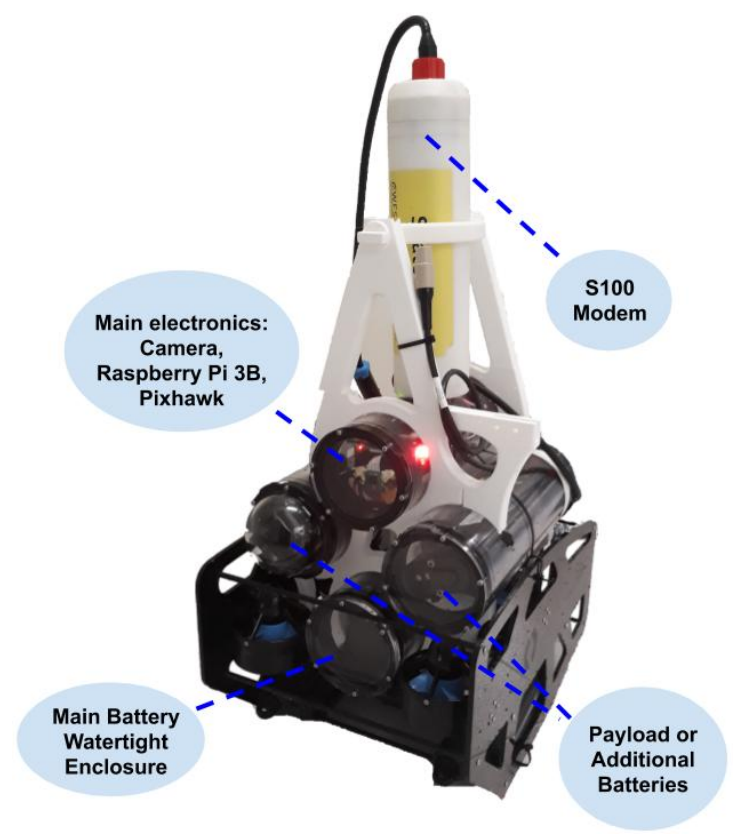

Figura 3.7: Experimental platform with the S100 modem integrated on the BlueROV v1

including a structure to hold a S100 RF underwater modem, manufactured by Wireless for Subsea (WFS), which connects with a second one installed in another vehicle or attached to a surface device, according to the project requirements. UWSim has proven to be an excellent tool for the simulation of part of the system, in order to evaluate the performance of the proposed architecture in a controlled environment, while allowing other features, such as the implementation of VR human-robot interfaces $[52]$.

The control of the BlueROV is based on a Pixhawk board [41] where the ArduSub software is executed. The communication between operator and ROV uses an umbilical wire. The BlueROV standard architecture is based on the MAVLink protocol. MAVLink messages are encapsulated into datagrams that are sent through the umbilical wire to the ROV. A software application called MAVProxy extracts the MAVLink messages from the UDP datagrams received by the ROV, and sends the MAVLink messages to the Pixhawk via a serial interface. Typical MAVLink messages are the charge level of the battery, geodesic position of the ROV, information related with the Inertial Measurement Unit (IMU), the compass, depth sensor or the Global Positioning System (GPS). There is a robot operating system (ROS) package named MAVROS that permits the publication of 
MAVLink messages as ROS topics and services. The MAVROS node also implements MAVProxy functionalities so that permits the control of the ROV. MAVLink messages are read from the ArduSub and sent to the WSF S100 RF underwater modems via serial interface for their transmission.

BlueROV has been upgraded in order to integrate a S100 RF modem. It includes not not only the mechanical design, but also the addition of four waterproof cylinders that provide enough space for the additional electronics. On the one side, the S100 modem was powered using the BlueROV batteries via a voltage regulator. An additional Raspberry Pi has been attached in order to control the S100 modem via the serial interface. It communicates directly via an Ethernet connection with the main Raspberry Pi on board the BlueROV.

\subsubsection{BlueROV Positioning Control}

The BlueROV positioning control is based on the Guided navigation mode of the ArduSub software. It is activated only when an external location system provides the actual position of the ROV. The Pixhawk firmware requires the input of the ROV location in geodesic coordinates. It executes an Extended Kalman Filter (EKF) that combines the information of the external location system with the rest of the sensors available in the Pixhawk, as the compass or the accelerometers, in order to obtain an estimation of the ROV position.

S2CR acoustic modems, considered in [15], implement a Ultra-Short Base Line (USBL) positioning system that can be used as the external positioning required by the Pixhawk. USBL positioning coordinates are transformed to geodesic coordinates and sent to the Pixhawk as a GPS_INPUT type MavLink message. USBL is a valid solution in open areas with little obstacles, however acoustic communications are strongly affected by multipath. Thus it is not a viable solution for the water tank of the UJI laboratory shown in Figure 3.2(a) where the experiments were done.

The external positioning, required by the Pixhawk in order to enable 
the positioning control, has been obtained by means of ArUco markers [31, 57] placed on the wall of the water tank of the UJI IRS Lab. The markers map shown in Figure 3.2(a) is built at runtime by the robot using the aruco_mapping library ${ }^{1}$. The robot uses this marker map to localize itself.

\subsubsection{UWSim-NET}

Experimentation in underwater scenarios require to handle multiple hardware elements, as ROVs, modems, sensors, and all they have to be properly assembled. Moreover, real scenarios at sea are not appropriate for test experiments because of the complexity of dealing with all the equipment required for the experiment. Space restrictions at the laboratory usually impede the realisation of test experiments to evaluate the whole system. Hardware-In-the-Loop (HIL) experiments, in which part of the hardware is evaluated and the rest is modelled by software, represent a key element in robotics research.

UWSim-NET [12] is a module aimed at modeling the behaviour of underwater wireless communications. It has been developed to conduct HIL experiments when the modems are not available. Network simulation in UWSim-NET is based on the real time scheduler and the functionalities of the NS3 (Network Simulator 3) library. UWSim-NET allows to simulate the behaviour of the S2CR acoustic modems and the S100 RF ones. It is based on a statistical model of each modem that has been constructed based on experimental measurements. Transmission times, errors in packet transmission are simulated while an UWSim scenario is executed. Transmission errors can be a consequence of signal attenuation, packet collision or packet loss when transmission or reception buffers are filled up.

The experiments to calculate the statistical model for the S100 RF modem entail measuring several transmission parameters while two S100 modems were submerged in the water tank of the UJI IRS Lab, (see Figure 3.8). The experiments include the transmission of 2000 packets while

\footnotetext{
${ }^{1}$ https://github.com/dcentelles/aruco_mapping. This depends on ArUco library to compute the position of the camera respect to a marker
} 


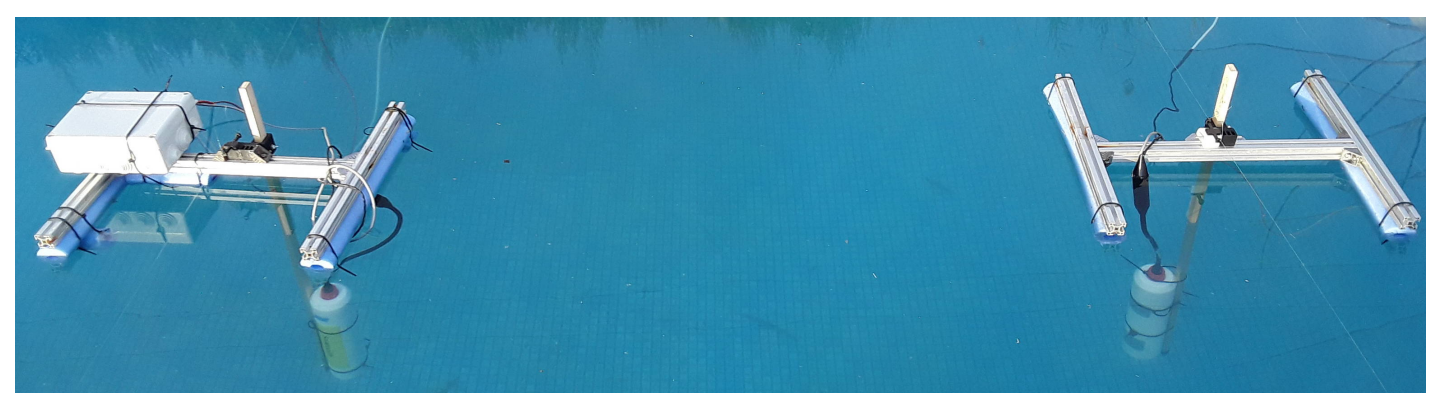

Figura 3.8: Underwater RF WFS S100 modems attached to a surface structure for HIL Experiments

measuring the times when each packet was sent and received. These measurements were used to calculate the intrinsic delay, the jitter and the bit rate that are shown in Table 3.3. After the calculation of the parameters of the statistical model, the UWSim-NET can be used to simulate the behaviour of the RF modems. The water tank where these experiments were performed was not big enough so as to measure any lost packets due to signal attenuation. However, UWSim-NET allows to adjust the Bit Error Rate (BER) depending on the separation of both modems, and this parameter will be adjusted in future experiments.

The statistical model for the S2CR acoustical modems was extracted from previous results presented in [15]. The measurements consisted on a HIL teleoperation experiment with a Girona 500 HROV [54]. Both modems were submerged in a water tank that causes multi-path and degrade the results shown in the acoustic column of Table 3.3. Results of the burst mode are exposed in column Burst of Table 3.3 and the results of the mode based on attaching the messages in the D-MAC acknowledgements are showed in column ACK. The performance of the acoustic modems is expected to improve in the sea, where the multi-path effect has little effect on the communication. The high intrinsic delay and jitter values in Table 3.3 are partly due to the burst mode used with S2CR. As mentioned in Sec. 3.3.4 the burst mode was used because it allows higher bitrates than the instant messages mode of the D-MAC. 
Cuadro 3.3: Results obtained in experiments for modeling RF and acoustic modems.

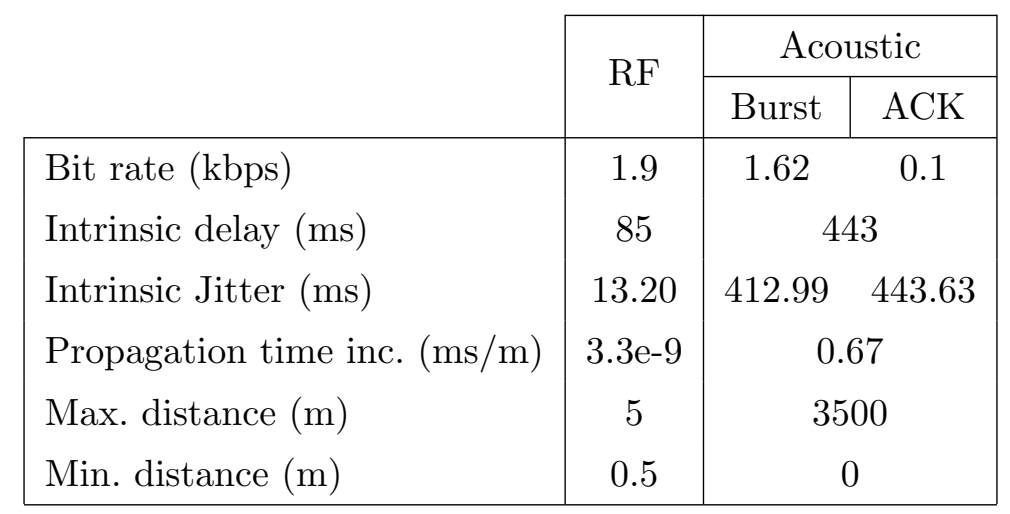

\subsection{Results}

The experiments presented in this paper follow a setup where the operator can teleoperate both a real and a virtual robot using the same UMCINA architecture. Teleoperations with the real robot have been performed using velocity control commands in a water tank. In order to focus on the network protocol design, HIL experiments are presented, using real RF modems as communication media. For this HIL experiments the robot side simulation is performed using the ArduSub SITL (Software In The Loop) simulator $^{2}$. First, in 3.5.1 it is described how the different components involved in the experiments are interconnected. Then in 3.5.2 and 3.5.3 the remote control results over a RF channel are presented.

\subsubsection{HIL Experiments Software Architecture}

Figure 3.9(b) shows the components of the performed experiments. The block identified as Robot represents the possibility of using a real BlueROV or a simulated one. The block identified as Wireless Channel represents the communication channel used, which will be based on either the S100 modems (HIL) or a simulation of them using UWSim-NET, depending on the experiment. The actual position of the ROV is displayed in the UWSim as a white ROV (see Figure 3.9(a)). This is possible because the ArduSub simulator sends FDM (Flight Dynamics Model) messages through an UDP

\footnotetext{
${ }^{2}$ http://ardupilot.org/dev/docs/sitl-simulator-software-in-the-loop.html. The fork of the SITL simulator used in these experiments is: https://github.com/dcentelles/ardupilot
} 


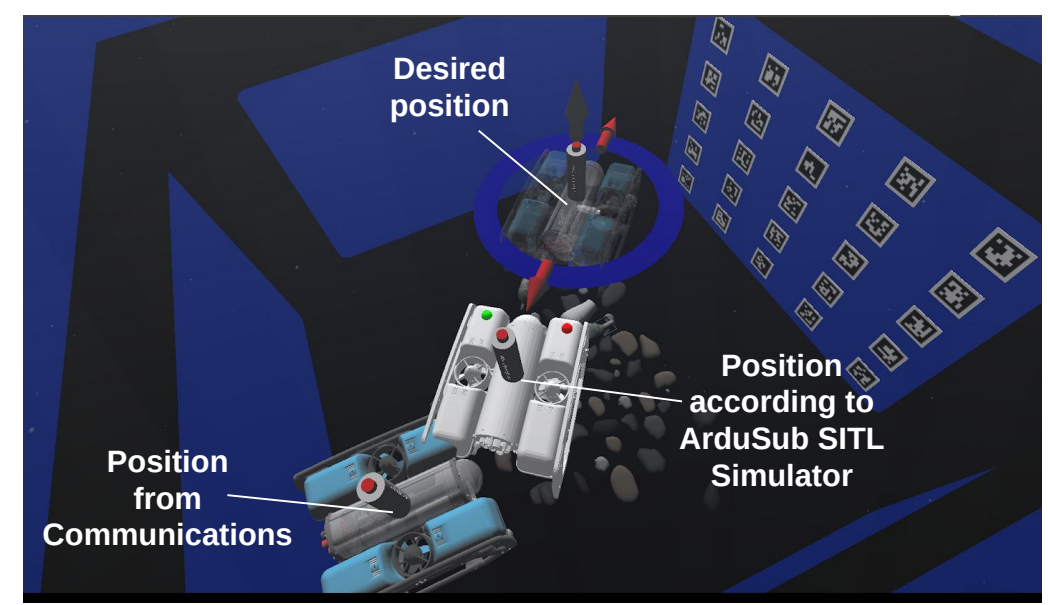

(a)

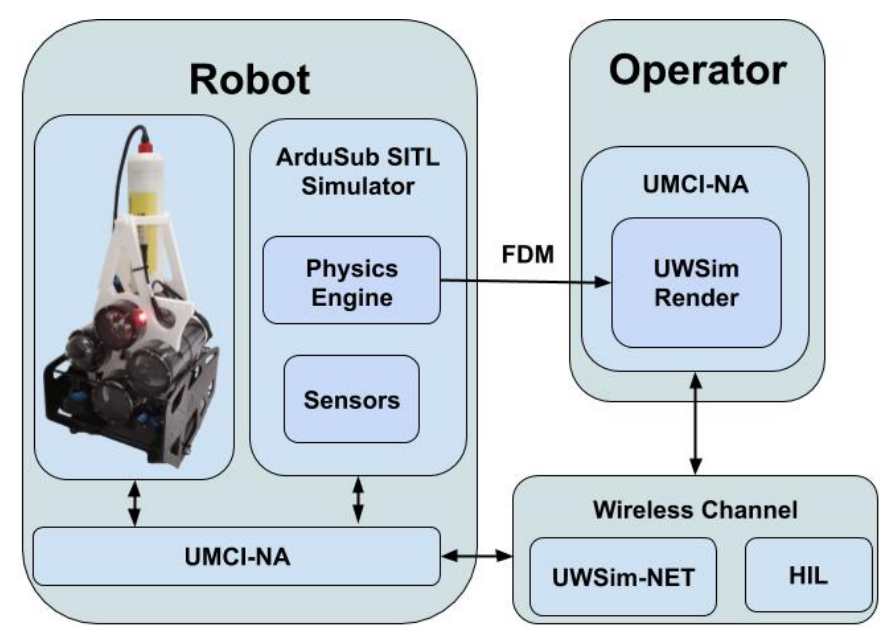

(b)

Figura 3.9: Experiments setup. (a) UWSim during a HIL teleoperation using the ArduSub SITL simulator. (b) All system modules including ArduSub SITL Simulator 


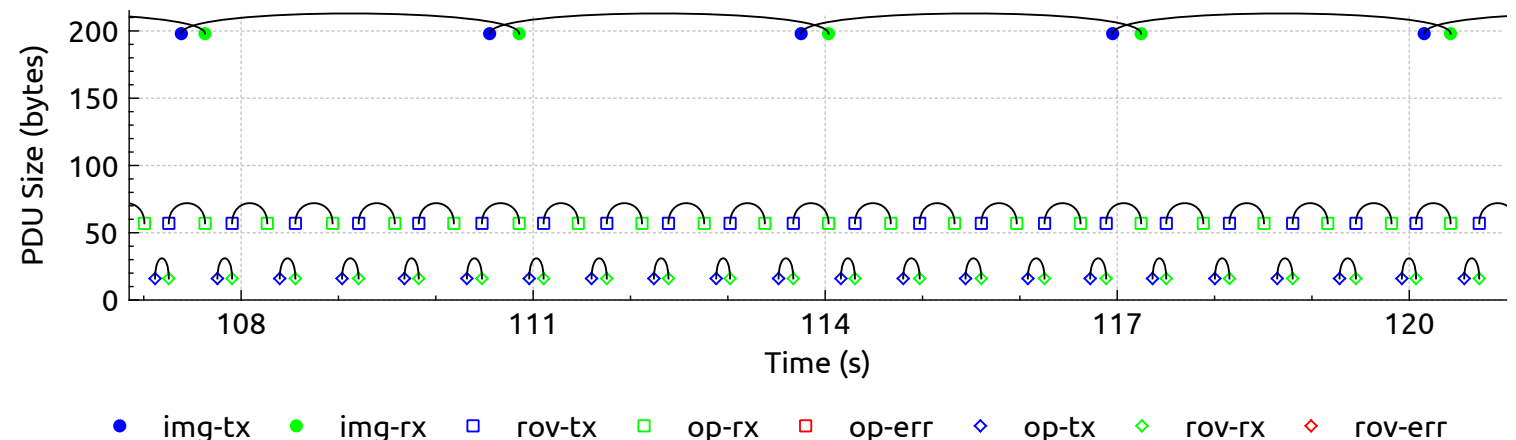

(a)

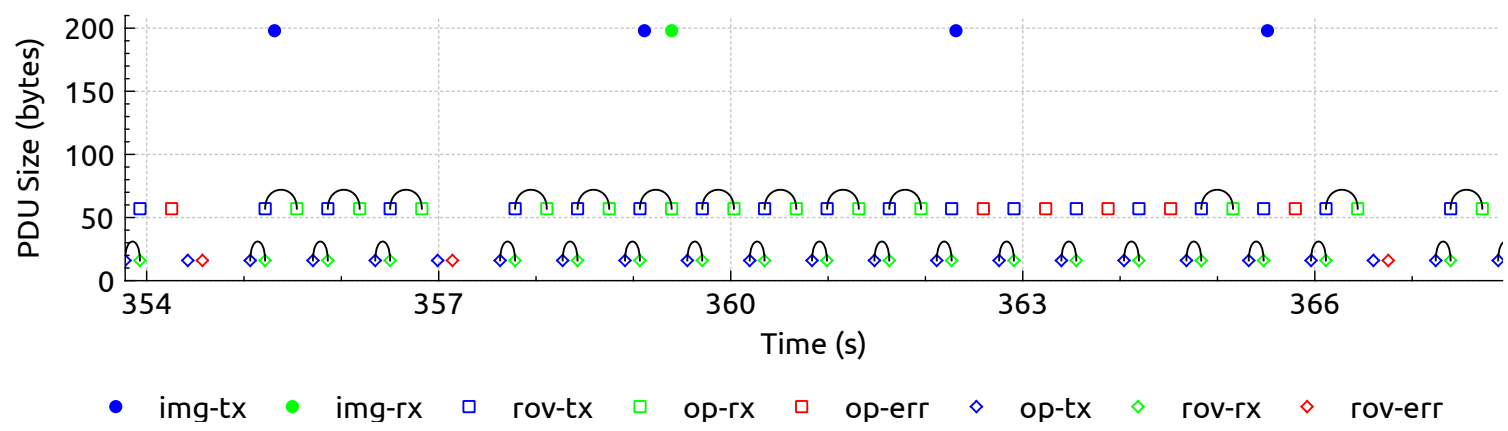

(b)

Figura 3.10: Time lapse of the S100 communication. Operator to ROV packets have a PDU size of 16 bytes, ROV to operator correspond to 57 bytes packets, and larger PDUs correspond to full image transmission. (a) Time measurements with the S100 modems. (b) Simmulated S100 considering a bit error rate (BER) of $0,07 \%$.

port in order to visualize the robot in an external application, such as FlightGear. In this work the UWSim has been extended to be able to place any robot in the position and orientation indicated in these FDM messages. Finally, the position received through the wireless channel is represented as a solid colorful ROV. Due to the delay produced by the wireless communications, this position is received with a lag respect to the actual position, represented by the white ROV.

\subsubsection{Teleoperation with RF modems}

In this section the results of a teleoperation over a RF link by velocity commands are presented. This experiment has been performed first using a BlueROV equipped with the S100 (see Figure 3.2(a)), then a HIL experiment with the S100 modems (see Figure 3.8), and finally modeling the RF modems considering a non-zero bit error ratio (BER). 


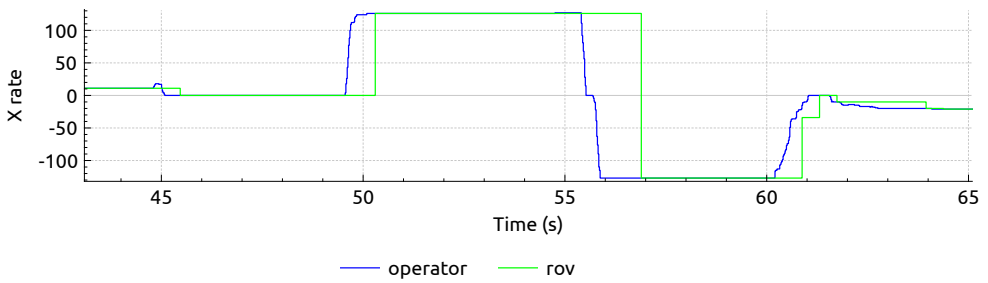

(a)

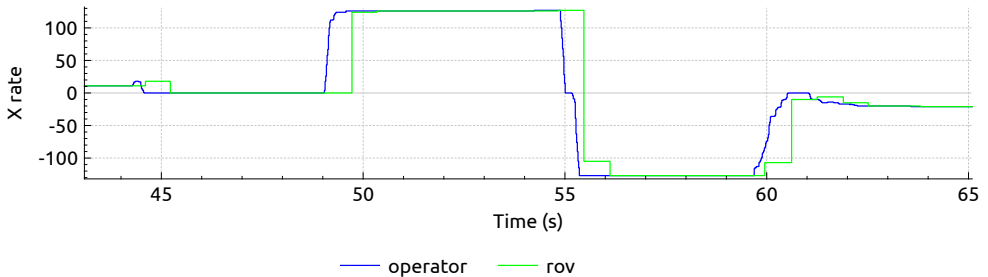

(b)

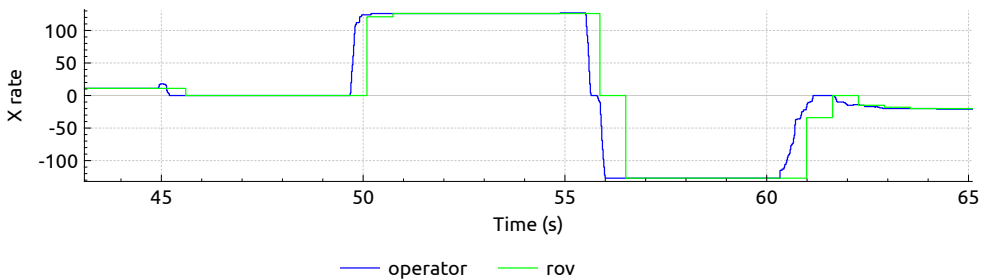

(c)

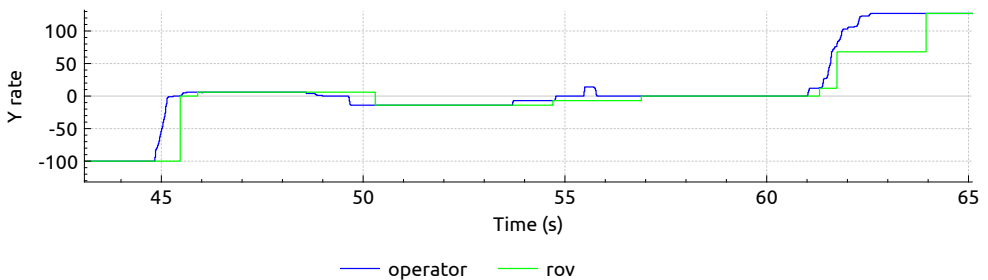

(d)

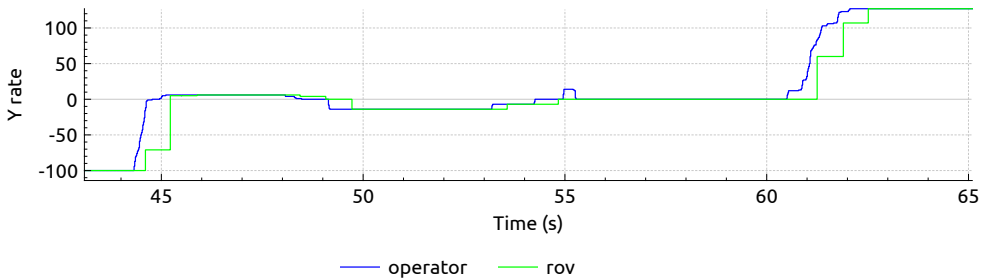

(e)

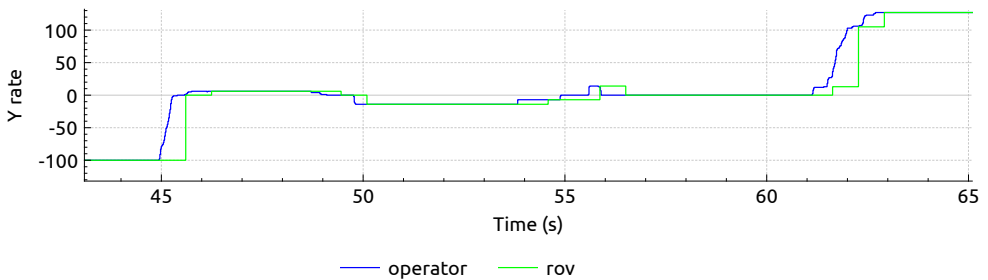

(f)

Figura 3.11: Difference between commanded velocities by the operator (blue) and their execution by the ROV (green). (a) and (d) are the $\mathrm{x}$ and y axis during a real experiment. (b) and (e) are the $\mathrm{x}$ and $\mathrm{y}$ axis during the HIL using simulated robot and real modems. (c) and (f) are the $\mathrm{x}$ and $y$ axis with simulated robot and simulating the communications considering a fixed BER of $0,07 \%$, and the parameters shown in the RF column of Table 3.3. 
Cuadro 3.4: Performance of the RF communication measured in a HIL experiment with the S100 modems, and modeling the S100 modems with UWSim-NET without considering packet loss (BER $0 \%$ ) and considering packet loss (BER 0.07\%).

\begin{tabular}{|l|cc|cc|cc|}
\cline { 2 - 7 } \multicolumn{1}{c|}{} & \multicolumn{2}{c|}{ HIL } & \multicolumn{2}{c|}{$\begin{array}{c}\text { UWSim-NET } \\
\text { (BER 0\%) }\end{array}$} & \multicolumn{2}{c|}{$\begin{array}{c}\text { UWSim-NET } \\
\text { (BER 0.07\%) }\end{array}$} \\
\cline { 2 - 7 } & Robot to & Operator & Robot to Operator & Robot to & Operator \\
& Operator & to Robot & Operator & to Robot & Operator & to Robot \\
\hline Through. (kbps) & 0.72 & 0.2 & 0.72 & 0.2 & 0.41 & 0.18 \\
Delay (ms) & 368.4 & 154.12 & 333.17 & 158.99 & 333.1 & 158.8 \\
Jitter (ms) & 13.42 & 10.55 & 12.84 & 10.05 & 10.42 & 9.05 \\
IAT (ms) & 640.38 & 640.53 & 640.21 & 640.36 & 726.56 & 640.42 \\
IAT $\sigma(\mathrm{ms})$ & 15.36 & 8.89 & 16.43 & 7.26 & 157.82 & 6.82 \\
\hline
\end{tabular}

In Figure 3.10(a) and Figure 3.10(b), a time lapse of the packet sending and receiving events during the teleoperation are shown. Figure 3.10(a) shows the results of the HIL (Hardware In The Loop) experiment with the S100 modems sunk in water and robot motion simulated with the ArduPilot simulator. In this figure, the capture and reception events of an image are also shown. The same teleoperation was replicated in Figure 3.10(b), but modeling the communications using UWSim-NET in order to account for transmission errors. Here a BER of $0.07 \%$ has been established.

During the experiment, the control of the ROV was carried out by means of velocity commands (using the joystick). Figures 3.11(a) and 3.11(d) show the status of the speed controls on the operator and the robot sides during real teleoperation. Figures 3.11(b) and 3.11(e) show the status of the speed controls on the operator and the robot sides during HIL teleoperation. Figures 3.11(c) and 3.11(f) show the same information but modeling the communications considering transmission errors. As can be seen, there is only a small signal lag, caused by the delay. Moreover, the robot's packet reception rate is high enough (see Inter Arrival Time (IAT) in Table 3.4) so as to visualize the virtual robot in its real position in the HRI. The larger signal lag between commanded (blue) and execution (green) times in Figures 3.11(a) and 3.11(d) is caused by the interference of the thrusters that lead to a slight increase of packet loss. However, it 
does not hamper teleoperation in real time.

Table 3.4 shows the numerical results of the experiment with real S100 modems. In order to validate the operation of UWSim-NET, the same teleoperation has been replicated considering a BER of $0 \%$ (see Table 3.4), which is the one obtained during the HIL. Finally, Table 3.4 also shows the results of the experiment with UWSim-NET having set a BER of $0.07 \%$. As can be apreciated, the resulting jitter during the teleoperation is comparable to the intrinsic jitter of the S100 modem, shown in Table 3.3. This is due to the TDMA strategy explained at 3.3.4 that ensures the media to be free before each message transmission, so that avoiding collisions without adding extra overhead to perform the media access control.

\subsubsection{Position Commands and Communication Recovery}

In this section the control of the BlueROV based on position commands is evaluated. The desired position was commanded by moving the semitransparent BlueROV in the UWSim scene. In this experiment, the communication was simulated using UWSim-NET, the maximum distance was set to 5 meters, and a constant BER of $0.07 \%$ was considered. With this configuration the robot will lose communication completely when the distance between the on-board and the surface modem is greater than 5 meters.

Figure 3.12 shows the current and target value of the distance between the operator's modem, located near the surface, and the modem integrated in the ROV. The target value is the distance that will exist between the modems once the robot arrives at the destination position. The maximum distance is shown as a dashed red line at the value of 5 meters. The Figure 3.13 shows the value of the last position to be recovered after the first loss of communication when passing the 5 meters. Finally, in Figure 3.14 is shown the value of the current and target position during the control.

The results in Figures 3.12 to 3.14 confirm that the proposed RCP permits to control a BlueROV in position mode. On the one hand, position 


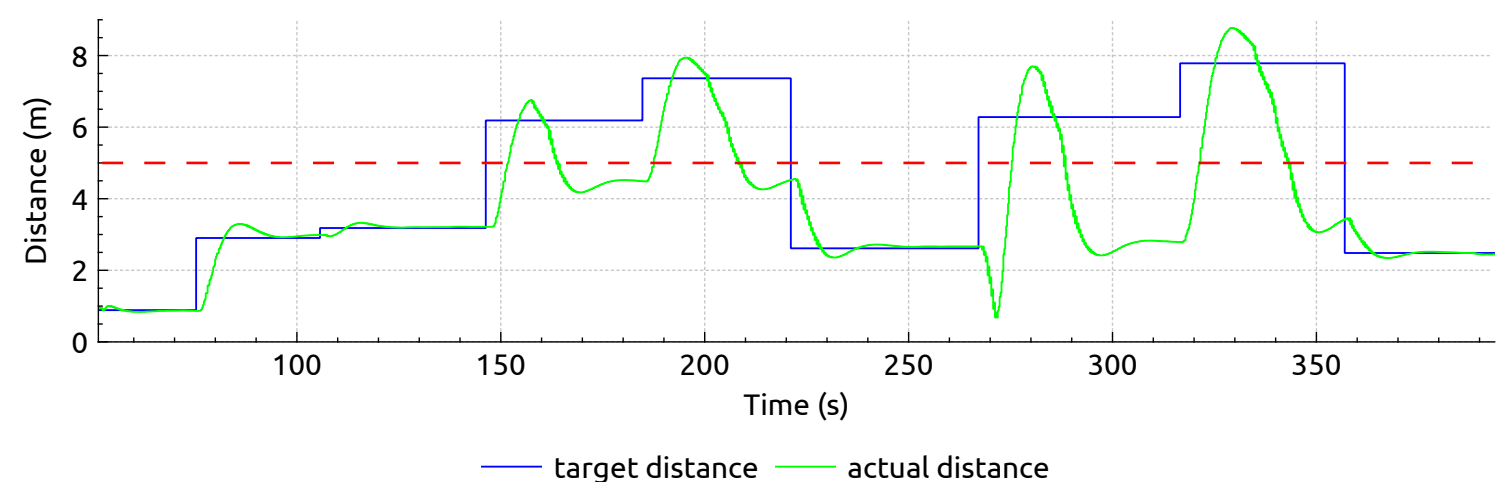

Figura 3.12: Current and actual distance from modem on buoy to modem on BlueROV and the target position's distance of the modem on the ROV. Modem's range at 5 meters is indicated as a straight line.

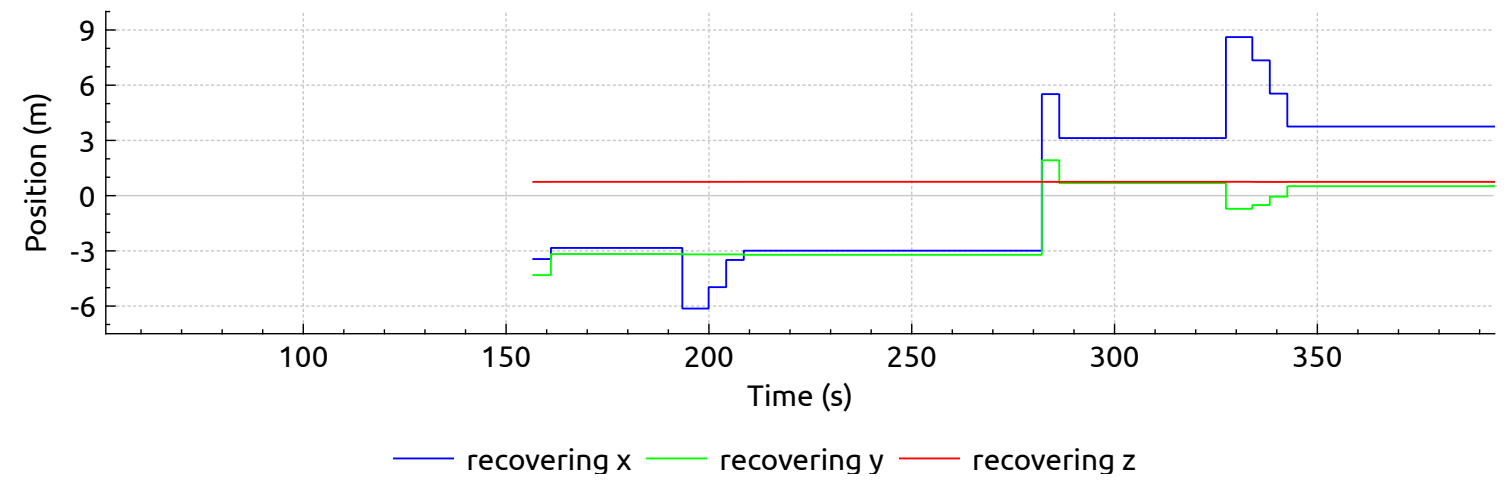

Figura 3.13: Recovering positions after the first communication lost.

commands are successfully received by the ROV which executes a PID that leads the ROV to the desired position. On the other hand, when the communication is lost, the ROV is capable of making its way back until the communication is recovered, as can be appreciated at second 160 in Figure 3.12 .

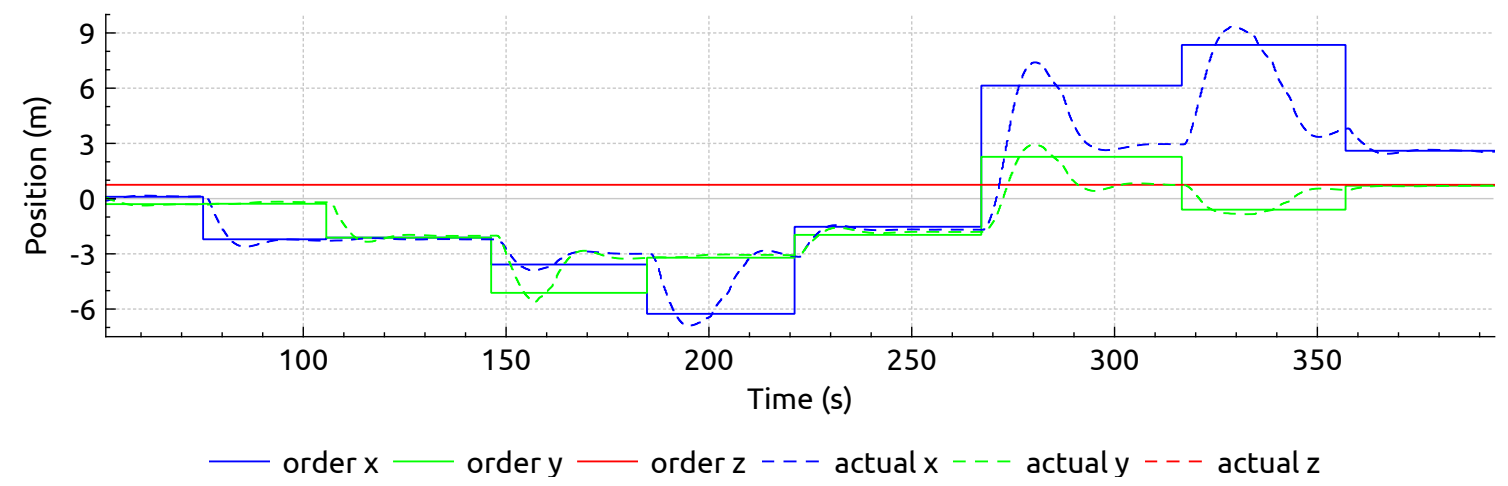

Figura 3.14: Target and actual NED positions. 


\subsection{Conclusions}

A protocol specific for underwater $\mathrm{RF}$ communications implemented within the framework of the MERBOTS project has been presented in this work. Taking into account the limitations of the channels in underwater scenarios with bandwidths lower than $1.9 \mathrm{kbps}$, an ad-hoc cross layer network protocol outside the TCP/IP stack is required.

The protocol described in this manuscript proposes to control the medium access that does not add extra overhead to the routing layer by using a dedicated TDMA algorithm. The master-slave strategy simplifies the protocol, and minimizes its overload by avoiding the requirement of request to send or clear to send signals in order to manage the medium access. Thus being able to make the most of the small bandwidth. The fact that the slave ROV only responds to the messages of the master might be appreciated as a limitation. But, it has been mitigated by forcing the master to send messages periodically, which ensures that the operator receives the odometry of the ROV at least once per second. The results achieved with such a protocol demonstrate the feasibility of wireless teleoperation of an underwater ROV. The proposed protocol is capable of providing the operator with visual feedback of the ROV. But the low image rate recommends the usage of either a VR module or a supervised control based on high level commands. The presented system allows both teleoperation in real time and a supervised control of the robot visualizing the result of the commands before being sent. In addition, it allows visual feedback with a region of interest at a constant rate thanks to the integration of the progressive compression algorithm DEBT.

Further work will be devoted to improve the visual feedback. The incorporation of a tracking system will facilitate the update of the ROI as the ROV moves. And a semantic analysis of the scene aimed at the recognition of shape, size and orientation of objects will reduce the amount of data required to transmit the visual information. 



\section{Capítulo 4}

\section{Underwater Multirobot Cooperative Intervention MAC Protocol}

\section{Publicación}

Diego Centelles, Antonio Soriano, José V Martí y Pedro J Sanz. "Underwater Multirobot Cooperative Intervention MAC Protocol". En: IEEE Access 8 (2020), págs. 60867-60876

This work introduces a Medium Access Control (MAC) protocol designed to allow a group of underwater robots that share a wireless communication channel to effectively communicate with each other. The goal of the Underwater Multirobot Cooperative Intervention MAC (UMCI-MAC) protocol presented in this work is to minimize the end to end delay and the jitter. The access to the medium in UMCI-MAC follows a Time Division Multiple Access (TDMA) strategy which is arbitrated by a master, which also has the capability to prioritize the transmission of some nodes over the rest of the network. Two experiments have been carried out with a team of four Autonomous Underwater Vehicles (AUV) in order to compare this protocol with Aloha-CS and S-FAMA MAC protocols used in Underwater Wireless Sensor Networks (UWSN). In the first experiment, the communications and the AUVs have been simulated using UWSim-NET. The objective of this experiment was to evaluate all three protocols in terms of delay, jitter, efficiency, collisions and throughput depending on the size of the data packet and the rate of packet delivery in the application layer for 
each robot. The results of this experiment proved that UMCI-MAC successfully avoids packet collisions and outperforms the other two protocols in terms of delay, jitter and efficiency. The second experiment consisted of a Hardware In The Loop (HIL) teleoperation of a team of four robots. One of the AUVs was a real BlueROV in a water tank, while the remaining AUVs and the communications were simulated with UWSim-NET. It demonstrates the impact of the MAC protocols in underwater acoustic links. Of the three MAC protocols evaluated in this work, UMCI-MAC was the only one which succeeded in the proposed teleoperation experiment. Thus demonstrating its suitability as a communications protocol in underwater cooperative robotics.

\subsection{Introduction}

The range of applications of Underwater Wireless Networks (UWN) has been increasing in recent years. Data collection, assisted navigation, prevention of natural disasters or maritime surveillance are among their most common applications $[33,2,1]$. Unlike terrestrial wireless networks, the suppression of wires in UWN applications is not straightforward. UWN are usually based on acoustic signals, since they are the only technology that enables devices under water and separated by several kilometres, to communicate with each other. However, acoustic modems suffer from high sensitivity to ambient acoustic noise; extremely limited bandwidth; large delays due to the low propagation speed of sound in water $(\approx 0,6 \mathrm{~ms} / \mathrm{m})$; high variability in propagation time and interference due to multi-path $[68,50]$. Commercial acoustic modems typically have a transmission rate of a few kbps [22]. When high data rates are needed, as is the case of the transmission of visual information in real time, communication links based on Visible Light Communication (VLC) are also considered. But, $\mathrm{VLC}$ is limited to a few tens of meters in case there is low ambient light and good visibility between the transceivers [36]. Radio Frequency (RF) links are another alternative to acoustic links for UWN applications [25]. By employing large antennas and greatly reducing the transmission speed, 
devices like the S100 from Wireless for Subsea [75] allow implementing robust links of up to 12 meters, but the strong attenuation of RF signals in water constraints the range of possible applications.

Because of the aforementioned limitations of underwater wireless communications, there are still situations in underwater robotic applications which require the use of umbilicals. In the field of cooperative robotics a team of Remotely Operated Vehicles (ROV), or Intervention AUVs (IAUV), work together in order to fulfill a given task such as grasping or transporting objects. Some examples of these applications are maintenance tasks in the oil and the gas industries [66], underwater rescue or archaeology [35] [42]. In these applications the exchange of messages among the robots, and also with the supervisor, has to be in real time and also in a robust way. When sending commands from robot to robot, or from robot to operator, it is necessary to have as little delay as possible and a very small fluctuation of the delay (jitter) [67]. The main source of jitter in wired networks is router congestion. Transport layer protocols in terrestrial networks are therefore designed to adapt the packet injection rate in order to avoid this congestion, while trying to reduce the jitter $[77,38]$. But this strategy is not appropriate for UWN because the source of the fluctuation of the delay is not only in the routing layer, but also in the access to the medium and physical layers.

The low bandwidth and the large and variable propagation time of acoustic links in UWN are the reasons why packet re-transmissions strongly contribute to introduce large delay and jitter, as is the case of Medium Access Control (MAC) protocols that do not completely avoid packet collisions. The impairment to performance caused by these factors and the high probability of errors in underwater communications justify the development of MAC protocols specific for these environments [50]. Because of the long delay in the communication, pure Carrier-Sense Multiple-Access (CSMA) approaches are not the most appropriate in scenarios where distant nodes can start to transmit at different times, because the space-time uncertainty might lead to the generation of many collisions [71]. 
Underwater Wireless Sensor Networks (UWSN) applications have boosted the design of protocols specific for UWN in recent years [50, 33, 19, 22]. These protocols are focused on minimizing the likelihood of collisions in acoustic channels, while trying to maximize their efficiency as it is related to the power consumption required for the communications. Despite the wide variety of strategies followed in UWN protocols, they can be categorized as contention-based or contention-free.

In contention-based protocols devices compete to access the channel. Some protocols are improvements on Aloha, such as Aloha with carrier sensing (Aloha-CS), with Collision Avoidance (Aloha-CA) or with Advanced Notification (Aloha-AN) [20]. As with the original Aloha, these protocols do not make a prior reserve of the channel, but try to avoid collisions by listening to the channel or to the messages from their neighbors. Other strategies consist of using reservation and synchronization mechanisms like the Slotted Floor Acquisition Multiple Access (S-FAMA ) [44]. S-FAMA divides the time into slots whose duration depends on the maximum propagation time plus the transmission time of a control message. Two control messages are considered in S-FAMA, Request To Send (RTS) messages, which are used to ask for permission to access the channel, and Clear To Send (CTS) messages, which are used to give permission to access the channel. S-FAMA prevents the collision of data packets but does not avoid the collision of control packets. Unlike S-FAMA, the Reservation-MAC protocol (R-MAC) [79] does not require the nodes to be synchronized, instead it requires the nodes to estimate their time differences by measuring the propagation time of the messages exchanged with their peers. The Tone Lohi protocol [70] proposes a strategy which avoids the exchange of RTS and CTS messages. Instead, it divides the time in a Contention Round into a Reservation Period (RP) and a Data Period. A node interested in transmitting a message sends a pure tone during the RP. If it does not receive a tone from another node during the RP then it starts the transmission, otherwise it waits for a random number of RPs.

Contention-free is the other category of protocols. These solutions allow 
nodes to access the channel at the same time, or without risk of collision. They are subdivided into: Frequency Division Multiple Access (FDMA), Code Division Multiple Access (CDMA) and Time Division Multiple Access (TDMA). Due to the narrow bandwidth of the acoustic links, a solution based solely on FDMA is not feasible for UWSN [68]. The encoding of the message in CDMA reduces the effective transmission rate [22]. However, the combination of CDMA with contention-based methods has proven to be suitable for UWSN [49]. Finally, in TDMA protocols each node is assigned a time slot in which it has exclusive access to the channel. In very large networks the need to wait for each node's time slot leads to large delays. Therefore, TDMA protocols specific for UWSN such as Multidimensional-Scaling-MAC (MDS-MAC) [74] or the one utilized in ACMENet [1] are usually considered for small clusters within a large network.

The Underwater Multirobot Cooperative Intervention MAC protocol (UMCI-MAC) is presented in this work. It has been designed to minimize delay and jitter, thus allowing an efficient communication among a group of AUVs in underwater cooperative interventions. UMCI-MAC proposes a TDMA strategy. One of the AUVs acts as master and coordinates the communication process, while the rest of AUVs react to master commands, in order to avoid packet collisions. Moreover, the protocol has the potential to prioritize the access to the channel of each slave as a service to the upper layers. The protocol is intented to be used in a small team of up to eight AUVs.

The rest of the paper is organized as follows. In Section 4.2 the UMCIMAC protocol is described in detail. In Section 4.3 the performance of UMCI-MAC is evaluated and compared with that of Aloha-CS and SFAMA protocols. In a first experiment throughput, efficiency, collisions, end to end delay and its fluctuation (jitter) are obtained for several combinations of packet size and application data rate. A second experiment consisting of a Hardware In The Loop (HIL) control of a team of underwater AUVs is also presented. In this experiment results in terms of command 
delay, jitter and position errors are also obtained. Finally, in Section 4.4 are summarized the main results presented in this manuscript.

\subsection{UMCI-MAC}

As mentioned in the previous section, delay and jitter are the parameters of communications that have the highest impact in robotic applications. In this work we introduce UMCI-MAC protocol for underwater acoustic channels the aim of which is to allow the control of up to 8 ROVs participating in a cooperative intervention.

The communication among the nodes in UMCI-MAC is organized by one of the nodes which is identified as master. The rest of the nodes are identified as slaves and act in response to the master's messages. The communication process is based on rounds which are divided into control and data phases. The control phase is initiated by the master through a very short synchronization packet (SYNC) that serves as a reference point for the slaves. After the reception of a SYNC, each slave is assigned a time slot to send their request to transmit in a control packet (CTRL). The duration of each time slot equals the transmission time of a CTRL plus the maximum network propagation time. During the data phase the master gives each slave permission to transmit by means of a CTS packet. On the reception of a CTS, the designated slave will transmit its DATA packet. At the end of the data phase, the master can optionally send a DATA packet to some designated slaves, and will start a new round. The master will use the SYNC packet of the next round to acknowledge all the messages received from the slaves. The slaves will use the next round's CTRL packet to acknowledge the messages they received.

Every transmitted packet has a common structure, with a header (Figure 4.1), a body (Figure 4.2) and a Cyclic Redundancy Check (CRC-16) hash of the information contained in the header and the body.

The header structure, shown in Figure 4.1, contains an 8-bit preamble (PRE) to synchronize the reception of a new packet, two 4-bit fields to 


\begin{tabular}{|c|c|c|c|c|}
8 bit & 4 bit & 4 bit & 6 bit & 2 bit \\
\hline PRE & SRC & DST & msb data size & TYPE \\
\hline
\end{tabular}

Figura 4.1: Header structure

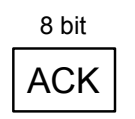

(a)

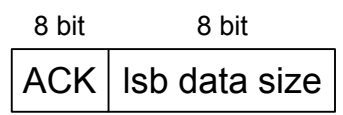

(b)

\begin{tabular}{|l|l|}
\hline \multicolumn{1}{c}{8 bit } & 8 bit \\
\hline $\mathrm{n} / \mathrm{u}$ & Isb data size \\
\hline
\end{tabular}

(c)

\begin{tabular}{|l|l|}
\hline \multicolumn{1}{c|}{8 bit } & data size \\
\hline Isb data size & PAYLOAD \\
\hline
\end{tabular}

(d)

Figura 4.2: Body structure of the four packet types considered in UMCI-MAC. (a) SYNC. (b) CTRL. (c) CTS. (d) DATA.

identify the transmitter (SRC) and the receiver (DST), a 6-bit field (msb data size) with the 6 most significant bits (MSB) of the message's length and a 2-bit field (TYPE) used to identify the four BODY messages considered in UMCI-MAC. All UMCI-MAC messages have the same header structure but different body structures shown in Figure 4.2.

The SYNC message is sent by the master to start each communication round. Its body is composed of a single 8-bit field (ACK), Figure 4.2(a), one per AUV. The master sets to "1" the bit corresponding to a slave in order to acknowledge the reception of a message from this slave during the previous round.

Each node sends a CTRL message (Figure 4.2(b)) during its time slot of the control phase which indicates the number of bytes that it wants to transmit in the current round. This number is encoded on 14 bits, the 6 MSB are in the header of the message, and the 8 less significant bits (LSB) are in the lsb data size field of the CTRL packet. The CTRL also contains an 8-bit ACK field that each node uses to acknowledge any packet received during the previous round, as the master uses the ACK field in the SYNC message.

CTS packets, shown in Fig 4.2(c), are sent by the master during the data phase in order to give permission to each slave to transmit the data requested in its CTRL packet. The 8 bit $l s b$ data size field contains the 


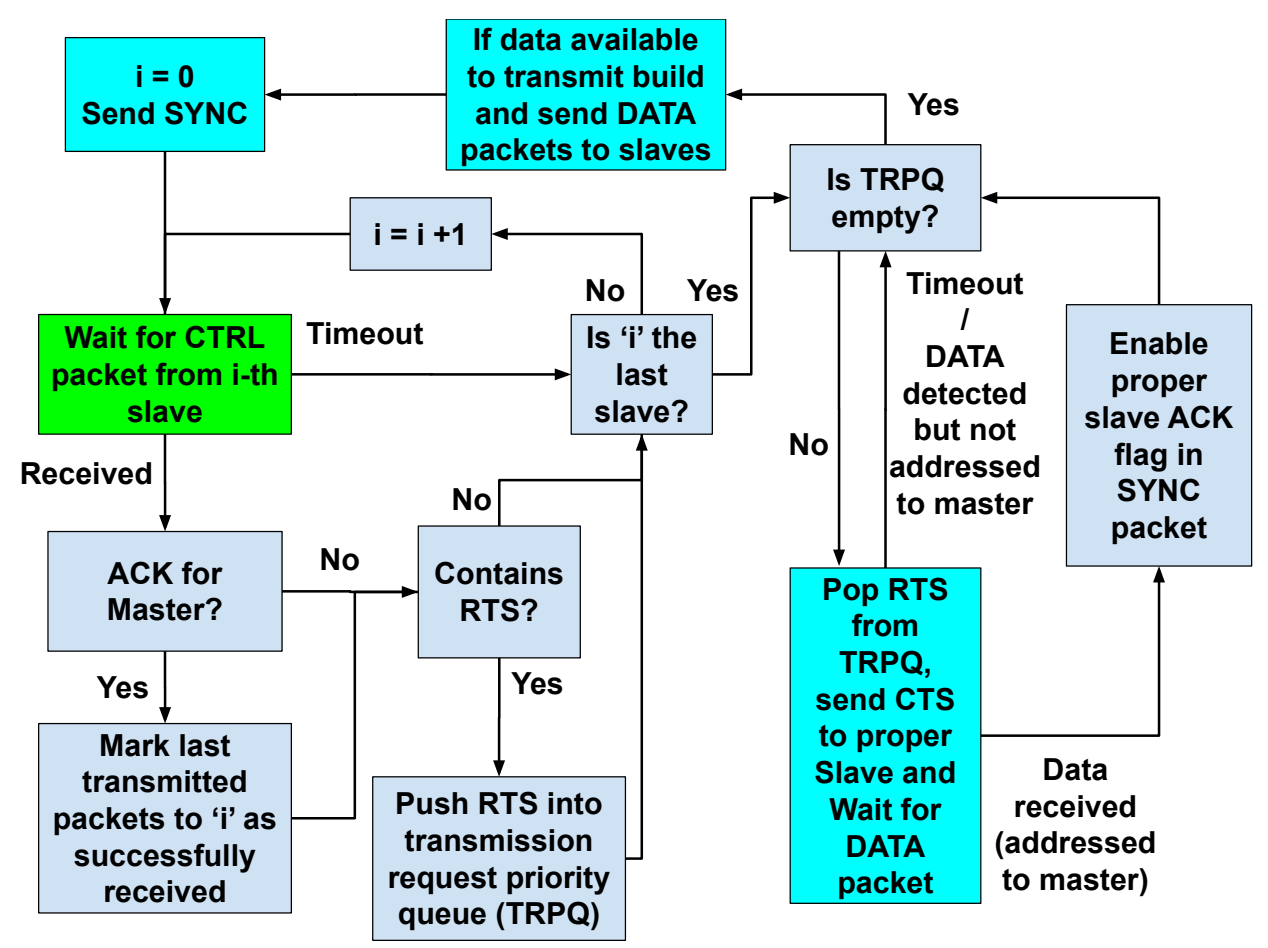

Figura 4.3: Workflow of actions carried by the master.

$8 \mathrm{LSB}$ of the number of bytes that the corresponding slave is allowed to transmit. The remaining 6 MSB bytes are encoded in the HEADER. This packet also contains an 8-bit field labeled as " $\mathrm{n} / \mathrm{u}$ " which have not been used but are reserved for future applications.

DATA is the only variable length packet, its structure can be seen in Fig $4.2(\mathbf{d})$. The first byte of the DATA packet contains the lower 8 bits (LSB) of the number of bytes in the payload. The remaining (MSB) 6 bits are included in the HEADER.

A high level view of the master's workflow is shown in Fig 4.3. The left side of the diagram corresponds to the control phase of each round, while the right side corresponds to the data phase of the round. The master starts each round broadcasting a SYNC packet and waits for the CTRL of the slaves. If the CTRL contains an ACK for the master, it dequeues such packet from its transmission queue. If the CTRL contains an RTS, the master places the request into the Transmission Request Priority Queue (TRPQ). During the data phase the master sends CTS messages of each transmission request in the TRPQ and waits for the maximum propagation time of the network plus the time the slave requires to transmit the amount 


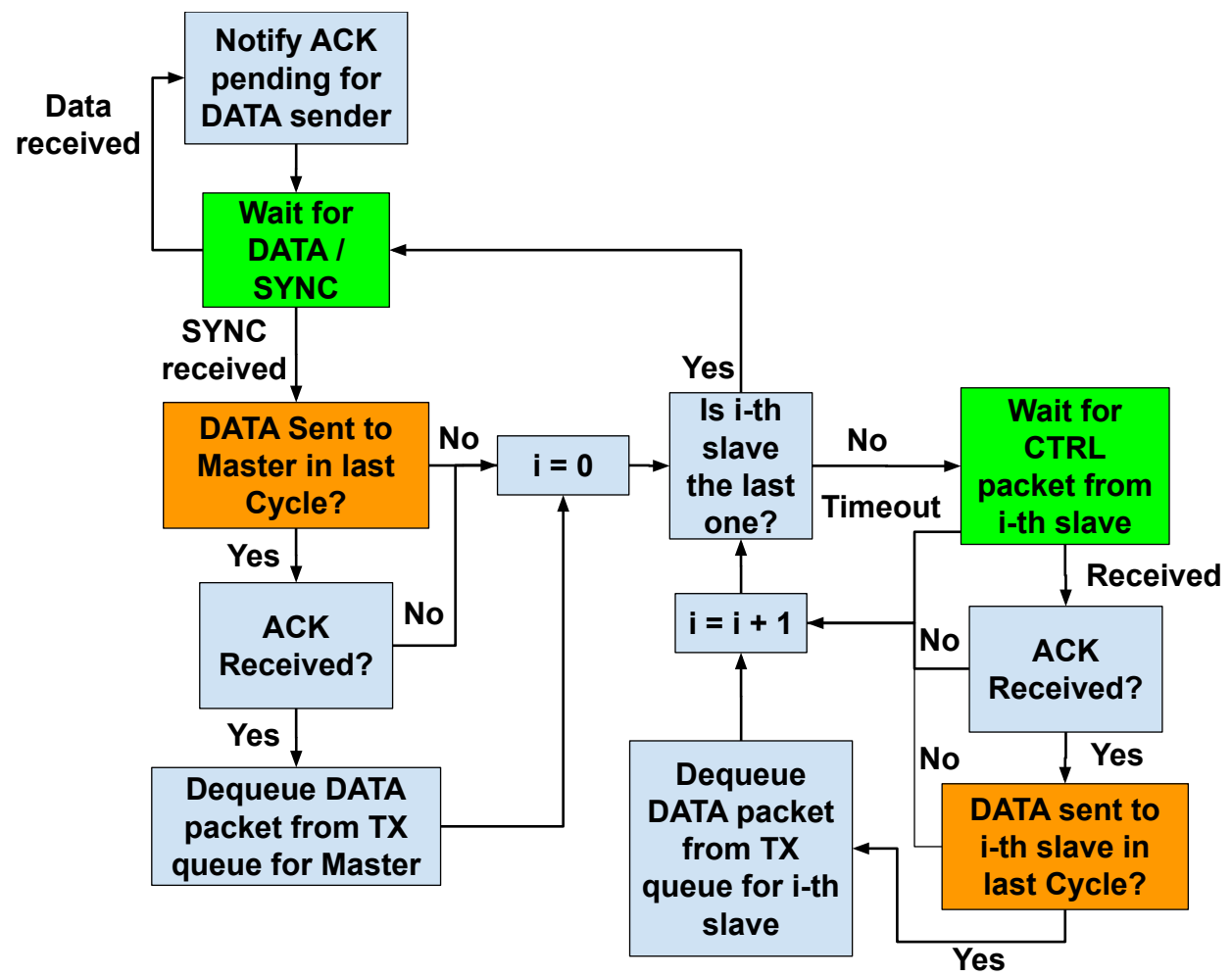

Figura 4.4: Workflow of the actions conducted by the slave to process the received messages.

of data requested in the control phase. After processing all transmission requests in TRPQ the master checks if it has DATA available to transmit to any slave and sends it.

In the case of the slaves the algorithm has been divided in two workflows which are executed concurrently, the one in Fig 4.4 focuses on the process of received messages, while the one in Fig. 4.5 prepares the messages to be sent by the slave. The workflow in Fig. 4.4 is in charge of processing received DATA packets, scheduling ACKs and dequeueing acknowledged DATA packets from the transmission queue. The actions described in this diagram are mainly related to the control phase. After the reception of the SYNC packet, the slave checks if the data sent to the master in the last round has been acknowledged. If so, it dequeues the data packet from the transmission queue. The slave applies the same procedure to the CTRL packets sent by the rest of slaves. After the control phase, this process will listen to the channel for DATA packets until it receives a new SYNC packet from the master. For each data packet received, the slave will schedule an ACK which will be sent in the next round's control phase. 


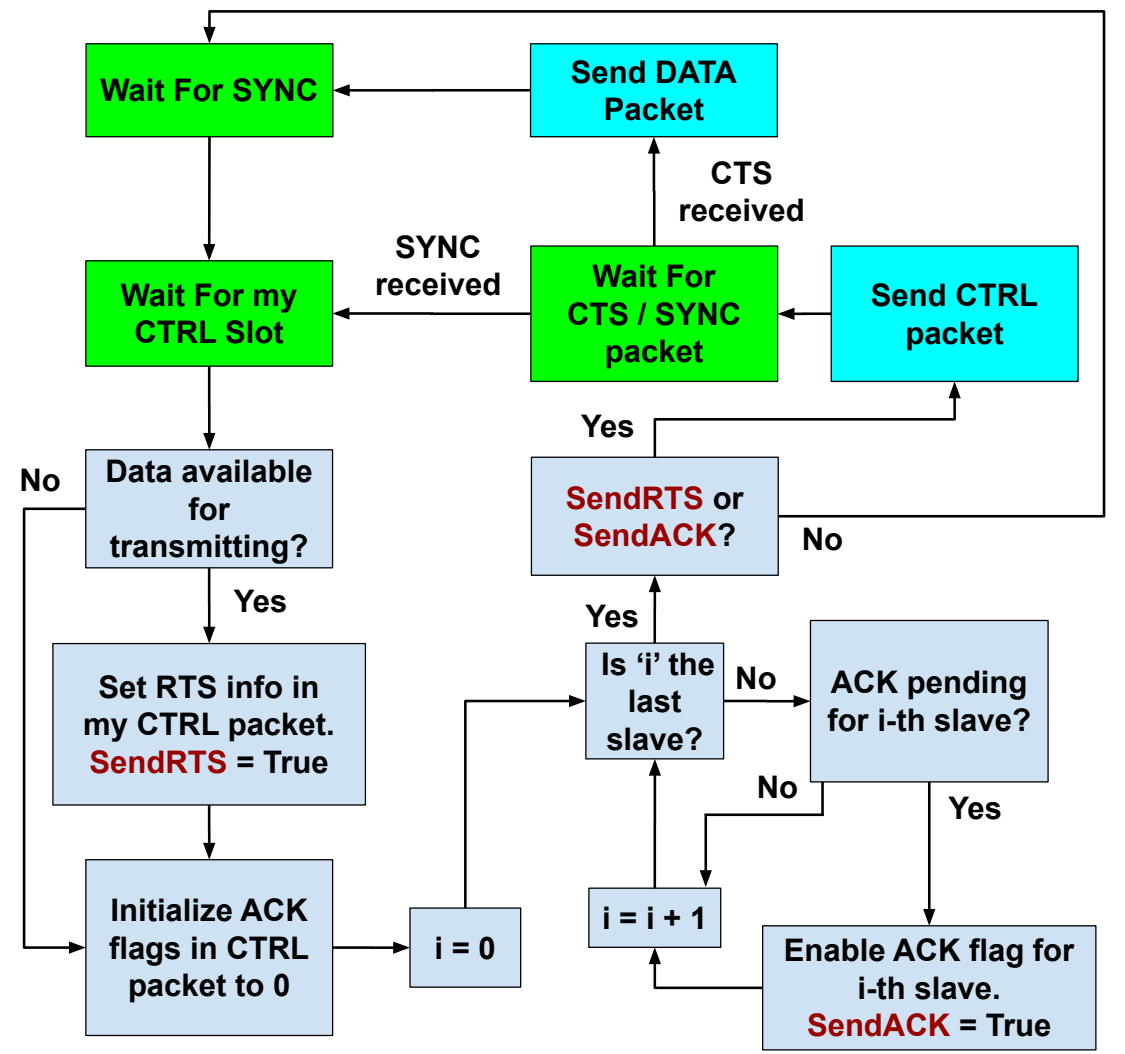

Figura 4.5: Workflow of the slave process dedicated to build and send DATA and CTRL packets.

The second process of the slave is dedicated to building and sending DATA and CTRL packets and it is shown in Fig. 4.5. After the reception of the SYNC packet the slave will compose a CTRL packet with the pending acknowledgements and the size of the DATA available to be transmitted. The slave will use its slot in the control phase to send a CTRL packet if needed. After the control phase, if the slave has not sent a RTS in a CTRL packet it will directly wait for the next SYNC packet. Otherwise it will wait for the CTS from the master. On the reception of the CTS packet, the slave will send its data and will wait for the next SYNC packet.

\subsection{Results}

\subsubsection{Performance evaluation of UMCI-MAC}

The performance of the UMCI-MAC in terms of throughput, efficiency, end to end delay, jitter and data collisions is evaluated in this section. The end to end delay results have been measured in the layer above the MAC. 
They correspond to the time elapsed since a given packet is placed into the MAC layer of the transmitter node until it is recovered from the MAC in the receiver node. UWSim-NET $[12,13]$ was used to model the communications of four AUVs sending packets to a fifth one which acts as a sink. The sink AUV acted as the master, while the transmitting AUVs were the slaves of the UMCI-MAC protocol. All vehicles were equipped with an acoustic modem which has a transmission rate of $1800 \mathrm{bps}$ and a maximum range of 100 meters. The transmission rate for the simulation of the modems in UWSim-NET has been configured considering the specification of the S2CR 18/34 acoustic modems [28,37] and our previous experience using them in scenarios with severe multipath interferences[13].

The experiment consisted in the transmission of 200 packets from each AUV. All MAC protocols were forced to re-transmit every packet as many times as required in order for the transmission to be successful. The same test was repeated for several combinations of data packet sizes, application data rate, and was conducted with Aloha-CS and S-FAMA in order to compare their performance against UMCI-MAC. Additionally, the impact of the relative position of the AUVs in the performance of the MAC protocols was evaluated by repeating the previous experiment considering two different topologies. A linear topology, in which the four slaves were arranged in straight line, being the master in one of the edges. In the square topology, the four AUVs were placed forming a square and the master was placed in its center.

\section{Linear topology}

In this first topology, the four transmitter AUVs were placed in straight line, 20 meters from each other. All of them at the same depth, and holding their positions during the experiment. The sink (master) was located at a depth of eight meters above the first transmitter.

The average end to end delay measured during the experiment with the three MAC protocols is shown in Figure 4.6. As it becomes apparent in Figs. 4.6(b)-4.6(d), the end to end delay slightly changes at low data 


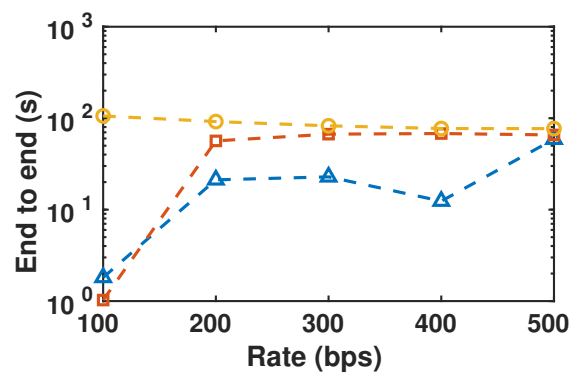

(a)

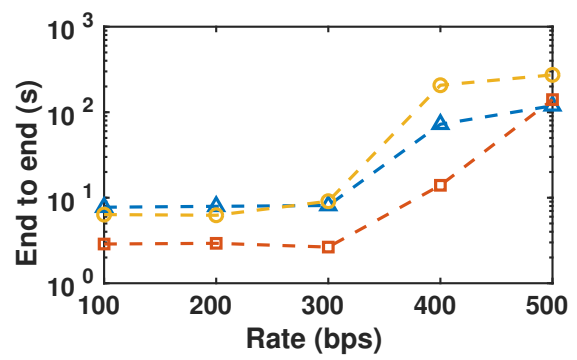

(c)

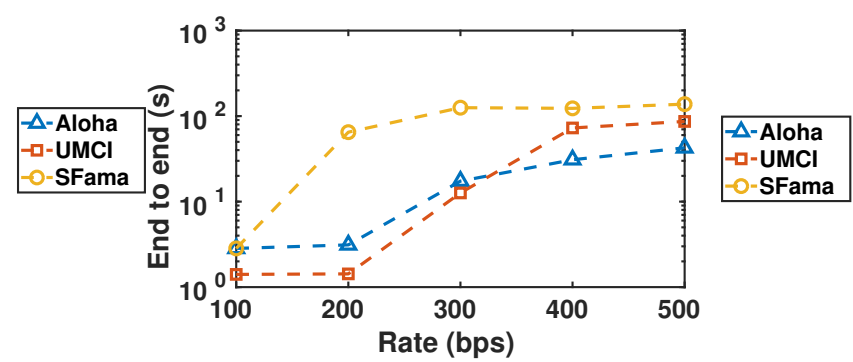

(b)

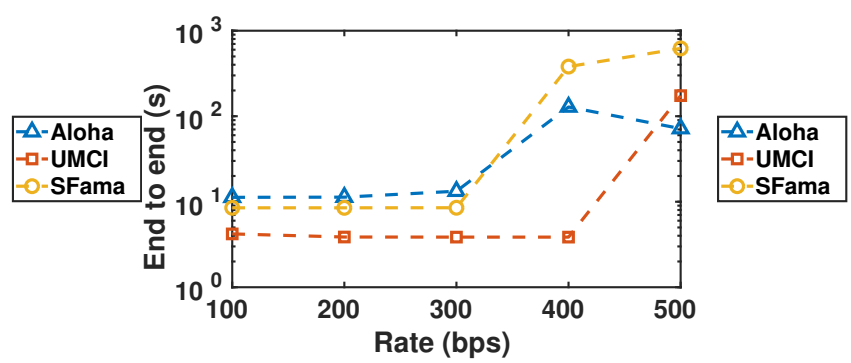

(d)

Figura 4.6: Variation of end to end delay for several packet sizes. (a) 20 bytes. (b) 100 bytes. (c) 400 bytes. (d) 600 bytes.

rates. This corresponds to a normal working regime, in which the nodes are able to send data packets as they are generated. At a given data rate, it is not possible to transmit all data packets so that they are accumulated in the transmission queue, which causes a rapid increase of the end to end delay. As it can be noticed in Figure 4.6, the maximum data rate for which the nodes are in normal regime increases with the packet size. The same behavior is appreciated in Figure 4.6(a), but this behavior is not clearly seen because the normal regime is achieved with a 100 bps data rate, and only for the UMCI-MAC and Aloha-CS protocols. As expected, the end to end delay of all three protocols increases with the packet size, because of the larger transmit and receive times for each packet. However, independently of the packet size the UMCI-MAC exhibits the lowest end to end delay of all three protocols in normal regime.

Figure 4.7 shows the average jitter measured during each experiment. Except for the results in Figure 4.7(a), where 20-byte long packets are considered, the UMCI-MAC achieved the smallest jitter of all three MAC protocols. The low jitter of UMCI-MAC is an indicator of its ability in delivering control messages at regular periods of time. When considering 


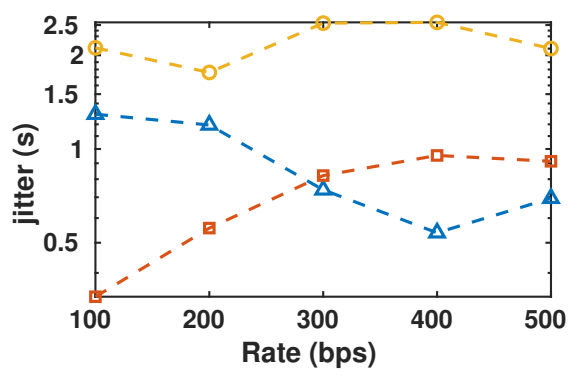

(a)

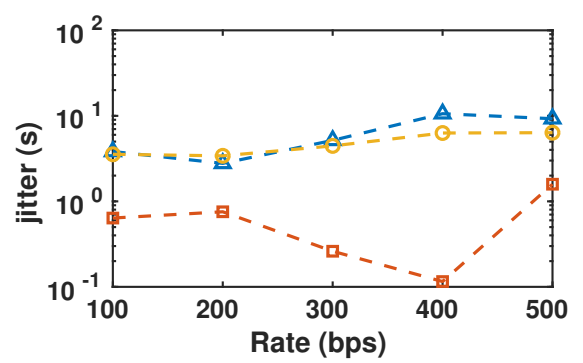

(c)

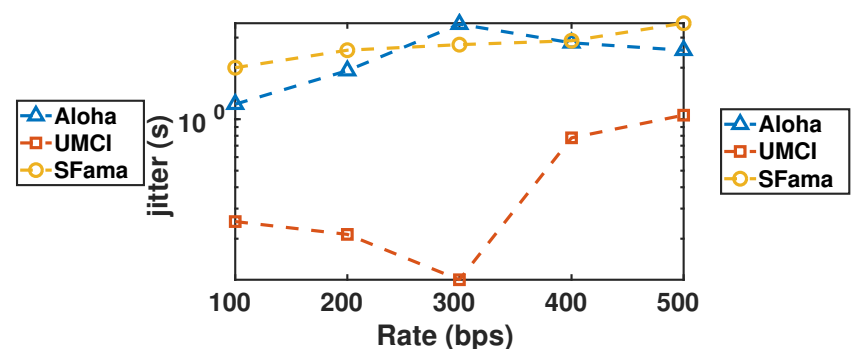

(b)

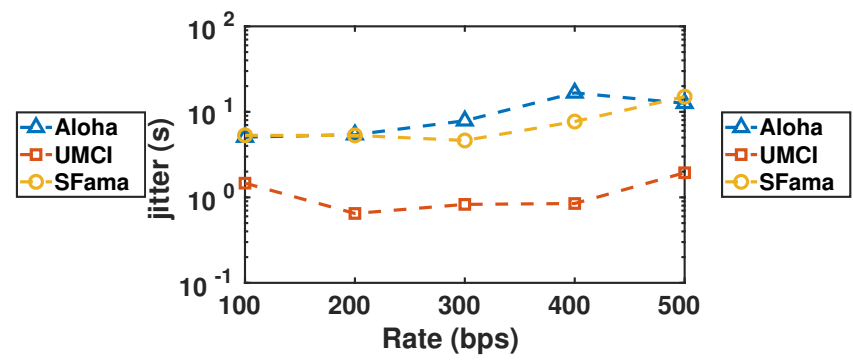

(d)

Figura 4.7: Variation of jitter for several packet sizes. (a) 20 bytes. (b) 100 bytes. (c) 400 bytes. (d) 600 bytes.

20-byte long packets, Aloha-CS exhibits the lowest jitter at high data rates, while UMCI-MAC achieves the best performance at low data rates, see Figure $4.7(\mathbf{a})$.

The efficiency is defined as the ratio between the number of bits in the message to the total amount of bits required to transmit the message (including re-transmissions). UMCI-MAC and S-FAMA exhibit a similar behavior in terms of efficiency, Figure 4.8. Their efficiency degrades when transmitting 20-byte long data packets because of the protocol overload of RTS and CTS messages (see Figure 4.8(a)). However, they reach an efficiency close to $100 \%$ when data packets larger than 100 bytes are considered, as seen in Figs. 4.8(b)-4.8(d). Aloha-CS exhibits a different behavior from UMCI-MAC and S-FAMA in terms of efficiency. Aloha-CS has a poor performance $(\approx 40 \%)$ at low data rates, which increases with data rate. The likelihood of detecting the channel occupied when trying to transmit a packet increases with the data rate. This strongly reduces the likelihood that two nodes start their transmissions at the same time. It also favours the fact that the nodes detect the channel occupied and wait until it is freed in order to start their transmission, thus making a more 


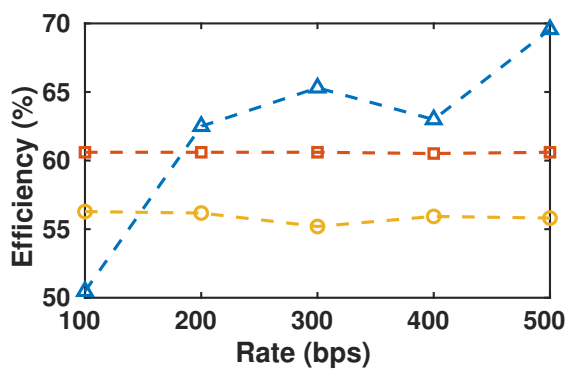

(a)

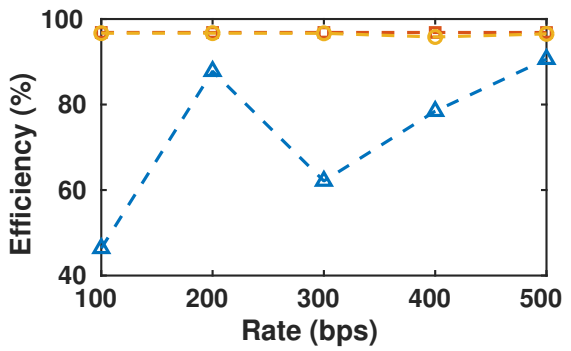

(c)

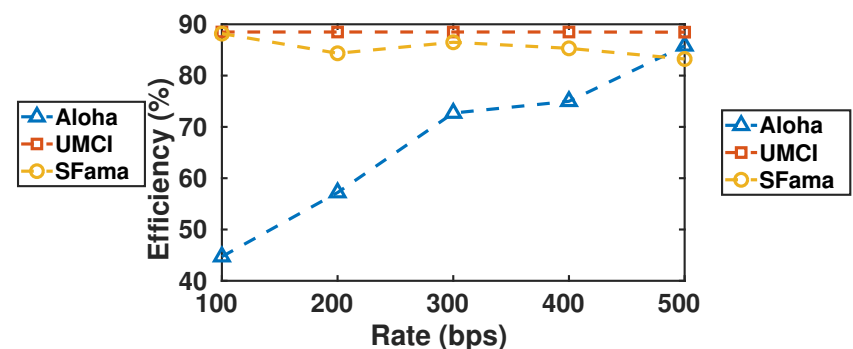

(b)

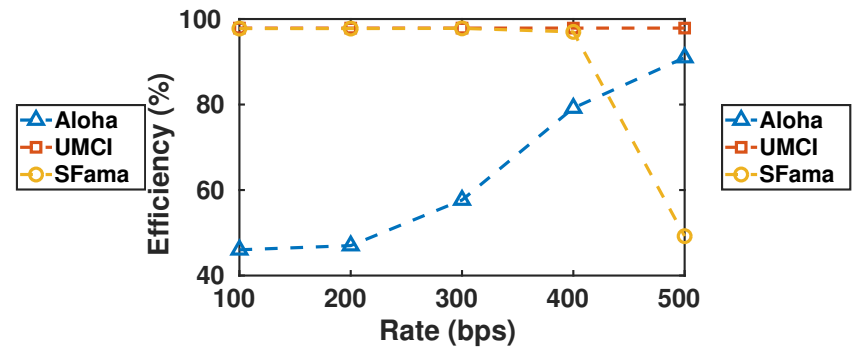

(d)

Figura 4.8: Variation of efficiency for several packet sizes. (a) 20 bytes. (b) 100 bytes. (c) 400 bytes. (d) 600 bytes.

efficient use of the channel.

The comparison of the throughput achieved with all three MAC protocols is shown in Figure 4.9. It is noticed that the measured throughput coincides with the data rate as long as the protocols work in normal regime. In all three protocols it is observed that at a given data rate the throughput saturates, and does not increase with the data rate anymore. A flat variation of throughput with data rate is seen in Figure 4.9 when the modems are out of their normal regime. For all four packet sizes considered in this experiment it is noticed that the lowest throughput is measured with the S-FAMA MAC protocol while Aloha-CS achieves the highest one. Except for the case shown in Figure 4.9(a), considering 20-byte long packets, the results in Figs. 4.9(b)-4.9(d) demonstrate that the performance of UMCI-MAC in terms of throughput is close to that exhibited by Aloha-CS.

Finally, in Figure 4.10 the total amount of collisions during each experiment is illustrated. Only the collisions of the S-FAMA and Aloha-CS are shown in Figure 4.10 because no collisions were measured with the UMCIMAC protocol. The fact that the access to the medium is arbitrated by 


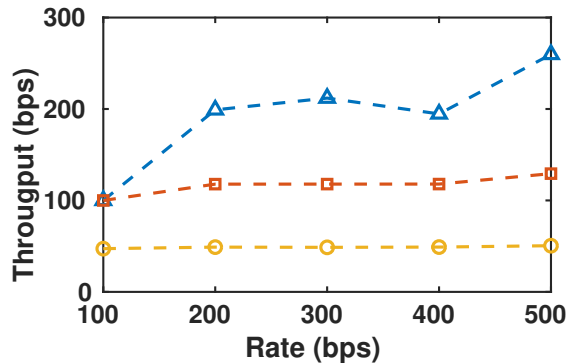

(a)

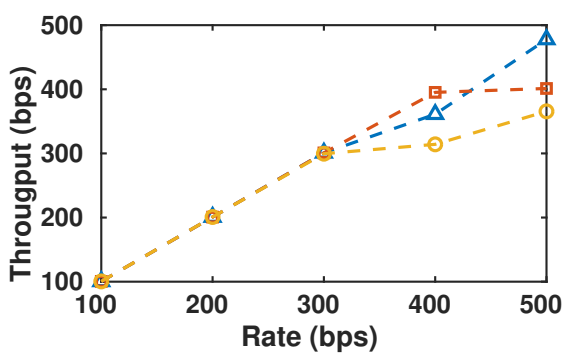

(c)

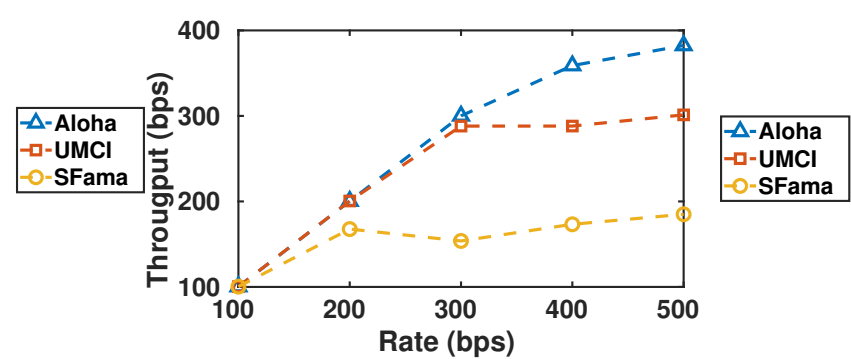

(b)

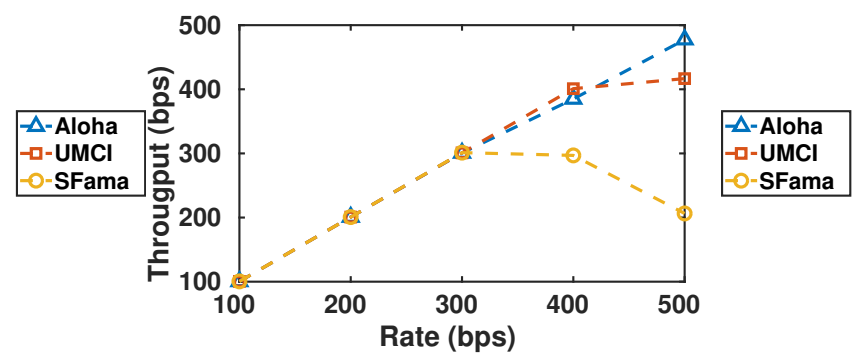

(d)

Figura 4.9: Variation of throughput for several packet sizes. (a) 20 bytes. (b) 100 bytes. (c) 400 bytes. (d) 600 bytes.

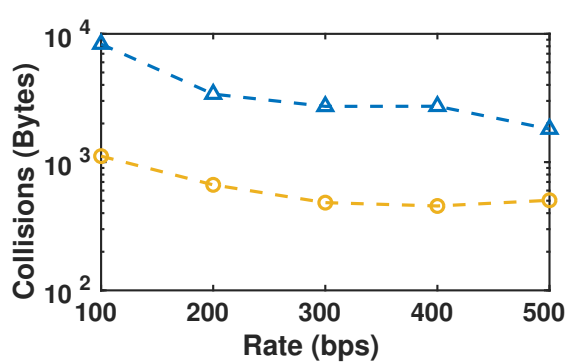

(a)

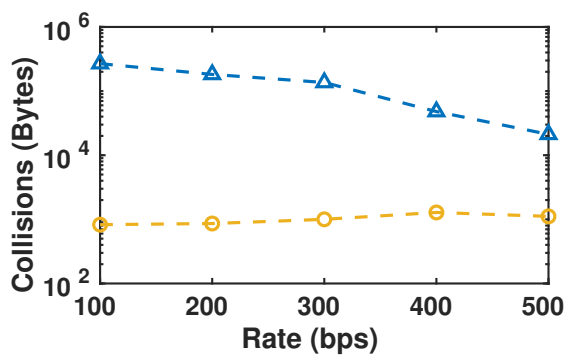

(c)

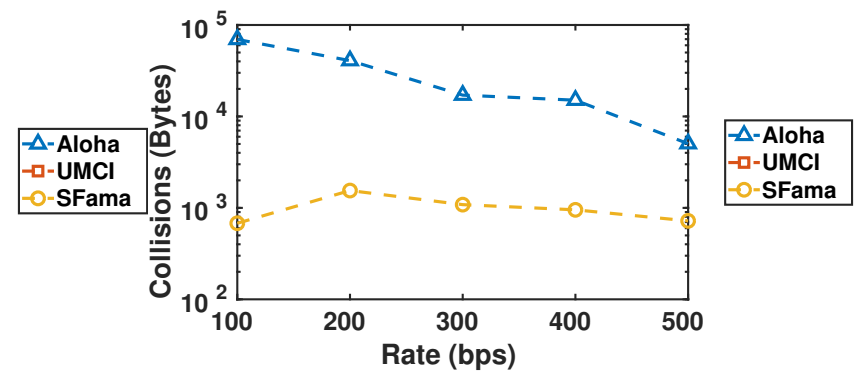

(b)

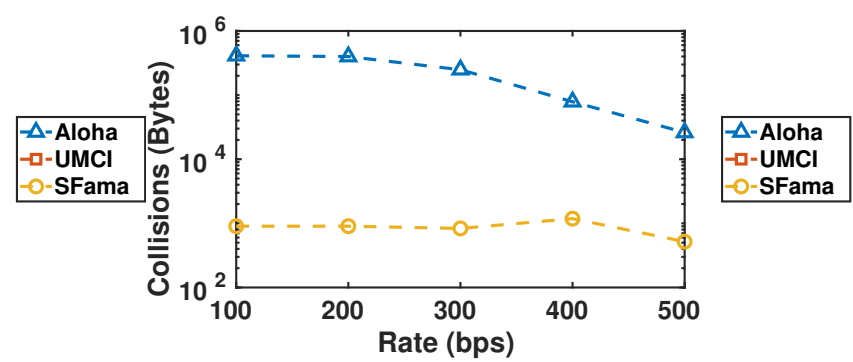

(d)

Figura 4.10: Variation of the amount of bytes collided bytes for several packet sizes. (a) 20 bytes. (b) 100 bytes. (c) 400 bytes. (d) 600 bytes. 


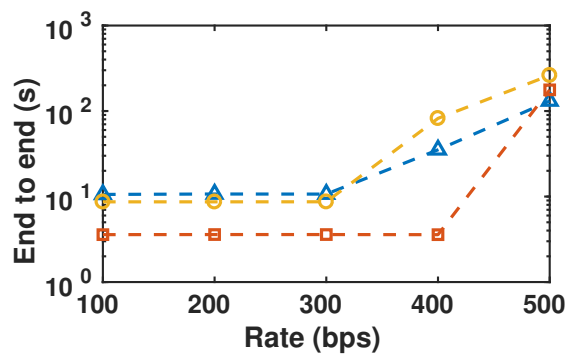

(a)

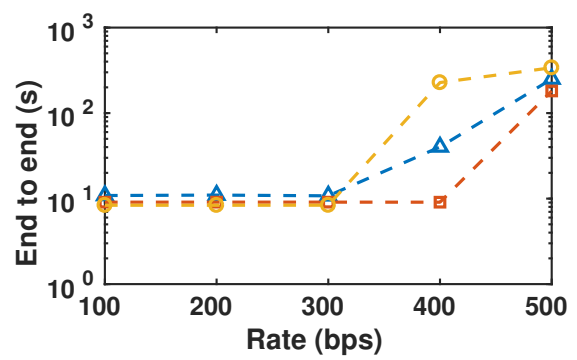

(c)

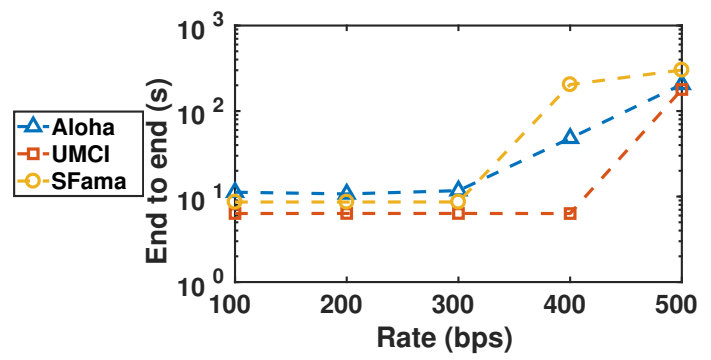

(b)

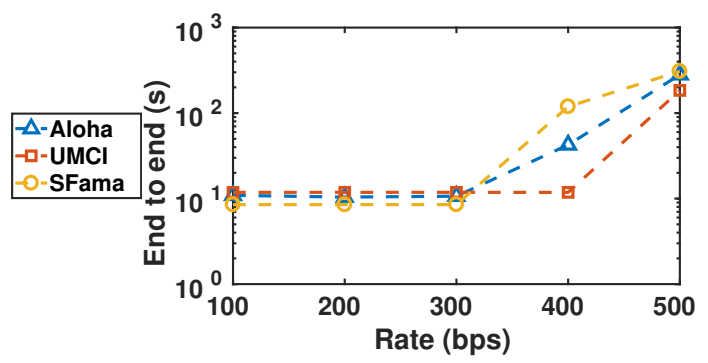

(d)
$-\triangle$-Aloha

$-\square-\mathrm{UMCl}$

-SFama

Figura 4.11: Variation of the end to end delay with the priority assigned to each AUV. All the measurements correspond to a $20 \mathrm{~m}$ square topology when sending 600 bytes long packets. (a) AUV 1. (b) AUV 2. (c) AUV 3. (d) AUV 4.

the master prevents that two nodes start to transmit at the same time in the UMCI-MAC protocol. Another effect shown in Figure 4.10 is the fact that the amount of collided bytes in the Aloha-CS protocol decrease with the data rate. When the channel occupancy is high it is less likely that two nodes detect the channel free and start to transmit at the same time.

\section{Square topology}

In the second topology considered in this work, the four transmitter AUVs were placed forming a square, all of them at the same depth. The master was placed in the center of the square, at a depth of eight meters above the rest of the AUVs. All the nodes hold their positions during the whole experiment. In order to evaluate the impact of the distance between the AUVs in the performance of the communication link, two different squares of $20 \mathrm{~m}$ and $60 \mathrm{~m}$ were considered in this work. In the remaining pages of the manuscript they are identified as $(20 \times 20)$ and $(60 \times 60)$, respectively.

The results obtained with the square topology, either with the $20 \times 20$ 


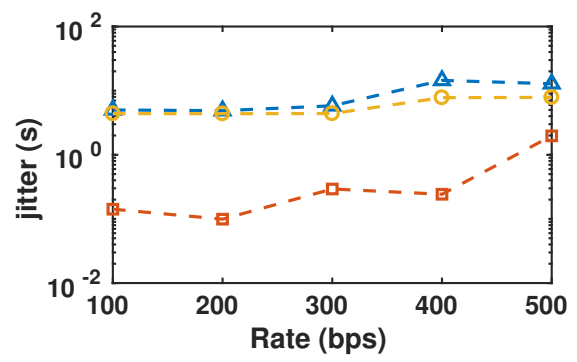

(a)

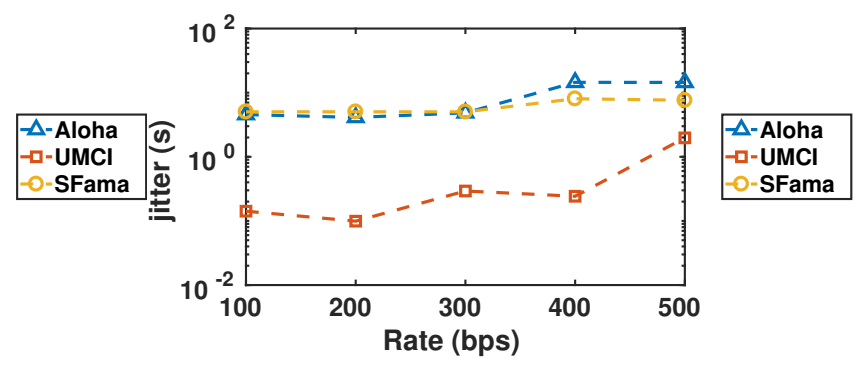

(b)

Figura 4.12: Variation of the jitter with the priority assigned to the AUV. All the measurements correspond to a $20 \mathrm{~m}$ square topology when sending 600 bytes long packets. (a) AUV 1. (b) AUV 4.

or with the $60 \times 60$ squares, were similar to those obtained previously with the linear topology. One of the consequences of assigning a transmission turn to each AUV in UMCI-MAC is that the end to end delay of the transmissions from the AUV which receives the first token is smaller than those measured with the rest of AUVs, as it is shown in Figure 4.11. This is explained by the fact that the master sends a CTS packet to each AUV in priority order, assigning the AUV 1 the highest priority and AUV 4 having the lowest one. In UMCI-MAC an AUV has to wait until all the AUVs with higher priority finish their transmission. This effect is more noticeable the larger the data packets are, as is the case of the transmission of 600 bytes long packets shown in Figure 4.11. When considering UMCIMAC the end to end delay measurement of the AUV 4 is the highest of all AUVs. However, its value is comparable to that obtained with Aloha-CS and S-FAMA which achieve similar end to end delay values in all AUVs. In this way, the UMCI-MAC permits to selectively improve the end to end delay of one of the AUVs by assigning it the first turn in each transmission round. The results shown in Figure 4.11 correspond to a square topology in which the AUVs formed a $20 \times 20 \mathrm{~m}$ square. Similar results were also appreciated with the $60 \times 60$ square and the linear topologies, however we have chosen these results because all the AUVs were at the same distance from the master .

Despite the variation in the end to end delay measurements of each AUV shown in Figure 4.11, the jitter measurements were not affected by the different priorities assigned to each AUV, as it is shown in Figure 4.12. 


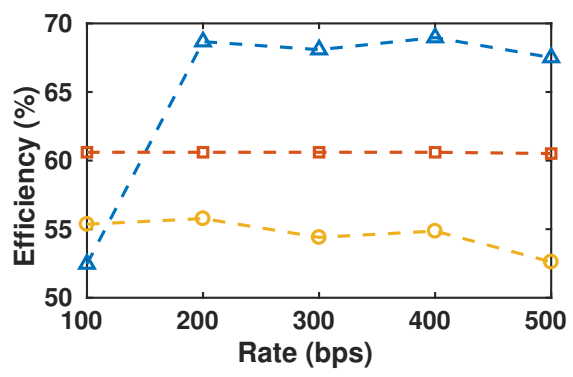

(a)

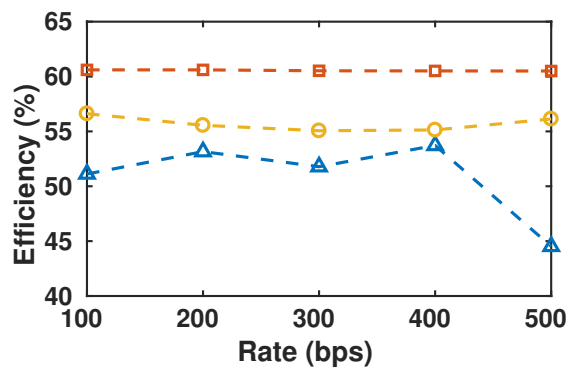

(c)

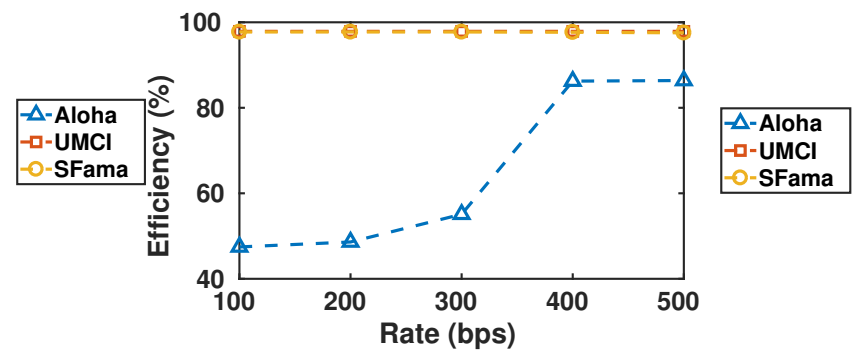

(b)

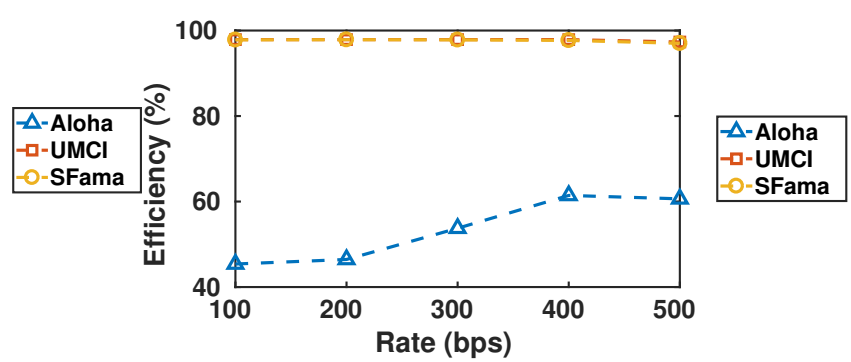

(d)

Figura 4.13: Variation of the protocol efficiency with the distance between the AUVs, when sending packets of 20 and 600 bytes in a 20x20 m and 60x60 m square topologies. (a) 20 bytes data packets in a $20 \times 20 \mathrm{~m}$ square topology. (b) 600 bytes data packets in a 20x20 m square topology. (c) 20 bytes data packets in a 60x60 m square topology. (d) 600 bytes data packets in a $60 x 60 \mathrm{~m}$ square topology.

The results shown in Figure 4.12 are comparable to those in Figure 4.7(d) corresponding to the linear topology. In both cases it is noticed how UMCIMAC achieved the lowest jitter of all the three protocols considered in this study. This proves the predictability of UMCI-MAC in the delivery of the messages.

The fact that all the AUVs are at the same distance in the square topology permits to analyze its impact on the performance of the communication links. The comparison of the results between the case in which the AUVs form a $20 \times 20 m$ square, and the $60 \times 60 m$ case has shown the decrease in the efficiency achieved with the Aloha-CS as the AUVs are more and more separated, see Figure 4.13. The efficiency achieved by Aloha-CS when sending 20 bytes and 600 bytes data packets in the $(20 \times 20)$ square, shown in Figure 4.13(a) and 4.13(b) respectively, decreases when the $(60 \times 60)$ square is considered, shown in Figure 4.13(c) and 4.13(d). On the contrary, the efficiencies measured with the S-FAMA and the UMCI-MAC are not affected by the separation among the AUVs, and exhibit similar 
Cuadro 4.1: Configuration of data flows from all the devices during the HIL expriment. Rate indicates the data rate (in bps) generated by the application. Size indicates the length of the DATA packet (in Bytes). Dest and Information indicate the receiver and the information contained in the data packet, respectively.

\begin{tabular}{l|c|c|c|l} 
& Rate & Size & Dest. & Information \\
\hline Buoy & 100 & 50 & BlueROV & Position commands \\
BlueROV & 100 & 50 & Broadcast & Own position (estimated) \\
AUVs & 300 & 600 & Buoy & Own position and images \\
\hline
\end{tabular}

values to those obtained in the linear topology Figure 4.8. The degradation of the efficiency in the case of the Aloha-CS might be explained by the fact that the more distant the AUVs are, the more time is required to detect that another AUV is transmitting. Thus increasing the number of collisions and re-transmissions. This does not occur with the S-FAMA and the UMCI-MAC because the permission to transmit is arbitrated by the RTS and CTS signals.

\subsubsection{UMCI-MAC Remote Control of a team of AUVs in HIL}

In this section a HIL experiment consisting of the remote control of a team of four AUVs in a water tank is presented. One of the AUVs is a real one based on the BlueROV platform while the remaining three are simulated using the UWSim-NET simulator. The three simulated AUVs try to keep a relative position to the real AUV, which acts as the leader, forming a square of 2.5 by 2.5 meters. As in the previous experiment, all the communication devices have a transmission rate of 1800 bps and a maximum range of $100 \mathrm{~m}$.

Movement commands are transmitted from a simulated buoy on the surface located on the vertical axis of the initial position of the formation of AUVs, which are $54.5 \mathrm{~m}$ deep. The commands sent from the buoy are the target position and orientation which the leader is expected to reach. The real BlueROV, acting as leader of the formation, broadcasts its position while the simulated AUVs transmit their positions and visual information of the seafloor. The data flows sent by each device during the experiment 
are detailed in Tab. 4.1 in terms of application data rate, packet size, destination and the information contained in DATA packets.

The position of the BlueROV is estimated by vision and using some ArUco markers[30] which have been placed on one of the walls of the water tank as shown in Fig. 4.14(a). Due to the space constraints of the water tank, movement commands sent to the leader do not have a distance greater than two meters. As can be seen in Fig. 4.14(b), the floor of the water tank and the markers have been replicated in UWSim-NET in order to create a virtual reality environment for the experiment. Also, the actual positions of the four vehicles are represented by opaque 3D models of BlueROV. In the case of the simulated vehicles their 3D model is white, while the model used for the leader has realistic colours. In addition, the desired position of each vehicle is represented using a transparent version of its 3D model. The desired position of the leader corresponds to the last command sent from the buoy. The desired position of each simulated AUV is where the vehicle should be in order to form a perfect square considering the actual position broadcasted by the leader.

The performance of all three protocols in this experiment is first evaluated in terms of end to end delay. The end to end delay of the communication between the Buoy and the leader is analyzed in Figure 4.15. The delay measured with Aloha-CS and S-FAMA increases during the experiment in both the transmission from the buoy to the BlueROV Figure 4.15(a) and the transmission from the BlueROV to the buoy Figure 4.15(b). The rise of the delay is caused by the filling of the transmission queue. Packet collisions force the re-transmission of packets and avoid the proper emptying of the transmission queue. Contrary to Aloha-CS and S-FAMA, the UMCI-MAC protocol is able to send all the packets within a reasonable and almost constant delay. The end to end delay of the packets sent from the simmulated AUVs to the buoy is shown in Figure 4.16. When transmitting large DATA packets Aloha-CS exhibits larger delays than UMCI-MAC and S-FAMA, this behavior was also noticed in the previous experiment. Comparable end to end delay measurements were achieved with UMCI- 


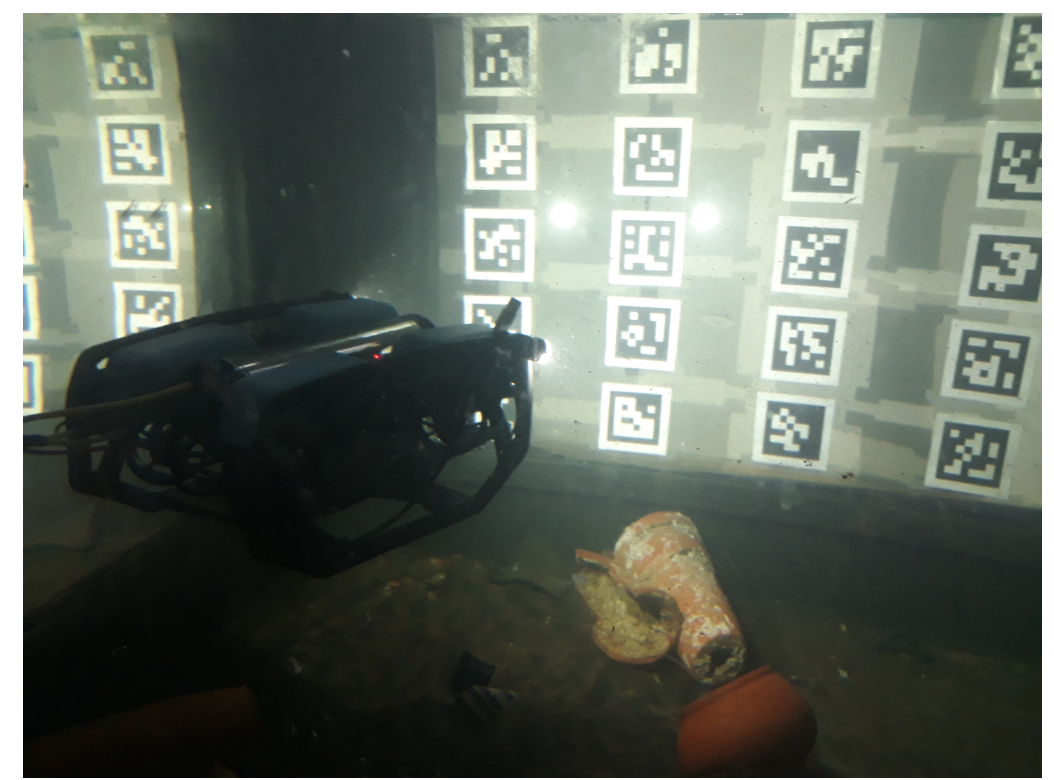

(a)

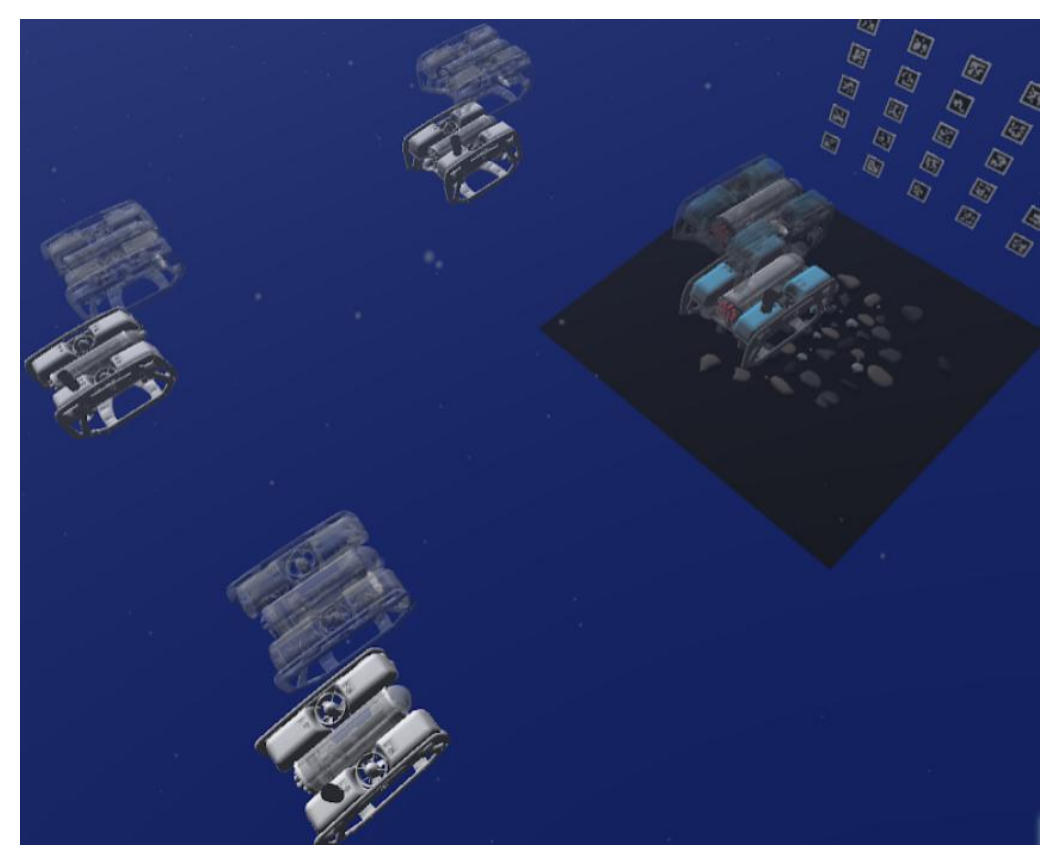

(b)

Figura 4.14: Detail of the HIL experiment: (a) Image of the real BlueROV inside the water tank during the experiment. (b) UWSim-NET virtual reality interface with an image of the whole experiment with the real and simulated AUVs. 


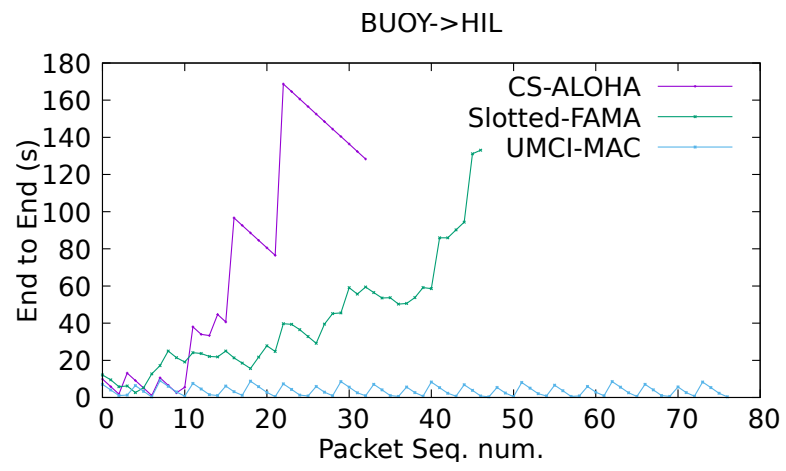

(a)

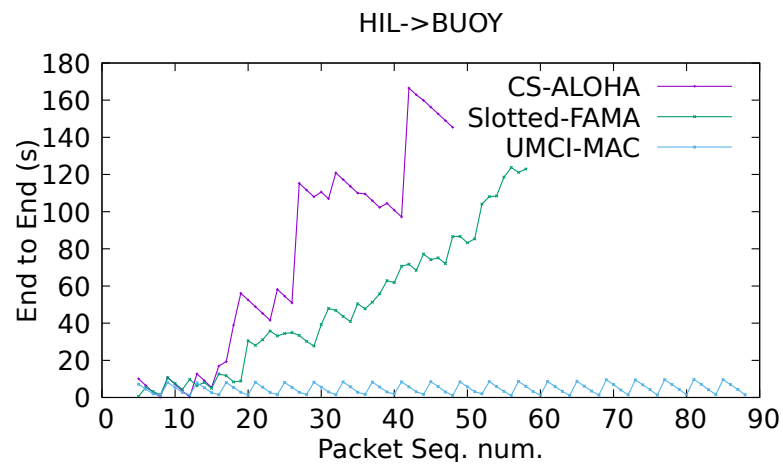

(b)

Figura 4.15: End to end delay (in s) of the transmitted packets. (a) From the buoy to the real BlueROV. (b) From the real BlueROV to the buoy

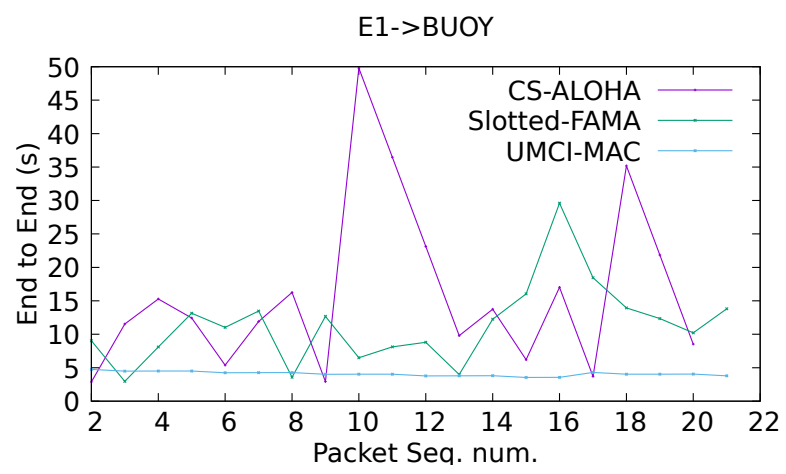

(a)

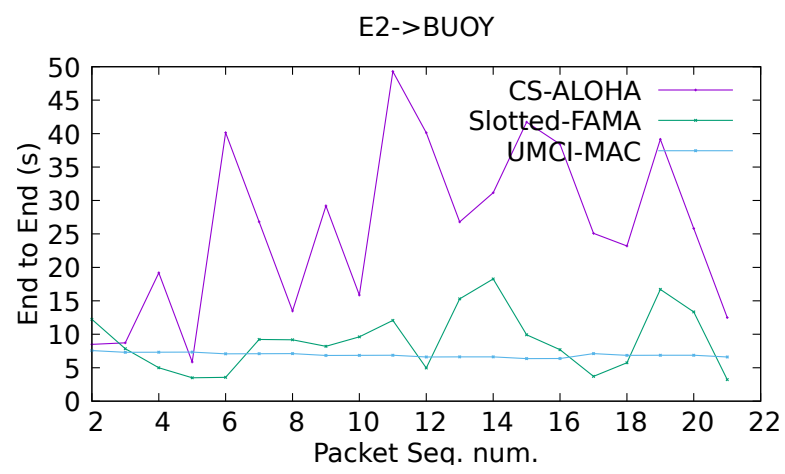

(b)

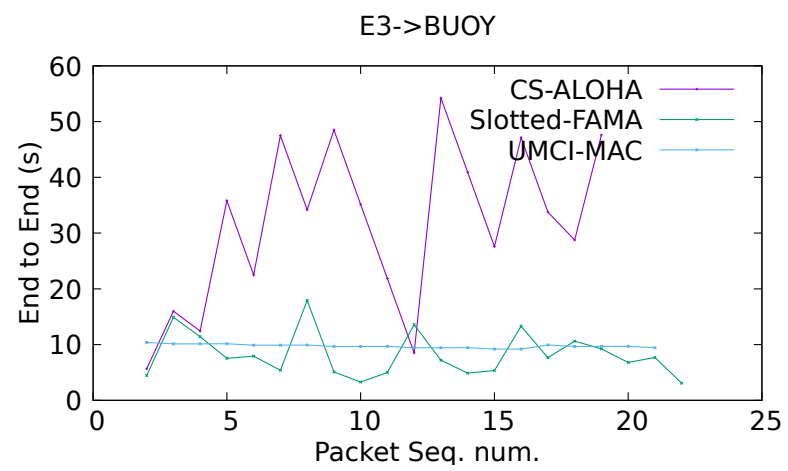

(c)

Figura 4.16: End to end delay (in s) of the transmitted packets from the AUVs to the buoy. (a) AUV 1, (b) AUV 2, (c) AUV 3. 
HIL

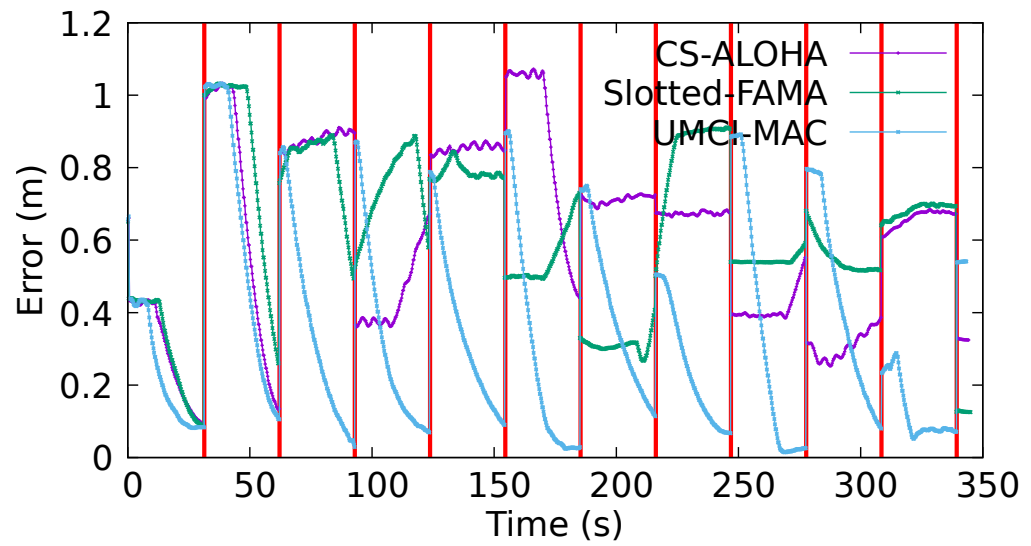

Figura 4.17: Difference between the actual and desired position of the BlueROV.

MAC and S-FAMA. The most remarkable result in this experiment is the increasing delay measured for the three AUVs with the UMCI-MAC protocol. This response is caused by the fact that AUV1 is assigned the highest priority, since it is the first one to receive the CTS from the master in every round. This is the reason why the end to end delays measured for AUV1, AUV2 and AUV3 were 5 s, 7 s and 10 s, respectively.

Finally, the errors between desired and actual positions of the AUVs are compared in order to evaluate the impact of the MAC protocol on the control of the AUVs. The position error of the leader BlueROV is illustrated in Figure 4.17. The times when the position command changes are indicated in vertical red lines. When the BlueROV receives the command it starts to move to the specified position and an exponential decrease of the error is appreciated in all three protocols. However, in the case of the experiment using Aloha-CS and S-FAMA, due to the rise of the delay in command reception the BlueROV will not receive the commands during the corresponding interval. This is the reason why a constant error is observed in Figure 4.17 during the whole time interval in the S-FAMA and Aloha-CS curves, especially from $t=100 \mathrm{~s}$ onwards. The lower end to end delay achieved with the UMCI-MAC protocol allows the delivery of all command messages before the position command is changed. Thus, the error decreases in all periods when the UMCI-MAC is considered.

The error between the actual and desired positions of the AUVs is 
Explorer1

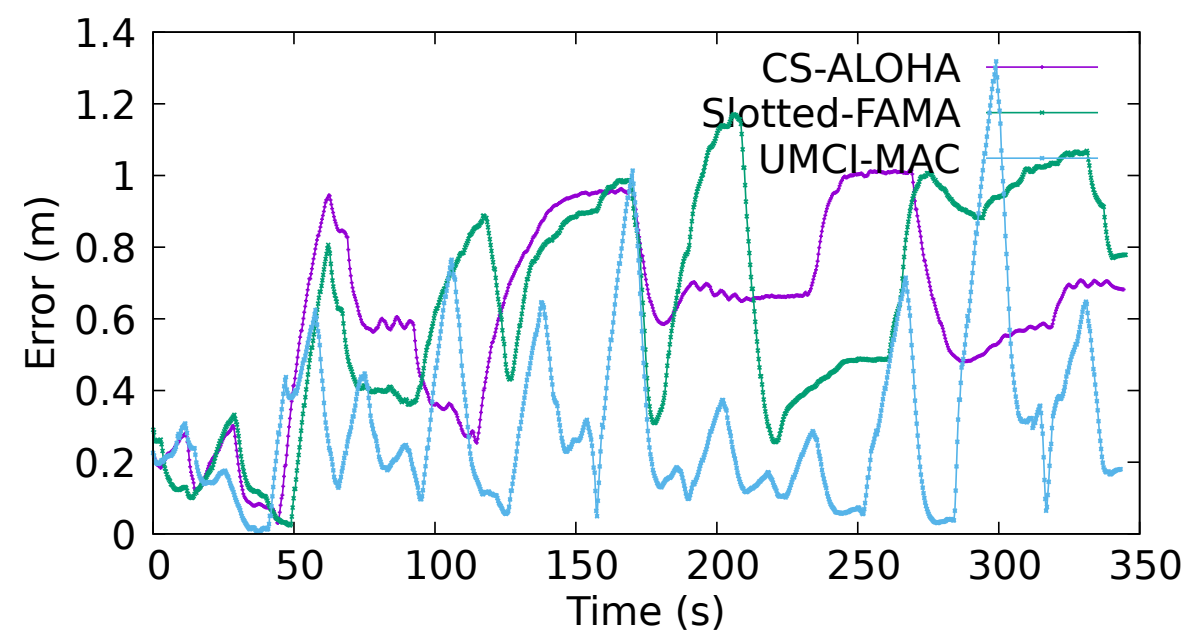

(a)

Explorer2

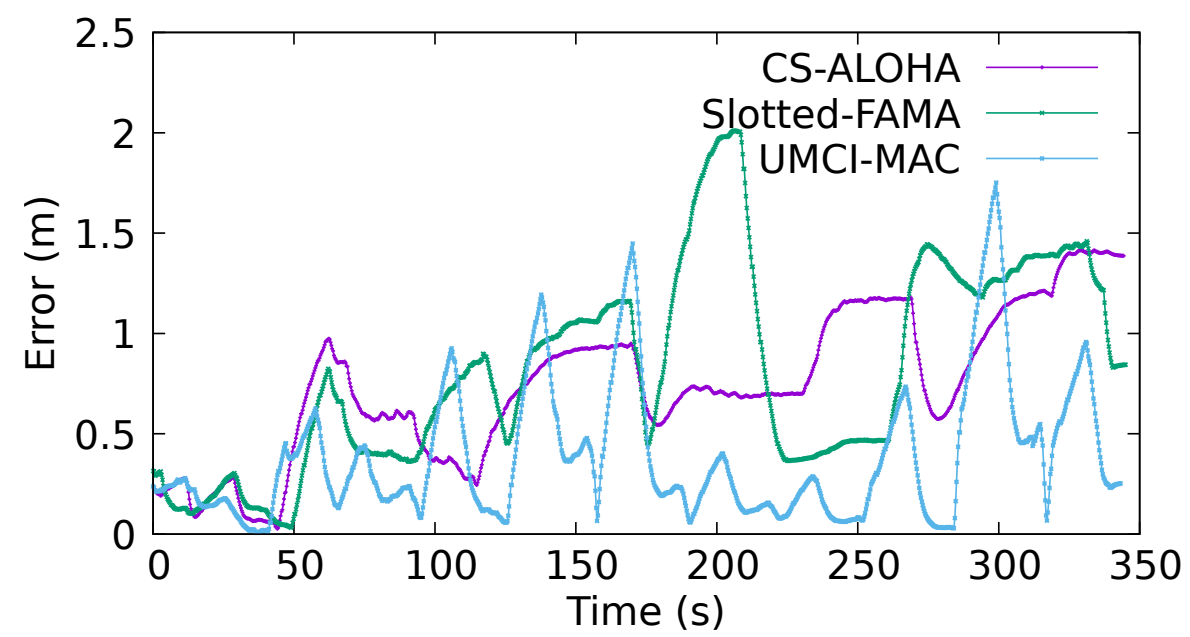

(b)

Explorer3

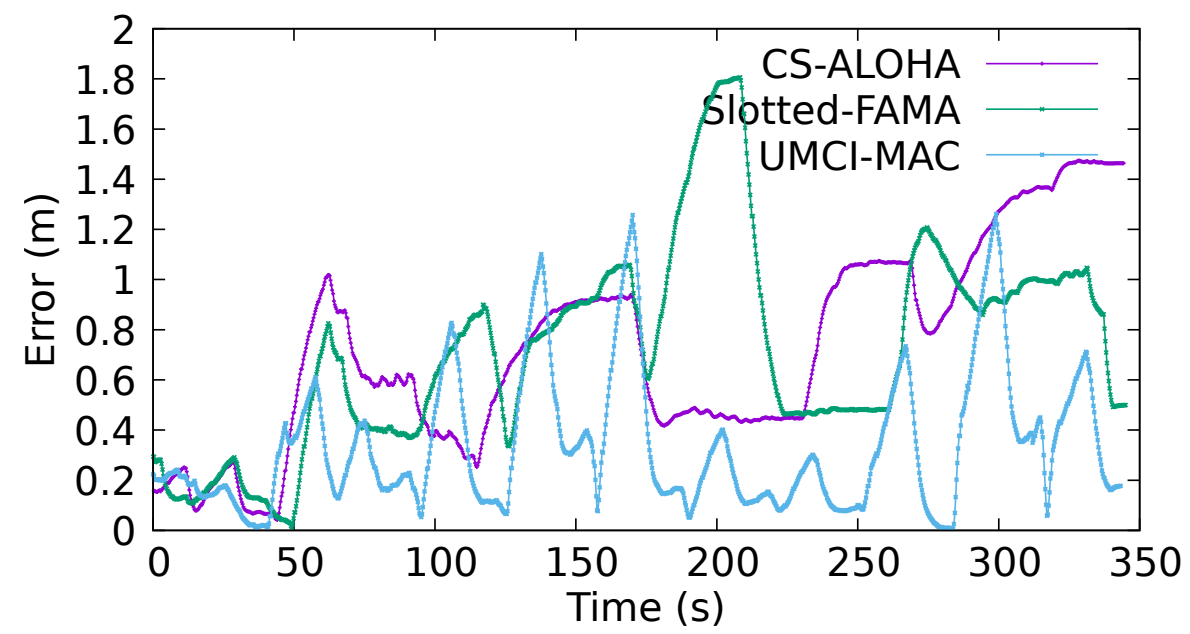

(c)

Figura 4.18: Differences between the actual and desired positions of the AUVs. (a) AUV 1, (b) AUV 2, (c) AUV 3. 
shown in Figure 4.18. In all three figures it can be seen how the UMCIMAC is able to broadcast the position of the leader in time and the AUVs update their positions according to the leader's, thus reducing the position error. However, the long delay of Aloha-CS and S-FAMA makes that the AUVs receive the message with the position of the leader after the actual position of the leader has changed. So they try to move to the previous position of the leader, this is the reason for the increase of the position error of the AUVs during the experiment.

\subsection{Conclusions}

The UMCI-MAC protocol specific for wireless communications in cooperative robotics is presented in this work. The purpose of the UMCI-MAC is to make it possible to control of a team of up to 8 AUVs during a cooperative intervention. It was designed in order to minimize delay and jitter in UWN based on acoustic links. It is based on a TDMA strategy with a master node in charge of the coordination of the access to the medium of all the nodes, thus avoiding packet collisions. The protocol gives the master the capability of prioritize the transmissions of some nodes.

The performance of UMCI-MAC is compared against that of the AlohaCS and S-FAMA. The performance of all three protocols is evaluated in the first experiment in terms of delay, jitter, throughput and collisions, considering several data rates and packet sizes. The results confirm that in all the scenarios considered in the first experiment the UMCI-MAC protocol achieved the lowest end to end delay and jitter values of all three protocols. The results presented in this manuscript also show how the UMCI-MAC permits to control which AUV will have the lowest end to end delay by assigning it the highest priority. The low delay and jitter measured with UMCI-MAC suggest that it might be considered for the control of a team of AUVs in underwater cooperative interventions. The arbitration of the access to the medium in UMCI-MAC makes it possible to avoid the packet collisions, and yields an efficiency superior to that measured with S-FAMA and Aloha-CS. The comparison of several topologies has 
shown that the S-FAMA and UMCI-MAC protocols were little affected by the relative positioning of the AUVs, since they exhibited a similar performance in all the topologies considered in this study. On the other hand, it has been observed how the efficiency of the Aloha-CS decreased as the distance among AUVs increased. The second experiment presented in this work consisted of a teleoperation of a team of 4 AUVs. This second experiment has demonstrated that the excellent performance of UMCIMAC in terms of end to end delay and jitter makes it suitable for use in robotic applications. Of the three protocols compared in this work UMCIMAC was the only one that was able to deliver the position commands in time so that the simulated AUVs were able to follow the movements of the leader. 



\section{Capítulo 5}

\section{Discusión y conclusiones}

En este capítulo se resume, en primer lugar, las conclusiones más importantes de esta tesis (sección 5.1). Seguidamente, en la sección 5.2 se exponen algunas propuestas de trabajos futuros. Por último, en la sección (5.3) se listan las publicaciones realizadas en el contexto de esta tesis doctoral agrupadas según el tipo de contribución, es decir, según si se trata de una publicación en revista, congreso internacional o nacional.

\subsection{Conclusiones}

Este trabajo ha supuesto un pequeño paso hacia una arquitectura de protocolos estándar para robótica cooperativa submarina.

En primer lugar se ha desarrollado una herramienta, hasta ahora inexistente, para la simulación y desarrollo de protocolos de red para robots submarinos en tiempo real. A continuación se enumeran las contribuciones que ha supuesto este simulador:

- Se trata del primer simulador de redes integrado en el sistema ROS. En consecuencia, resulta sencillo la experimentación HIL con robots reales integrados en ROS. A través de los sensores del robot es posible replicar la posición del mismo en un escenario virtual en UWSim-NET. De esta manera, la calidad de los enlaces de comunicación puede verse afectada en tiempo real por los movimientos del robot.

- UWSim-NET es la primera herramienta que permite representar con 
alto nivel de detalle el entorno subacuático de una red de nodos inalámbricos y en tiempo real. En este sentido, supone una mejora respecto a módulos de NS3 para simulación de redes submarinas, como AquaSim NG o UAN.

- A diferencia de otros simuladores que solo permiten el modelado de enlaces acústicos mediante parámetros físicos como la salinidad del agua, temperatura, etc. UWSim-NET utiliza un modelo estadístico de alto nivel de un dispositivo de comunicación permitiendo, de esta forma, la simulación de cualquier tecnología de comunicación inalámbrica submarina. En este trabajo se ha demostrado cómo UWSim-NET ha podido modelar, con bastante acierto, tanto un módem acústico Evologics S2CR como un módem de RF Seatooth S100.

- El simulador utiliza una API para el intercambio de unidades de protocolo (PDU) por IPC (Inter Process Communication) que habilita a otros procesos del sistema el envío y la recepción de paquetes a través de módems modelados en un escenario de UWSim-NET. De esta manera se crea una capa de abstracción del dispositivo de comunicación, permitiendo aprovechar el mismo código del programa de usuario o programa que genera y recibe tráfico de red, tanto para un dispositivo simulado como para uno real. De esta manera, también resulta posible la simulación de una red donde parte de los dispositivos son simulados y otra parte son reales. Esto solo tiene sentido cuando los dispositivos simulados y los reales no comparten canal de comunicación o pertenecen a tecnologías diferentes (RF, VLC, Acústico).

En segundo lugar, se ha desarrollado un sistema de supervisión de vehículos submarinos que permite a un operador controlar un equipo de robots sobre canales que no superan los 1.9 kbps:

- Este sistema permite al supervisor asegurar un ratio de recepción de imágenes constante independientemente del ancho de banda disponible gracias al uso del algoritmo de compresión progresivo DEBT integrado en el protocolo. 
- DEBT ha hecho posible que, cuando la calidad del objeto de interés en la imagen resulta insuficiente, el supervisor pueda especificar, a través del HRI, una región de interés sobre el objeto para mejorar su detalle. Esta acción mantiene constante el tamaño codificado de la imagen, a costa de provocar una pérdida de detalles en las zonas que están fuera de la región de interés.

- Debido al poco ancho de banda, la calidad de la imagen recibida o la frecuencia de recepción no son suficientes como para permitir a un supervisor controlar el robot mediante comandos de bajo nivel. Por este motivo, el sistema desarrollado utiliza el propio UWSim-NET como interfaz de realidad virtual, donde se visualiza una representación del AUV en tiempo real. Por otro lado, el supervisor puede utilizar comandos de alto nivel para el posicionamiento, delegando en el robot la navegación hacia la posición objetivo.

- Para los casos en los que hay una pérdida de la comunicación, un módulo en el AUV hace que éste recupere posiciones anteriores hasta recuperar el enlace con el supervisor.

- Los experimentos realizados, tanto con módems acústicos como de RF, sobre un prototipo de AUV, fruto de una adaptación del modelo de ROV BlueROV, han demostrado la viabilidad del sistema y motivado futuras mejoras.

- Se han obtenido los mismos resultados repitiendo experimentos utilizando un modelo de los módems en UWSim-NET, obtenido previamente de forma empírica. Esto ha demostrado, la utilidad de esta herramienta para el desarrollo de este tipo de sistemas cuando no se dispone de las condiciones necesarias para poder utilizar dispositivos de comunicación reales.

El algoritmo de acceso al medio utilizado en los experimentos con UMCI-RCP resulta poco eficiente cuando existe más de un robot en el escenario. Por este motivo ha sido desarrollado el protocolo UMCI-MAC. A continuación se enumeran los aspectos y conclusiones más relevantes 
relacionadas con este nuevo protocolo:

- UMCI-MAC utiliza una estrategia TDMA y el arbitraje de un nodo maestro para evitar completamente las colisiones y reducir al máximo la variación del retardo o jitter.

- La implementación realizada posibilita la comunicación de un equipo de hasta 8 AUVs sobre enlaces con muy poco ancho de banda.

- Se ha evaluado UMCI-MAC contra dos protocolos ampliamente conocidos para redes acústicas submarinas: Slotted-FAMA y ALOHA-CS, realizando múltiples experimentos en simulación. Estos experimentos se han ejecutado sobre diferentes topologías de red y con varias combinaciones de valores de tamaño de paquete de datos y velocidades de inyección de estos paquetes desde la capa superior. Los resultados han demostrado cómo UMCI-MAC consigue los valores más bajos de retardo y jitter con la máxima eficiencia. Además, solo ALOHA-CS supera por poco el throughput máximo de la red conseguido mediante UMCI-MAC.

- Se ha realizado un experimento HIL de telecontrol de un equipo de cuatro AUVs cooperativos, donde tres de ellos, simulados, intentan mantener una posición relativa al líder de la formación, el cual ha sido un AUV real basado en el modelo de ROV BlueROV2. Este experimento se ha repetido tres veces, cada una utilizando un protocolo MAC diferente: UMCI-MAC, Slotted-FAMA y ALOHA-CS. Al igual que en los experimentos en simulación, UMCI-MAC ha demostrado obtener el mejor rendimiento en términos de retardo y jitter. Además, ha sido el único capaz de realizar la entrega de todos los paquetes del líder a tiempo, haciendo posible que los demás AUVs mantuviesen la formación durante todo el experimento.

- Por lo tanto, podemos concluir que UMCI-MAC es el protocolo, de entre los analizados, más apropiado para la ejecución de tareas de robótica cooperativa submarina. 


\subsection{Trabajo futuro}

A continuación se proponen una serie de líneas de trabajo que mejorarían los métodos y algoritmos presentados en esta tesis:

- Experimentar los sistemas desarrollados sobre el reciente estándar para comunicaciones inalámbricas submarinas JANUS [51]. Este estándar especifica funciones de un protocolo de capa física y de acceso al medio para redes acústicas. Se trata de un protocolo eficaz, a la vez que genérico, y que resulta ampliamente compatible con multitud de dispositivos.

- El módulo de comunicaciones de UWSim-NET utiliza funcionalidades de la biblioteca NS3, la más potente y extendida para la simulación de redes. Esto facilitará la inclusión, en un futuro, de nuevos tipos de dispositivos de red, como módulos Wi-Fi, Ethernet o GSM que podrían ser interesantes para la simulación de redes marinas heterogéneas en un escenario realista en UWSim-NET. Estas redes podrían estar compuestas por AUVs, sensores y boyas de superficie con transmisores de RF para la comunicación con tierra mediante Wi-Fi, GSM o vía satélite.

- Estudiar la posibilidad de integración de algunos módulos del simulador para UWN DESERT [40], basado en NS2 (anterior versión del ya mencionado NS3), en UWSim-NET. DESERT consiste en un conjunto de bibliotecas escritas en $\mathrm{C} / \mathrm{C}+$ con implementaciones de protocolos específicos para UWN. De esta manera UWSim-NET posibilitaría la simulación de otros protocolos MAC, como T-Lohi [70] y DACAP [47]. La implementación de estos protocolos ha sido probada con éxito en escenarios reales gracias a unos módulos para la ejecución de experimentos Software In The Loop (SITL) con algunos módems acústicos, como pueden ser los WHOI micro-modems y los S2C de EvoLogics.

- Integración de UWSim-NET en el nuevo framework para diseño, desarrollo y simulación de redes submarinas UnetStack $[21]^{1}$. Una de las

\footnotetext{
${ }^{1}$ https://unetstack.net/
} 
diferencias más importantes entre UnetStack y los demás frameworks para el desarrollo de UWN es que no está basado en ninguna de las versiones de NS. En su lugar, utiliza el framework fjåge ${ }^{2}$ para la comunicación entre los agentes dentro de un mismo nodo. fjåge se basa en un mecanismo publish-subscribe, parecido al utilizado por ROS, que facilita el desarrollo de protocolos cross-layer. Esto posibilitaría, por ejemplo, que un protocolo de cualquier nivel en la pila adaptase la potencia del transmisor, el canal de comunicación o la modulación. No obstante, puesto que UWSim-NET ya integra, a través de ROS, un mecanismo publish-subscribe, los motivos por los cuales la integración de UWSim-NET en UnetStack resultaría interesante son otros.

Más que un conjunto de protocolos en capas, UnetStack ofrece, por un lado, un conjunto de módulos o agentes que implementan funcionalidades básicas de capa de transporte, enrutamiento, de enlace de datos y física, además de otros tipos de funciones. Por otro lado, habilita mecanismos, a través de APIs en distintos lenguajes y otros servicios, con los que se puede interactuar con cada uno de estos agentes desde otra aplicación. Además, el framework permite el desarrollo de nuevos agentes ofreciendo los mismos servicios para interactuar con ellos, tanto en simulación como con dispositivos que soporten UnetStack. De esta manera, por ejemplo, el mecanismo que tiene un agente o una aplicación externa para averiguar si el módem está en estado IDLE u ocupado recibiendo/transmitiendo una trama sería el mismo, tanto si se trata de un dispositivo en el simulador de UnetStack, como si se trata de un módem S2C de EvoLogic. Por último, otro aspecto a destacar es el soporte del estándar JANUS en el servicio de capa física y el simulador en tiempo real de redes acústicas integrado.

El framework habilita una API, a través de un puerto TCP, para la comunicación con los agentes de los nodos en un escenario del simulador UnetStack, además de la actualización de propiedades de los nodos como su geolocalización y orientación. La integración de UWSim-NET en UnetStack consistiría en enlazar los dispositivos de comunicación

\footnotetext{
${ }^{2}$ https://github.com/org-arl/fjage
} 
de los AUVs de una escena de UWSim-NET con el nodo correspondiente en el simulador de UnetStack a través de esta API. De esta manera se conseguirían las siguientes mejoras:

* UWSim-NET habilitaría la posibilidad de utilizar un canal de transmisión acústico modelado mediante parámetros físicos, como puede ser la potencia de transmisión o la frecuencia de la portadora. Esto se realizaría incluyendo nuevos atributos en la sección del xml de la escena UWSim-NET asociada al vehículo. Uno de estos atributos sería el puerto TCP de la API para la comunicación con el nodo en UnetStack.

* UnetStack incluiría, a través de UWSim-NET, una representación realista en 3D del escenario en tiempo real. Esto motivaría una posible mejora de la API del simulador de UnetStat para implementar un modelo de efecto multi-path teniendo en cuenta la disposición y la forma de los objetos en el escenario.

* Automáticamente, la posición de los nodos del simulador en UnetStack podría actualizarse mediante cualquier otra aplicación integrada en ROS.

* Cualquier protocolo desarrollado con la API DCComms ${ }^{3}$, como es el caso de UMCI-MAC ${ }^{4}$, podría probarse directamente sobre dispositivos simulados en UnetStack y, en consecuencia, sobre el estándar JANUS.

- Siguiendo la línea de otros trabajos [1] [74], el diseño de una arquitectura de red submarina basada en clusters de nodos funcionando sobre UMCI-MAC permitiría aumentar el área de acción de una intervencion robótica. Para el enrutamiento entre clusters se utilizarían enlaces acústicos de largo alcance, siendo el maestro de cada cluster el encargado de realizar el enrutamiento. Con tal de eliminar las interferencias de los enlaces de largo alcance con los nodos de cada cluster, para las comunicaciones dentro de un mismo cluster se utilizaría una

\footnotetext{
${ }^{3}$ Como se vió en el capítulo dedicado a UWSim-NET, esta API se utiliza para el paso de unidades de protocolo entre dos procesos.

${ }^{4}$ https://github.com/dcentelles/umci-mac
} 
tecnología diferente a la acústica, como VLC o RF. Además, debido al corto alcance de los dispositivos VLC o RF, se reducirían las interferencias entre clusters cercanos. No obstante, se podría conseguir que clusters colindantes estuviesen en un dominio de colisión diferente utilizando un código CDMA distinto o, a ser posible, un canal diferente (método FDMA). UWSim-NET facilitaría la experimentación en simulación de la red, evitando así los costes que implicaría un despliegue de los nodos en un escenario real durante la etapa de diseño.

- Parte de esta tesis se ha desarrollado dentro del contexto del proyecto TWINBOT, el cual ha sido descrito en los capítulos anteriores. Uno de los objetivos pendientes es la integración de un protocolo, posiblemente UMCI-MAC o una mejora del mismo, en los módems EvoLogics WiSE [27] integrados en los AUVs involucrados en TWINBOT.

\subsection{Lista de publicaciones}

\subsubsection{Revistas}

- Diego Centelles, Antonio Soriano-Asensi, José Vicente Martí, Raúl Marín y Pedro J. Sanz. "Underwater Wireless Communications for Cooperative Robotics with UWSim-NET". En: Applied Sciences 9.17 (2019). ISSN: 2076-3417. DOI: 10 . 3390/app9173526. URL: https : //www .mdpi.com/2076-3417/9/17/3526

- Diego Centelles, Antonio Soriano, Raul Marin y Pedro J Sanz. "Wireless HROV Control with Compressed Visual Feedback Using Acoustic and RF Links". En: Journal of Intelligent $\&$ Robotic Systems (2020), págs. 1-16

- Diego Centelles, Antonio Soriano, José V Martí y Pedro J Sanz. "Underwater Multirobot Cooperative Intervention MAC Protocol". En: IEEE Access 8 (2020), págs. 60867-60876

- Eduardo M Rubino, D Centelles, Jorge Sales, José V Martí, Raúl Marín, Alberto J Alvares y Pedro J Sanz. "Sistema de visión subacuáti- 
co inalámbrico usando un algoritmo de compresión progresivo con región de interés". En: Revista Iberoamericana de Automática e Informática industrial 15.1 (2017), págs. 46-57

- Eduardo M Rubino, Diego Centelles, Jorge Sales, José V Martí, Raúl Marín, Pedro J Sanz y Alberto J Álvares. "Underwater radio frequency image sensor using progressive image compression and region of interest". En: Journal of the Brazilian Society of Mechanical Sciences and Engineering 39.10 (2017), págs. 4115-4134

- Eduardo M Rubino, Diego Centelles, Jorge Sales, Jose Vte Marti, Raul Marin y Pedro J Sanz. "Wireless Image Compression and Transmission for Underwater Robotic Applications". En: IFAC-PapersOnLine 48.2 (2015), págs. 288-293

\subsubsection{Congresos Internacionales}

- Diego Centelles, Antonio Soriano, J Vicente Martí, Raúl Marin y Pedro J Sanz. "UWSim-NET: An open-source framework for experimentation in communications for underwater robotics". En: OCEANS 2019-Marseille. IEEE. 2019, págs. 1-8

- Diego Centelles, Eduardo Moscoso, Guillem Vallicrosa, Narcis Palomeras, Jorge Sales, J. Vicente Marti, Raul Marin, Pere Ridao y Pedro J. Sanz. "Wireless HROV control with compressed visual feedback over an acoustic link". En: OCEANS 2017 - Aberdeen. IEEE, 201706, págs. 1-7. ISBN: 978-1-5090-5278-3. DOI: 10.1109/OCEANSE. 2017. 8084979. URL: http://ieeexplore.ieee.org/document/8084979/

- D. Centelles, E. Rubino, M. Soler, J. V. Martí, J. Sales, R. Marin y P. J. Sanz. "Underwater radio frequency based localization and image transmission system, including specific compression techniques, for autonomous manipulation". En: OCEANS 2015 - Genova. 2015, págs. $1-5$

- Eduardo M Rubino, Diego Centelles, Jorge Sales, Jose V Marti, Raul Marin, Pedro J Sanz y Alberto J Alvares. "Progressive image compres- 
sion and transmission with region of interest in underwater robotics". En: OCEANS 2017-Aberdeen. IEEE. 2017, págs. 1-9

- D. Centelles Beltran, A. Soriano Asensi, R. Marín Prades, J.V. Martí Avilés y P.J. Sanz Valero. "UWSIM-NET: AN OPEN-SOURCE EDUCATIONAL TOOL FOR LEARNING ROBOTICS AND COMMUNICATIONS". En: INTED2019 Proceedings. 13th International Technology, Education and Development Conference. Valencia, Spain: IATED, 2019, págs. 9609-9615. ISBN: 978-84-09-08619-1. DOI: 10.21125/ inted . 2019 . 2390. URL: http: //dx . doi .org/10 . 21125/inted . 2019.2390

\subsubsection{Congresos Nacionales}

- Diego Centelles, Antonio Soriano, Raúl Marín y Pedro J Sanz. "Arquitectura para teleoperación inalámbrica con realimentación visual de ROVs basados en ArduSub". En: XXXIX Jornadas de Automática, Badajoz. Comité Español de Automática (CEA). 2018

- Diego Centelles, Rafael Mayo, Eduardo Moscoso, Raúl Marın y Pedro J Sanz. "Evaluación de la arquitectura ARMv7-A para el desarrollo de HROV's eficientes". En: XXXVII Jornadas Nacionales de Automática, Madrid. Comité Español de Automática (CEA). 2016

- Diego Centelles, J. Sales, Raúl Marín, Jose Vicente Martí, David Fornas y Pedro J. Sanz. "Desarrollo de un sensor subacuático ultrasónico y RF para posicionamiento en tareas de manipulación robótica". En: XX Jornadas de Automática 2014. Comité Español de Automática (CEA). 2014 


\section{Bibliografía}

[1] Guray Acar y A.E. Adams. "ACMENet: An underwater acoustic sensor network protocol for real-time environmental monitoring in coastal areas". En: Radar, Sonar and Navigation, IEE Proceedings - 153 (2006-09), págs. 365-380. DOI: 10.1049/ip-rsn: 20045060.

[2] Ian F Akyildiz, Dario Pompili y Tommaso Melodia. "Underwater acoustic sensor networks: research challenges". En: Ad hoc networks 3.3 (2005), págs. 257-279.

[3] Muhammad Ayaz, Imran Baig, Azween Abdullah e Ibrahima Faye. "Review: A Survey on Routing Techniques in Underwater Wireless Sensor Networks". En: J. Netw. Comput. Appl. 34.6 (2011), págs. 1908-1927. ISSN: 1084-8045. DOI: 10.1016/j.jnca. 2011.06 . 009. URL: http://dx.doi.org/10.1016/j.jnca.2011.06.009.

[4] G. Ayela y J. M. Coudeville. "TIVA: A long range, high baud rate image/data acoustic transmission system for underwater applications". En: Underwater Defence Technol. Conf. Paris, France. 1991.

[5] James W. Bales y Chrussostomos Chryssostomidis. "High-bandwidth, low-power, short-range optical communication underwater". En: 9th International Symposium on Unmanned, Untethered Submersible Technology, Durham, New Hampshire. 1995.

[6] A. Caiti, K. Grythe, J. M. Hovem, S. M. Jesus, A. Lie, A. Munafò, T. A. Reinen, A. Silva y F. Zabel. "Linking Acoustic Communications and Network Performance: Integration and Experimentation of an Underwater Acoustic Network". En: IEEE Journal of Oceanic Engineering 38.4 (2013), págs. 758-771. ISSN: 0364-9059. DOI: 10.1109/ JOE. 2013. 2279472.

[7] D. Centelles, E. Rubino, M. Soler, J. V. Martí, J. Sales, R. Marin y P. J. Sanz. "Underwater radio frequency based localization and 
image transmission system, including specific compression techniques, for autonomous manipulation". En: OCEANS 2015 - Genova. 2015, págs. 1-5.

[8] Diego Centelles, Antonio Soriano, Raúl Marín y Pedro J Sanz. "Arquitectura para teleoperación inalámbrica con realimentación visual de ROVs basados en ArduSub". En: XXXIX Jornadas de Automática, Badajoz. Comité Español de Automática (CEA). 2018.

[9] Diego Centelles, J. Sales, Raúl Marín, Jose Vicente Martí, David Fornas y Pedro J. Sanz. "Desarrollo de un sensor subacuático ultrasónico y RF para posicionamiento en tareas de manipulación robótica". En: XX Jornadas de Automática 2014. Comité Español de Automática (CEA). 2014.

[10] Diego Centelles, Rafael Mayo, Eduardo Moscoso, Raúl Marın y Pedro J Sanz. "Evaluación de la arquitectura ARMv7-A para el desarrollo de HROV's eficientes". En: XXXVII Jornadas Nacionales de Automática, Madrid. Comité Español de Automática (CEA). 2016.

[11] Diego Centelles, Antonio Soriano, José V Martí y Pedro J Sanz. "Underwater Multirobot Cooperative Intervention MAC Protocol". En: IEEE Access 8 (2020), págs. 60867-60876.

[12] Diego Centelles, Antonio Soriano-Asensi, José Vicente Martí, Raúl Marín y Pedro J. Sanz. "Underwater Wireless Communications for Cooperative Robotics with UWSim-NET". En: Applied Sciences 9.17 (2019). ISSN: 2076-3417. DOI: 10 . $3390 /$ app9173526. URL: https : //www.mdpi. com/2076-3417/9/17/3526.

[13] Diego Centelles, Antonio Soriano, Jose V. Martí, Raúl Marın y Pedro J Sanz. "UWSim-NET: An open-source framework for experimentation in communications for underwater robotics". En: OCEANS 2019 - Marseille. 2019.

[14] Diego Centelles, Antonio Soriano, J Vicente Martí, Raúl Marin y Pedro J Sanz. "UWSim-NET: An open-source framework for experimentation in communications for underwater robotics". En: OCEANS 2019-Marseille. IEEE. 2019, págs. 1-8.

[15] Diego Centelles, Eduardo Moscoso, Guillem Vallicrosa, Narcis Palomeras, Jorge Sales, J. Vicente Marti, Raul Marin, Pere Ridao y Pedro J. Sanz. "Wireless HROV control with compressed visual feedback 
over an acoustic link". En: OCEANS 2017 - Aberdeen. IEEE, 201706, págs. 1-7. ISBN: 978-1-5090-5278-3. DOI: 10.1109/OCEANSE. 2017. 8084979. URL: http://ieeexplore.ieee.org/document/8084979/.

[16] Diego Centelles, Antonio Soriano, Raul Marin y Pedro J Sanz. "Wireless HROV Control with Compressed Visual Feedback Using Acoustic and RF Links". En: Journal of Intelligent \& Robotic Systems (2020), págs. 1-16.

[17] D. Centelles Beltran, A. Soriano Asensi, R. Marín Prades, J.V. Martí Avilés y P.J. Sanz Valero. "UWSIM-NET: AN OPEN-SOURCE EDUCATIONAL TOOL FOR LEARNING ROBOTICS AND COMMUNICATIONS". En: INTED2019 Proceedings. 13th International Technology, Education and Development Conference. Valencia, Spain: IATED, 2019, págs. 9609-9615. ISBN: 978-84-09-08619-1. DOI: 10.21125/ inted . 2019 . 2390. URL: http://dx . doi .org/10 .21125/inted . 2019.2390.

[18] X. Che, I. Wells, G. Dickers, P. Kear y X. Gong. "Re-Evaluation of RF Electromagnetic Communication in Underwater Sensor Networks". En: IEEE Communications Magazine 48.12 (2010), págs. 143-151.

[19] K. Chen, M. Ma, E. Cheng, F. Yuan y W. Su. "A Survey on MAC Protocols for Underwater Wireless Sensor Networks". En: IEEE Communications Surveys Tutorials 16.3 (2014), págs. 1433-1447. ISSN: 2373-745X. DOI: 10.1109/SURV.2014.013014.00032.

[20] N. Chirdchoo, W. . Soh y K. C. Chua. "Aloha-Based MAC Protocols with Collision Avoidance for Underwater Acoustic Networks". En: IEEE INFOCOM 2007 - 26th IEEE International Conference on Computer Communications. 2007, págs. 2271-2275. DOI: $10.1109 /$ INFCOM . 2007. 263.

[21] M. Chitre, R. Bhatnagar y W. Soh. "UnetStack: An agent-based software stack and simulator for underwater networks". En: 2014 Oceans - St. John's. 2014, págs. 1-10.

[22] Salvador Climent, Antonio Sanchez, Juan Capella, Nirvana Meratnia y Juan Serrano. "Underwater acoustic wireless sensor networks: advances and future trends in physical, MAC and routing layers". En: Sensors 14.1 (2014), págs. 795-833. 
[23] G. Cossu, R. Corsini, A.M. Khalid, S. Balestrino, A. Coppelli, A. Caiti y E. Ciaramella. "Experimental demonstration of high speed underwater visible light communications". En: Optical Wireless Communications (IWOW), 2013 2nd International Workshop on. 2013, págs. 11-15. DOI: 10.1109/IWOW.2013.6777767.

[24] Anjana P Das y Sabu M Thampi. "Simulation tools for underwater sensor networks: a survey". En: Network Protocols and Algorithms 8.4 (2017), págs. 41-55.

[25] Jack Dea, Dusan Radosevic, Nghia Tran, Jose Chavez y Burton Neuner III. Land and Undersea Field Testing of Very Low Frequency RF Antennas and Loop Transceivers. Inf. téc. SSC Pacific San Diego United States, 2017.

[26] Evologics. Datasheet of S2C $R 7 / 17$ underwater acoustic modem. https : / / evologics . de/acoustic-modem/7-17. Accessed 202002-27.

[27] Evologics. S2C R White Line Science Edition (WiSE). https : / / evologics.de/wise-dev. Accessed 2020-07-6.

[28] Evologics. Specifications of S2CR 18/34 underwater acoustic modem. https://evologics.de/acoustic-modem/18-34. Accessed 2020-0227.

[29] N. Farr, A. Bowen, J. Ware, C. Pontbriand y M. Tivey. "An integrated, underwater optical /acoustic communications system". En: OCEANS 2010 IEEE - Sydney. 2010, págs. 1-6. DOI: 10.1109/OCEANSSYD . 2010.5603510 .

[30] S. Garrido-Jurado, R. Muñoz-Salinas, F.J. Madrid-Cuevas y M.J. Marín-Jiménez. "Automatic generation and detection of highly reliable fiducial markers under occlusion". En: Pattern Recognition 47.6 (2014), págs. 2280 -2292. ISSN: 0031-3203. DOI: https ://doi .org/10. 1016/j . patcog. 2014.01.005. URL: http://www. sciencedirect. com/science/article/pii/S0031320314000235.

[31] S. Garrido-Jurado, R. Muñoz-Salinas, F.J. Madrid-Cuevas y M.J. Marín-Jiménez. "Automatic generation and detection of highly reliable fiducial markers under occlusion". En: Pattern Recognition 47.6 (2014), págs. 2280 -2292. ISSN: 0031-3203. DOI: https : //doi .org/10. 
1016/j . patcog . 2014.01.005. URL: http: //www . sciencedirect . com/science/article/pii/S0031320314000235.

[32] John Heidemann, Milica Stojanovic y Michele Zorzi. "Underwater sensor networks: applications, advances and challenges". En: Philosophical Transactions of the Royal Society of London A: Mathematical, Physical and Engineering Sciences 370.1958 (2012), págs. 158-175. ISSN: 1364-503X. DOI: 10 . $1098 /$ rsta . 2011 . 0214. eprint: http : //rsta. royalsocietypublishing . org/content/370/1958/158. full . pdf. URL: http : / / rsta . royalsocietypublishing . org / content/370/1958/158.

[33] John Heidemann, Milica Stojanovic y Michele Zorzi. "Underwater sensor networks: applications, advances and challenges". En: Philosophical Transactions of the Royal Society of London A: Mathematical, Physical and Engineering Sciences 370.1958 (2012), págs. 158-175. ISSN: 1364-503X. DOI: 10 . $1098 /$ rsta . 2011 . 0214. eprint: http : //rsta.royalsocietypublishing . org/content/370/1958/158. full . pdf. URL: http : / / rsta . royalsocietypublishing . org / content/370/1958/158.

[34] Patricia K. Immich, Ravi S. Bhagavatula y Dr. Ravi Pendse. "Performance analysis of five interprocess communication mechanisms across UNIX operating systems". En: Journal of Systems and Software 68.1 (2003), págs. 27 -43. ISSN: 0164-1212. DOI: https ://doi .org/10. 1016/S0164-1212(02)00134-6. URL: http://www. sciencedirect. com/science/article/pii/S0164121202001346.

[35] IRSLab. TWINBOT Research Project. 2018. uRL: http://www.irs . uji.es/twinbot/.

[36] H. Kaushal y G. Kaddoum. "Underwater Optical Wireless Communication". En: IEEE Access 4 (2016), págs. 1518-1547.

[37] O. Kebkal, M. Komar, K. Kebkal y R. Bannasch. "D-MAC: Media access control architecture for underwater acoustic sensor networks". En: OCEANS 2011 IEEE - Spain. 2011, págs. 1-8. DOI: 10.1109/ Oceans-Spain.2011.6003586.

[38] P. X. Liu, M. Q. H. Meng, P. R. Liu y S. X. Yang. "An end-toend transmission architecture for the remote control of robots over IP networks". En: IEEE/ASME Transactions on Mechatronics 10.5 
(2005), págs. 560-570. ISSN: 1083-4435. DOI: 10 . 1109/TMECH . 2005. 856110.

[39] Robert Martin, Sanguthevar Rajasekaran y Zheng Peng. "Aqua-Sim Next Generation: An NS-3 Based Underwater Sensor Network Simulator". En: Proceedings of the International Conference on Underwater Networks \&S Systems. WUWNET'17. Halifax, NS, Canada: ACM, 2017, 3:1-3:8. ISBN: 978-1-4503-5561-2. DOI: 10.1145/3148675. 3148679. URL: http://doi.acm.org/10.1145/3148675.3148679.

[40] R. Masiero, S. Azad, F. Favaro, M. Petrani, G. Toso, F. Guerra, P. Casari y M. Zorzi. "DESERT Underwater: An NS-Miracle-based framework to design, simulate, emulate and realize test-beds for underwater network protocols". En: 2012 Oceans - Yeosu. 2012, págs. 1-10.

[41] Lorenz Meier, Petri Tanskanen, Lionel Heng, Gim Hee Lee, Friedrich Fraundorfer y Marc Pollefeys. "PIXHAWK: A micro aerial vehicle design for autonomous flight using onboard computer vision". En: Autonomous Robots 33.1-2 (2012), págs. 21-39.

[42] MERBOTS Research Project. 2015. URL: http://www.irs.uji.es/ merbots/.

[43] S. Merriam y D. Porta. "DSP-based acoustic telemetry modems". En: Sea Technol. 1993.

[44] M. Molins y M. Stojanovic. "Slotted FAMA: a MAC protocol for underwater acoustic networks". En: OCEANS 2006 - Asia Pacific. 2006, págs. 1-7. DOI: 10.1109/OCEANSAP. 2006.4393832.

[45] N. Palomeras, A. El-Fakdi, M. Carreras y P. Ridao. "COLA2: A Control Architecture for AUVs". En: IEEE Journal of Oceanic Engineering 37.4 (2012), págs. 695-716. ISSN: 0364-9059. DOI: 10.1109/ JOE. 2012.2205638.

[46] N. Parrish, L. Tracy, Roy S., P. Arabshahi y W. Fox. "System Design Considerations for Undersea Networks: Link and Multiple Access Protocols". En: IEEE Journal on Selected Areas in Communications 26 (2008), págs. 1720-1730. DOI: 10.1109/JSAC. 2008.081211.

[47] B. Peleato y M. Stojanovic. "Distance aware collision avoidance protocol for ad-hoc underwater acoustic sensor networks". En: IEEE Communications Letters 11.12 (2007), págs. 1025-1027. 
[48] C. Pelekanakis, M. Stojanovic y L. Freitag. "High rate acoustic link for underwater video transmission". En: OCEANS 2003. Proceedings. Vol. 2. 2003, 1091-1097 Vol.2. DOI: 10.1109/OCEANS. 2003.178494.

[49] D. Pompili, T. Melodia e I. F. Akyildiz. "A CDMA-based Medium Access Control for UnderWater Acoustic Sensor Networks". En: IEEE Transactions on Wireless Communications 8.4 (2009), págs. 1899-1909. ISSN: 1558-2248. DOI: 10.1109/TWC.2009.080195.

[50] D. Pompili e I. F. Akyildiz. "Overview of networking protocols for underwater wireless communications". En: IEEE Communications Magazine 47.1 (2009), págs. 97-102. ISSN: 1558-1896. DOI: $10.1109 /$ MCOM. 2009. 4752684.

[51] John Potter, Joao Alves, Dale Green, Giovanni Zappa, Ivor Nissen y Kim McCoy. "The JANUS underwater communications standard". En: 2014 Underwater Communications and Networking (UComms). IEEE. 2014, págs. 1-4.

[52] M. Prats, J. Pérez, J.J. Fernández y P.J. Sanz. "An open source tool for simulation and supervision of underwater intervention missions". En: Intelligent Robots and Systems (IROS), 2012 IEEE/RSJ International Conference on. 2012, págs. 2577-2582. DOI: 10.1109/IROS . 2012.6385788 .

[53] Morgan Quigley, Ken Conley, Brian Gerkey, Josh Faust, Tully Foote, Jeremy Leibs, Rob Wheeler y Andrew Y Ng. "ROS: an open-source Robot Operating System". En: ICRA workshop on open source software. Vol. 3. 3.2. Kobe, Japan. 2009, pág. 5.

[54] D. Ribas, N. Palomeras, P. Ridao, M. Carreras y A. Mallios. "Girona 500 AUV: From Survey to Intervention". En: Mechatronics, IEEE/ASME Transactions on 17.1 (2012), págs. 46-53. ISSN: 1083-4435. DOI: 10 . 1109/TMECH. 2011.2174065.

[55] David Ribas, Pere Ridao, Alessio Turetta, Claudio Melchiorri, Gianluca Palli, Jose Javier Fernandez y Pedro Jose Sanz. "I-AUV Mechatronics Integration for the TRIDENT FP7 Project". En: IEEE/ASME Transactions on Mechatronics 20.5 (2015-10), págs. 2583-2592. ISSN: 1083-4435. DOI: 10 . 1109 / TMECH . 2015 . 2395413. URL: http : / / ieexplore . ieee . org/lpdocs / epic03/wrapper . htm? arnumber= 7047908. 
[56] J. Ribas, D. Sura y M. Stojanovic. "Underwater wireless video transmission for supervisory control and inspection using acoustic OFDM". En: OCEANS 2010. 2010, págs. 1-9. DOI: 10 .1109/OCEANS . 2010. 5663839.

[57] Francisco J. Romero-Ramirez, Rafael Muñoz-Salinas y Rafael MedinaCarnicer. "Speeded up detection of squared fiducial markers". En: Image and Vision Computing 76 (2018), págs. 38 -47. ISSN: 02628856. DOI: https://doi .org/10.1016/j. imavis . 2018.05.004. URL: http : / / www . sciencedirect . com/science / article/pii / S0262885618300799.

[58] Eduardo M. Rubino, Diego Centelles, Jorge Sales, Jose V. Marti, Raul Marin, Pedro J. Sanz y Alberto J. Alvares. "Progressive image compression and transmission with region of interest in underwater robotics". En: OCEANS 2017 - Aberdeen. IEEE, 2017-06, págs. 1-9. ISBN: 978-1-5090-5278-3. DOI: 10 . 1109 / OCEANSE . 2017 . 8084999. URL: http://ieeexplore.ieee.org/document/8084999/.

[59] Eduardo M Rubino, Diego Centelles, Jorge Sales, Jose V Marti, Raul Marin, Pedro J Sanz y Alberto J Alvares. "Progressive image compression and transmission with region of interest in underwater robotics". En: OCEANS 2017-Aberdeen. IEEE. 2017, págs. 1-9.

[60] Eduardo M Rubino, D Centelles, Jorge Sales, José V Martí, Raúl Marín, Alberto J Alvares y Pedro J Sanz. "Sistema de visión subacuático inalámbrico usando un algoritmo de compresión progresivo con región de interés". En: Revista Iberoamericana de Automática e Informática industrial 15.1 (2017), págs. 46-57.

[61] Eduardo M. Rubino, Diego Centelles, Jorge Sales, José V. Martí, Raúl Marín, Pedro J. Sanz y Alberto J. Álvares. "Underwater radio frequency image sensor using progressive image compression and region of interest". En: Journal of the Brazilian Society of Mechanical Sciences and Engineering (2017). ISSN: 1806-3691. DOI: 10.1007 / s40430-017-0894-6. URL: https : //doi .org/10 . 1007/s40430017-0894-6.

[62] Eduardo M Rubino, Diego Centelles, Jorge Sales, José V Martí, Raúl Marín, Pedro J Sanz y Alberto J Álvares. "Underwater radio frequency image sensor using progressive image compression and region 
of interest". En: Journal of the Brazilian Society of Mechanical Sciences and Engineering 39.10 (2017), págs. 4115-4134.

[63] Eduardo M Rubino, Diego Centelles, Jorge Sales, Jose Vte Marti, Raul Marin y Pedro J Sanz. "Wireless Image Compression and Transmission for Underwater Robotic Applications". En: IFAC-PapersOnLine 48.2 (2015), págs. 288-293.

[64] Toby Schneider y Henrik Schmidt. "Unified command and control for heterogeneous marine sensing networks". En: Journal of Field Robotics 27.6 (2010-11), págs. 876-889. ISSN: 15564959. DOI: 10.1002/ rob.20346. URL: http://doi.wiley.com/10.1002/rob. 20346.

[65] A. Shaw, A.I. Al-Shamma'a, S.R. Wylie y D. Toal. "Experimental Investigations of Electromagnetic Wave Propagation in Seawater". En: Microwave Conference, 2006. 36th European. 2006, págs. 572-575. DOI: $10.1109 /$ EUMC . 2006.281456.

[66] Amit Shukla y Hamad Karki. "Application of robotics in offshore oil and gas industry - A review Part II". En: Robotics and Autonomous Systems 75 (2016), págs. 508-524.

[67] T. Slama, A. Trevisani, D. Aubry, R. Oboe y F. Kratz. "Experimental Analysis of an Internet-Based Bilateral Teleoperation System With Motion and Force Scaling Using a Model Predictive Controller". En: IEEE Transactions on Industrial Electronics 55.9 (2008), págs. 3290-3299. ISSN: 1557-9948. DOI: 10.1109/TIE.2008.928120.

[68] M. Stojanovic y J. Preisig. "Underwater acoustic communication channels: Propagation models and statistical characterization". En: IEEE Communications Magazine 47.1 (2009), págs. 84-89. ISSN: 15581896. DOI: $10.1109 /$ MCOM. 2009.4752682.

[69] M. Suzuki, T. Sasaki y T. Tsuchiya. "Digital Acoustic Image Transmission System For Deep-sea Research Submersible". En: OCEANS '92. Mastering the Oceans Through Technology. Proceedings. Vol. 2. 1992, págs. 567-570. DOI: 10.1109/0CEANS.1992.607839.

[70] A. A. Syed, W. Ye y J. Heidemann. "T-Lohi: A New Class of MAC Protocols for Underwater Acoustic Sensor Networks". En: IEEE INFOCOM 2008 - The 27th Conference on Computer Communications. 2008, págs. 231-235. DOI: 10.1109/INFOCOM.2008.55. 
[71] Affan A. Syed, Wei Ye, John Heidemann y Bhaskar Krishnamachari. "Understanding Spatio-temporal Uncertainty in Medium Access with ALOHA Protocols". En: Proceedings of the Second Workshop on Underwater Networks. WuWNet '07. Montreal, Quebec, Canada: ACM, 2007, págs. 41-48. ISBN: 978-1-59593-736-0. DOI: 10.1145/1287812 . 1287822. URL: http://doi.acm.org/10.1145/1287812.1287822.

[72] TRITON. Multisensory Based Underwater Intervention through Cooperative Marine Robots. http://www.irs.uji.es/triton/.

[73] Elio Tuci, Muhanad H. M. Alkilabi y Otar Akanyeti. "Cooperative Object Transport in Multi-Robot Systems: A Review of the State-ofthe-Art". En: Frontiers in Robotics and AI 5 (2018-05), pág. 59. ISSN: 2296-9144. DOI: $10.3389 /$ frobt . 2018 .00059. URL: https: //www . frontiersin.org/article/10.3389/frobt.2018.00059/full.

[74] W. Van Kleunen, N. Meratnia y P. J. M. Havinga. "MDS-Mac: A Scheduled MAC for Localization, Time-Synchronisation and Communication in Underwater Acoustic Networks". En: 2012 IEEE 15th International Conference on Computational Science and Engineering. 2012, págs. 666-672. DOI: 10.1109/ICCSE.2012.95.

[75] Wireless for Subsea. Datasheet of Seatooth S100-L wireless subsea controller. http://www.wfs-tech.com/wp-content/uploads/2017/ 11/Seatooth-S100-L-Extended-Range-17 .11 .1.pdf. Accessed 2020-02-27.

[76] Wireless for Subsea. Datasheet of Seatooth S100-L wireless subsea controller. http://www.wfs-tech.com/wp-content/uploads/2017/ 06/Seatooth-S100-17.-01.-1.pdf. Accessed 2020-02-27.

[77] R. Wirz, R. Marin, M. Ferre, J. Barrio, J. M. Claver y J. Ortego. "Bidirectional Transport Protocol for Teleoperated Robots". En: IEEE Transactions on Industrial Electronics 56.9 (2009), págs. 3772-3781. ISSN: 0278-0046. DOI: 10.1109/TIE.2009.2025291.

[78] P. Xie, Z. Zhou, Z. Peng, H. Yan, T. Hu, J. Cui, Z. Shi, Y. Fei y S. Zhou. "Aqua-Sim: An NS-2 based simulator for underwater sensor networks". En: OCEANS 2009. 2009, págs. 1-7. DOI: 10.23919/ OCEANS . 2009. 5422081.

[79] P. Xie y J. Cui. "R-MAC: An Energy-Efficient MAC Protocol for Underwater Sensor Networks". En: International Conference on Wireless 
Algorithms, Systems and Applications (WASA 2007). 2007, págs. 187-198. DOI: 10.1109/WASA . 2007.37. 



\section{AVANCES EN}

\section{TELEROBÓTICA INALÁMBRICA SUBMARINA}

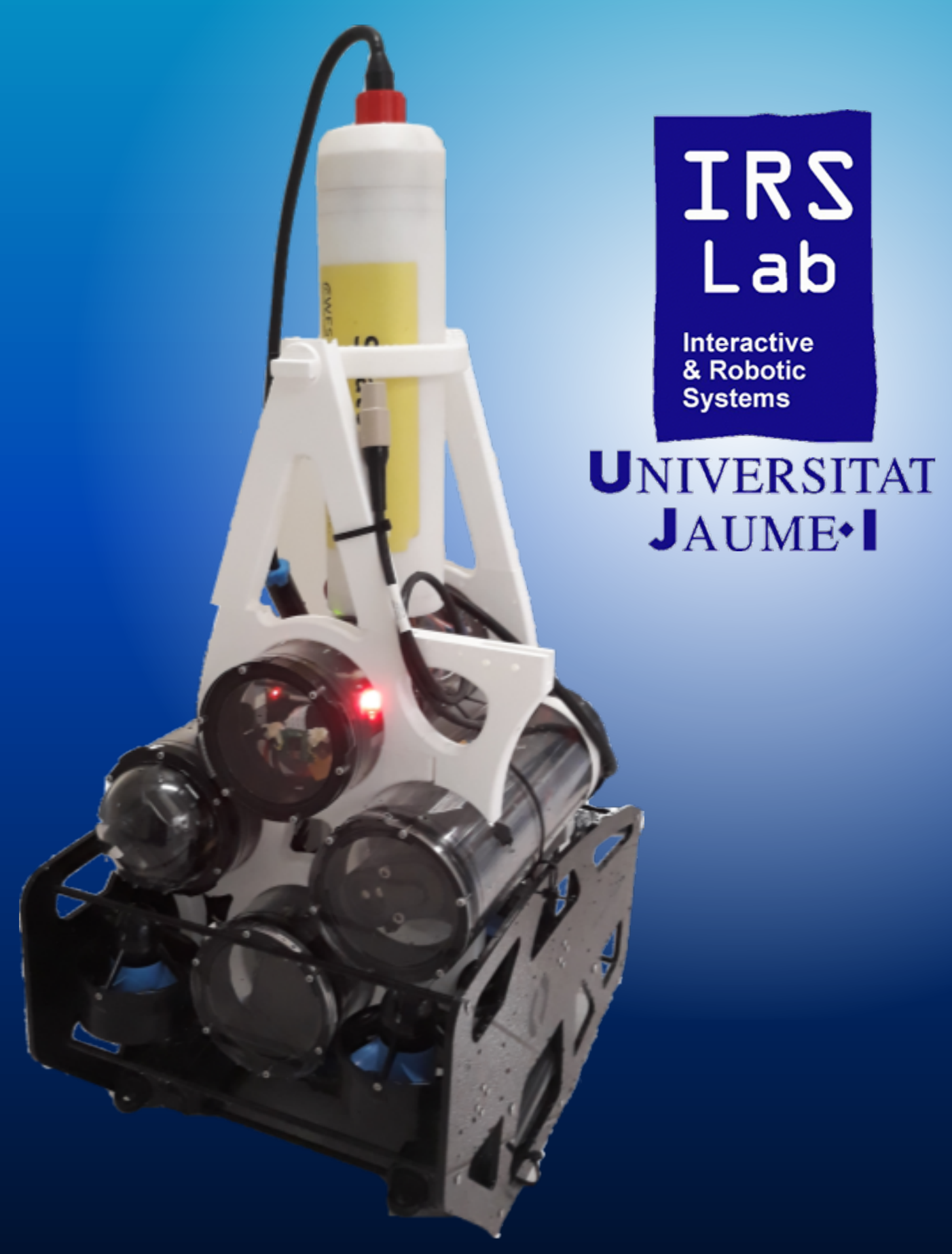

